Portland State University

PDXScholar

Spring 7-16-2018

\title{
Utilitarian Skateboarding: Insight into an Emergent Mode of Mobility
}

Michael Joseph Harpool

Portland State University

Follow this and additional works at: https://pdxscholar.library.pdx.edu/open_access_etds

Part of the Transportation Commons, and the Urban Studies Commons Let us know how access to this document benefits you.

\section{Recommended Citation}

Harpool, Michael Joseph, "Utilitarian Skateboarding: Insight into an Emergent Mode of Mobility" (2018). Dissertations and Theses. Paper 4452.

https://doi.org/10.15760/etd.6336

This Thesis is brought to you for free and open access. It has been accepted for inclusion in Dissertations and Theses by an authorized administrator of PDXScholar. Please contact us if we can make this document more accessible: pdxscholar@pdx.edu. 
Utilitarian Skateboarding: Insight into an Emergent Mode of Mobility

by
Michael Joseph Harpool

A thesis submitted in partial fulfillment of the requirements for the degree

\author{
Master of Urban Studies \\ in \\ Urban Studies \\ Thesis Committee: \\ Jennifer Dill, Chair \\ Aaron Golub \\ Naomi Adiv
}

Portland State University

2018 
(C) 2018 Michael Joseph Harpool 


\begin{abstract}
In recent years research and planning efforts to enhance the conditions and opportunities for active transportation modes have increased significantly; however, these efforts have primarily focused on pedestrians and bicyclists. Skateboarding and other alternative modes of mobility remain an untapped potential for healthy and sustainable travel. This research addresses numerous knowledge gaps in the literature on utilitarian skateboarding under the larger umbrella of active transportation. Analysis of online survey results and semi-structured interviews with skateboarders in Portland, OR provides insight into the motivations and barriers of traveling by skateboard and the demographics and perceptions of utilitarian skateboarders. Like bicyclists and pedestrians, skateboarders value safe, comfortable, and aesthetically pleasing places to travel and are sensitive to surface conditions, distance, and slope. These similarities present a unique opportunity for cities to create facilities that accommodate diverse users. Disaggregating results by the respondents' gender, skill level, and frequency of transportation-oriented skateboarding highlights significant differences in levels of perceived safety and the practicality of utilitarian skateboarding. The findings have implications for the future of active transportation planning which support Elaine Stratford's vision of "generous geographies that allow for more, and playful, mobilities in the city" (2016, p.351).
\end{abstract}




\section{Table of Contents}

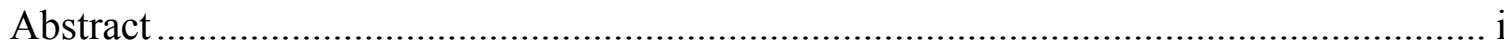

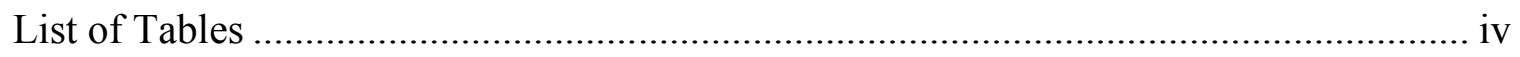

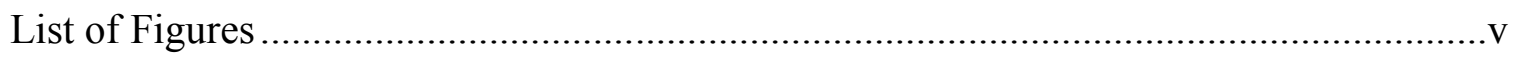

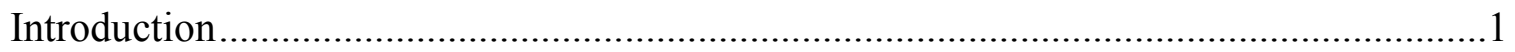

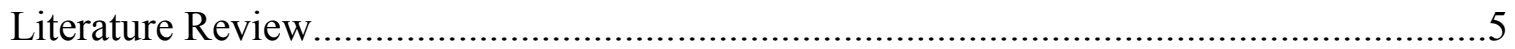

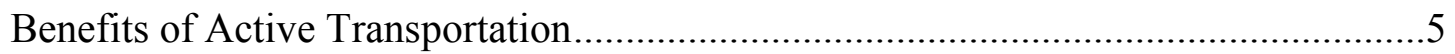

Bicycle and Pedestrian Mode and Route Choice ...................................................... 10

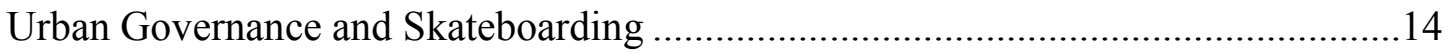

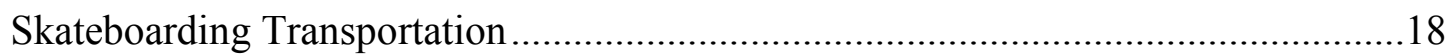

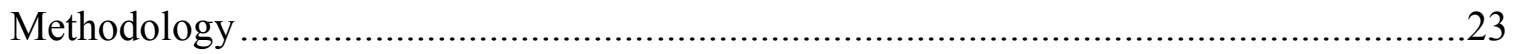

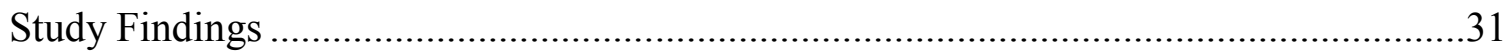

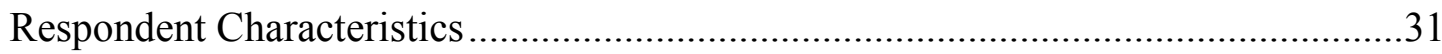

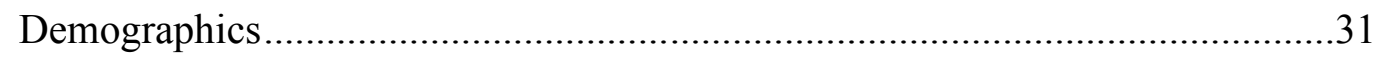

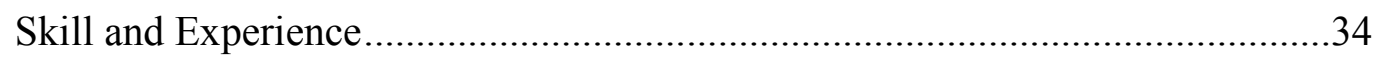

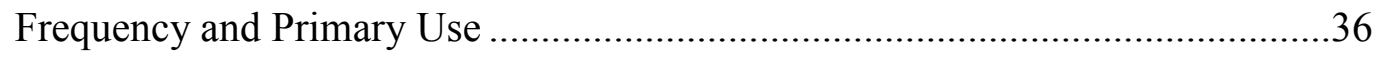

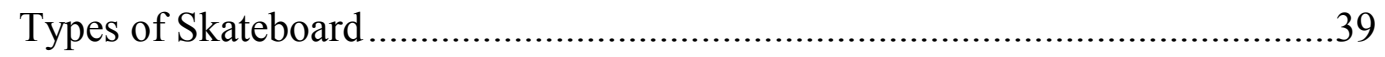

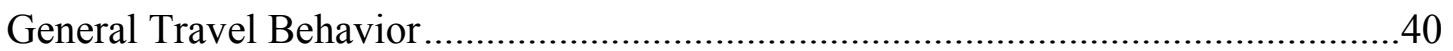

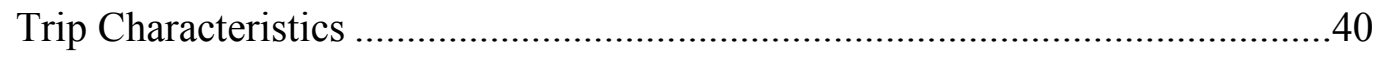

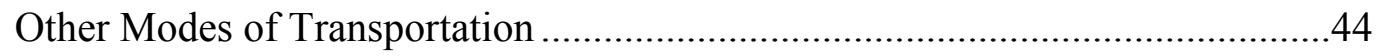

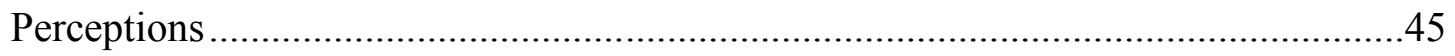

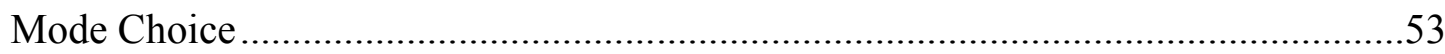

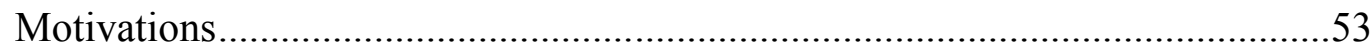

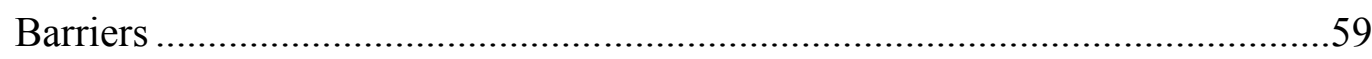

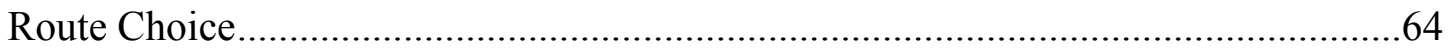

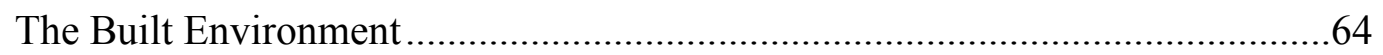

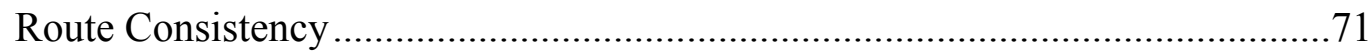

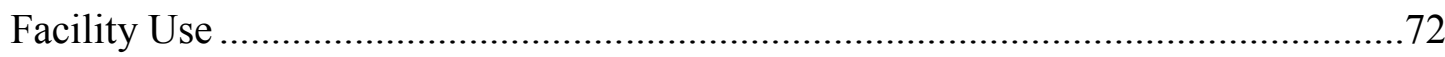

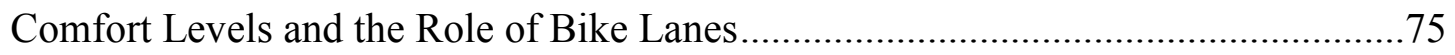

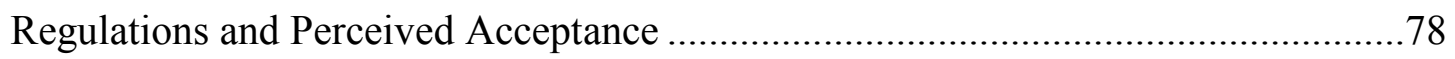

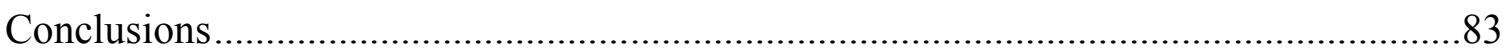

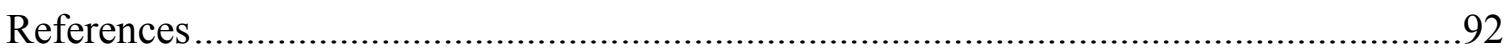

Appendix A: Online Survey Questionnaire ..........................................................97 


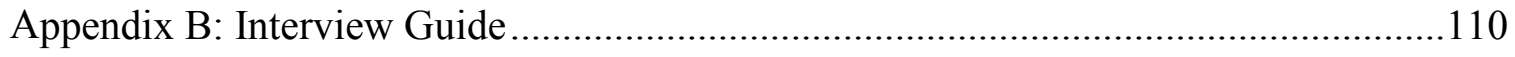

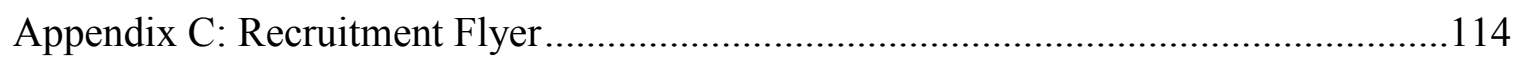

Appendix D: HSRRC Approval Memo ………………......................................115

Appendix E: Significant Differences in Perceptions ..................................................116

Appendix F: Binary Logistic Regression..............................................................118 


\section{List of Tables}

Table 1: Responses by State \& Breakdown of International Responses ........................ 27

Table 2: Individual and Household Demographic Characteristics ................................ 32

Table 3: Age Started Skateboarding for Recreational and Transpotation Purposes ......... 35

Table 4: Frequency of Transportation-Oriented Skateboarding by Demographics.......... 37

Table 5: Primary Use by Demographic Characteristics............................................... 39

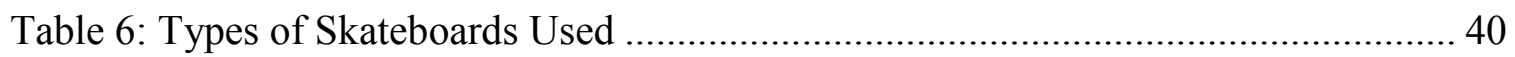

Table 7: Types of Trip Made by Skateboard by Selected Characteristics ...................... 41

Table 8: Summary of Independent Samples T-Test Results....................................... 49

Table 9: Motivations by Gender, Skill Level, and Frequency of Use ............................ 58

Table 10: Barriers Selected by Gender, Skill Level, and Frequency of Use ................... 63

Table 11: 'Desired' Route Features by Gender, Skill Level, and Frequency of Use ....... 70

Table 12: 'Avoided' Route Features by Gender, Skill Level, and Frequency of Use ...... 71

Table 13: Differences in Mean Comfort Levels: Independent Samples T-Test ............... 77 


\section{List of Figures}

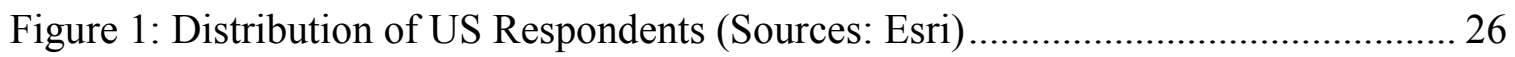

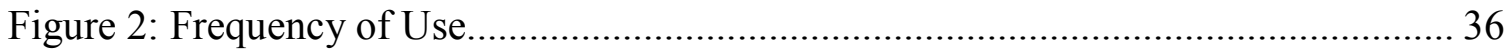

Figure 3: Types of Skateboards (image from www.boardriding.com) ........................... 40

Figure 4: Destination and Environmental Trip Deterrents for Skateboarding................. 43

Figure 5: Other types of Modes Used by Respondents in the Past Month $(n=388)$........ 45

Figure 6: Perceptions of Skateboard Transportation $(n=390)$...................................... 46

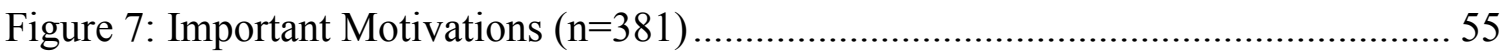

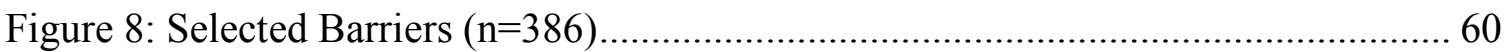

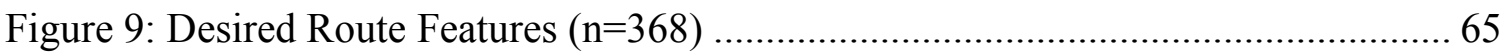

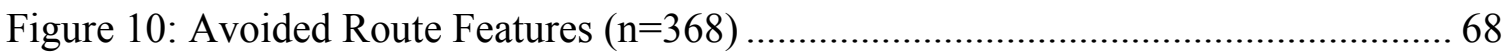

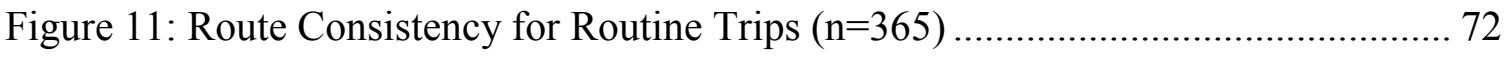

Figure 12: Transportation Facility Use by Skateboarders $(n=368)$.............................. 73

Figure 13: Bike Lanes and Comfort: Paired Samples T-Tests $(\mathrm{n}=368)$........................ 75

Figure 14: Attitudes towards Regulations and Acceptance $(n=368)$............................. 79 


\section{Introduction}

In recent decades, efforts to promote active transportation have grown significantly (Litman, 2017; Lyons et al. 2014; Biton et al., 2017). Increasing concern for public health and environmental issues within urbanized areas have pushed urban planners and researchers to explore ways to enhance the use of active transportation to address complex urban issues. These issues include environmental degradation, livability, economic development, public health, and transportation equity (Litman, 2017).

However, both active transportation policy and research efforts have been overwhelmingly geared towards bicycling and walking. Thus, skateboarding and other alternative modes of mobility remain an untapped potential for healthy and sustainable travel. For cities to create truly inclusive and equitable transportation networks, urban planners, engineers, activists, politicians, and researchers must seek to understand how to accommodate the needs and desires of these users. This process will be critical to the future growth of active transportation. As Elaine Stratford argues, "There is a need to consider how to create generous geographies that allow for more, and playful, mobilities in the city, no matter how modest" (2016, p. 351). Stratford believes that opening the city to new and playful mobilities (i.e. skateboarding) could not only benefit public health and the environment, but encourage the acceptance of social difference and promote civility amongst citizens.

In the United States, utilitarian skateboarding was first pursued as an academic research topic in the early 2010s (Walker, 2013; Fang, 2013). The lack of attention payed to skateboarding by transportation planners and researchers is not a reflection of the lack 
of utilitarian skateboarding. In fact, a study in California revealed that the presence of utilitarian skateboarding is significant enough to warrant its consideration as a legitimate mode of travel (Fang, 2015). However, skateboarding is most commonly thought of and studied as a recreational activity which defies social and legal norms and contests the prescribed use of space (Chiu, 2009; Howell, 2001; Nemeth 2006).

In the 1990s "street skateboarding" became the most popular form of recreational skateboarding, where skateboarders creatively appropriate urban streets, plazas, and other spaces not designated for skateboarding. Street skateboarding commonly involves performing stunts on handrails, staircases, and street furniture, which can cause property damage in the form of paint residue and chipped concrete. In turn, it quickly became a thorn in the side of urban planners, architects, landscape architects, and law enforcement. Skateboarders' use of urban space is often perceived as disorderly, as it undermines the prescribed uses of the built environment and the "high velocity" maneuvers may cause apprehension within the general public (Flusty, 2000). Thus, skateboarders are commonly stigmatized by both citizens and local authorities. These social stigmas have been utilized to justify laws and regulations which criminalize skateboarding and subject participants to penalty of fines, skateboard confiscation, and even arrest (Fang, 2013; Vivoni, 2013; Wooley and Johns, 2001). While these laws are deployed to deter recreational skateboarders from the public realm, they have a ripple effect on the use of a healthy and efficient mode of travel (Fang, 2013; Fang and Handy, 2017b; Walker, 2013).

Despite the barriers, a few scholars have begun to pave the way for skateboarding transportation research. Walker (2013) provided exploratory insight into the perceptions 
and experiences of utilitarian skateboarders across the United States and Canada. Her work and a later study by Fang and Handy (2017b) identified fundamental mode choice factors (i.e. fun, fitness, convenience, and speed) and route choice preferences (i.e. slope, surface condition, and automobile traffic) amongst skateboarders. Through comparing their findings to the bicycle transportation research, they find that skateboarders and bicyclists are motivated by similar factors and prefer similar route features; thus suggesting a seemingly simple transition towards planning shared route networks for bicyclists and skateboarders.

Currently, skateboarding provides the potential to serve as a viable mode of active transportation for millions of people in the United States (Stratford, 2016; Howell, 2008; Fang, 2015); yet, regulations and a lack of knowledge about skateboarding in local jurisdictions confine that potential. This study seeks to support and enhance the limited research on skateboard transportation, while providing insight into issues which have yet to be explored. Utilizing data from an online survey and semi-structured interviews I will address the complexities of travel behavior, mode choice factors (i.e. motivations and barriers), and route choice preferences of utilitarian skateboarders. I will also discuss route choice consistency; the role of existing transportation infrastructure; on-street comfort levels; perceived social acceptance; and the relationship between identity, lifestyle and transportation amongst utilitarian skateboarders. A larger sample size and relatively high female response rate allowed me to overcome some of the statistical challenges faced by previous studies on utilitarian skateboarding and make meaningful comparisons across populations. This research also attempts to address the large gap in 
active transportation literature by shifting away from bicycle and pedestrian travel. The findings presented in this study could inform policy makers of the various benefits and limitations of skateboarding transportation. Furthermore, this research could support cities and advocacy groups who hope to provide a more inclusive transportation network within their communities. 


\section{Literature Review}

While active transportation research has reached impressive heights in recent years, there is limited research on skateboarding as a mode of utilitarian transportation. Active transportation scholars have focused almost entirely on bicycle and pedestrian travel. The review that follows engages with the literature around the benefits of active transportation, mode and route choice factors for active commuters, the spatial politics of skateboarding, and skateboard transportation. The design of this review is meant to reveal the contradiction between the growing importance attributed to active transportation (i.e. walking and biking) and the regulations which prohibit travel by skateboard, while illuminating some of the similarities between the modes.

\section{Benefits of Active Transportation}

The Federal Highway Administration (FHWA), the largest funder of non-motorized transportation programs, promotes the belief that enhancing rates of active transportation will support a myriad of regional goals, including transportation equity, environmental sustainability, livability, public health, and tourism (Biton et al., 2017). In support of this claim, transportation and public health researchers continuously demonstrate the environmental, economic, and social benefits of active transportation, especially walking and bicycling.

Increasing the proportion of citizens that travel by active modes, which produce virtually no pollution, can dramatically decrease the number of vehicle miles traveled and harmful pollutants emitted into the environment. Frank et al. (2006) found that residents living in areas with high walkability tend to have higher rates of active transportation, 
and as such, they tend to drive less and have lower per capita pollution emissions. A shift towards active modes for short urban trips can result in a significant reduction in emissions, given that per mile emissions tend to be greatest for these trips due to cold starts and congestion (Litman, 2017). This, in turn, could also lead to a decrease in the demand for vehicle production, which is responsible for considerable amounts of energy consumption and pollution worldwide. Furthermore, active transportation infrastructure has a much lower ecological footprint than motor vehicle only infrastructure, and it often supports the use of green infrastructure and other forms of sustainable development. Reducing the amount of impervious surface can have a significant impact on the local environment by reducing the urban heat island effect, reducing damage caused to rivers and riparian zones through improved storm water management, and reducing the transport of pollutants into the hydrological system (Litman, 2017).

Enhancing the use of active transportation and expanding pedestrian and bicycle infrastructure has demonstrated to have a positive impact on the local economy in numerous ways. Active transportation networks connect non-motorist consumers to restaurants and bars, retailers, recreational facilities, and other establishments that they may otherwise never visit, due to a gap in the transportation system. Thus, constructing these networks and filling this gap can enhance local consumption. Clifton et al. (2012) found that people travel to commercial destinations by foot and bicycle tend to be competitive consumers when compared to motorists. They find that active commuters, on average, spend similar amounts or more than those who arrived by automobile. Their results also suggest that non-motorists tend to be more frequent patrons, making more 
regular trips to local establishments than their counterparts. In addition to enhancing general retail consumption patterns, active transportation can also benefit particular industries such as bike shops, livability-oriented real estate development, and tourism (Litman, 2017).

Well planned and strategically executed pedestrian- and bicycling-oriented infrastructure are a significant source of tourism and have shown to have a positive impact on property values (Bartholomew and Ewing, 2011; Litman, 2017). A study in the state of Wisconsin valued the revenue generated by bicycle tourism at nearly one billion dollars per year (referred to in Clifton et al. 2012). Off-street trails, bicycle greenways, bike share infrastructure, and pedestrian friendly neighborhoods have become sought after urban amenities which can enhance economic activity. As such, these amenities are continuously used by entrepreneurial cities as a neoliberal marketing strategy to attract environmentally-minded elites and private investment meant to enhance the local economy (Long, 2016). It is important to acknowledge that while these strategies may enhance local economic growth they may also have negative impacts on socioeconomically disadvantaged populations effected by rising property values and social reconfiguration of neighborhoods (Flanagan et al., 2016).

A study conducted by Garret-Peltier (2011) revealed that pedestrian- and transportation-oriented infrastructure projects have positive benefit on the local labor market. She found that the construction of pedestrian and bicycle infrastructure generates between nine and 11.4 jobs per one million dollars spent, compared to an average of 7.8 jobs for road-only infrastructure. When considering out-of-state employment, an 
additional three full time equivalent positions can be expected for ever million dollars spent on pedestrian and bicycle infrastructure. Importantly, the jobs that are created range from entry-level to highly specialized positions, offering employment to individuals with various abilities. Increasing rates of active transportation can also reduce the costs of congestion, road maintenance, parking facilities, health care, and accidents bore by both the government and individuals. Furthermore, reducing overall costs for commuters (i.e. vehicle and fuel expenditures) by shifting to active modes can positively affect regional economic activity (Litman, 2017).

The links between physical activity, public health, and active transportation have been well established by researchers. Pucher et al. (2010) found significant inverse relationships between levels of active travel and obesity utilizing data from 14 countries, all 50 U.S. states, and 47 of the 50 largest U.S. cities. A study by Frank et al. (2006) supports the argument that the walkability of neighborhoods can have a significant impact on the levels of physical activity and body mass index (BMI); their results indicate that residents of neighborhoods with high walkability tend to spend more time physically active and have lower BMIs. In a review of the literature, Pucher and Buehler (2010) reveal that active transportation is directly related to improved health in older adults, decreased mortality rates, and improved resting blood pressure. Their findings suggest that walking and cycling to work can be one of the most practical and effective ways to meet recommended physical activity levels. On a similar note, Sallis et al. (2004) claim that active transportation has the capacity to contribute significantly to overall levels of physical activity and that even small increases in physical activity can improve 
public health levels. These studies demonstrate that active transportation could be a partial solution to the dramatic increases in sedentary lifestyles and associated health risks, such as cardiovascular disease, obesity, diabetes, and depression.

In the majority of communities, between $20 \%$ and $40 \%$ of the population cannot or should not operate a motor vehicle due to low income, age, and disability (Litman, 2017). If properly supported active transportation can provide a safe and affordable alternative for those populations, which could help to alleviate social disparities in opportunity. Litman (2017) claims that various components of active transportation improvements serve to reduce the "barrier effect" in urban areas. The barrier effect refers to the travel delay and limitations imposed on active modes by vehicle traffic and autooriented infrastructure. While the construction of highways and the widening of roads has created significant barriers, traffic calming techniques, paths and trials separated from the roadway, improved sidewalks, pedestrian overpasses, and land use changes can minimize their impact. Furthermore, active travel has the benefit of posing minimal risk to other road users, which can create safer environments; Marshall and Garrick (2011) found that cities with higher bicycling rates tend to have a much lower risk of fatal crashes for all road users when compared to cities with lower bicycling rates. This is critical provided that in 2013 there were nearly 66,000 injuries and 4,700 pedestrian deaths in the United States alone (Coughenour et al., 2017).

Drawing on the work of Mokhtarian and Salomon (2001) which contests the notion that travel is a derived demand, numerous studies have shown that active transportation can benefit individuals' mental health and social well-being. Gatersleben 
and Uzzell (2007) found that those who commute by bicycle or foot tend to find their journeys to be exciting and relaxing, in comparison motorists and transit riders who find their commute to be stressful and boring. Smith (2017) claims that walking and bicycling can have a positive effect on commute well-being. He found that those who walk and bike to work tend to be happier with their commutes than those who drive or utilize some other mode (i.e. public transit). On a similar note, Rogers et al. (2011) provided evidence that levels of social capital are higher in neighborhoods which support active travel when compared to those which do not. Strong social networks, personal connections, and other aspects of social capital are important components of quality of life and can benefit both communities' and individuals' social well-being. The following section discusses the environmental and social factors influence the propensity to actively travel.

\section{Bicycle and Pedestrian Mode and Route Choice}

Aside from acknowledging the benefits, if active transportation is going to be successfully promoted and enhanced it is essential to understand the factors which contribute to an increased propensity to actively travel. Researchers have focused on how the physical environment or objective factors (e.g. infrastructure, distance, climate, and topography), subjective factors (e.g. convenience, perceptions, and peer approval), and demographic factors (e.g. race, ethnicity, income, health) may influence an individual's decisions to actively commute. Policies and programs (e.g. complete streets, bike share, and Safe Routes to School) have also been studied as a factor influencing the propensity to actively travel (for an extensive review of policies see Pucher et al., 2010). 
Much of the research regarding the relationship between the physical environment and the propensity to utilize active modes, especially walking and bicycling, focuses on topography, urban form, and the presence of non-motorized infrastructure. In a study of U.S. cities, Dill and Carr (2003) found that cities with above average measures of bicycle infrastructure tend to have above average levels of bicycle commuting. These results support findings from the Non-motorized Transportation Pilot Program which suggest that investments into properly planned active transportation networks can lead to a significant increase in active travel (Lyons et al., 2014). In a study of commuters at the University of North Carolina-Chapel Hill, Rodriguez and Joo (2004) found that slope and sidewalk availability contribute significantly to the odds an individual will choose to travel by foot or bicycle. Similarly, Dill and Voros (2007) found that traffic, a lack of safe places to ride, the presence of hills, and trip distance are amongst the leading barriers to commuting by bicycle.

Dill and Voros (2007) also explored some of the subjective indicators of the propensity to ride a bicycle for utilitarian purposes. Their findings indicate that individuals who feel their local infrastructure provides safe and convenient connections to places, regardless of the actual conditions, tend to ride more frequently and for utilitarian purposes. Their results also suggest that those who frequently witness other adults biking, have positive attitudes towards biking, and are concerned with the environment are more likely to be regular and utilitarian bicyclists. Interestingly, individuals who had who rode a bicycle as a child for reasons other than to get to school (i.e. recreation) were more likely to ride for utilitarian purposes as an adult. These 
findings indicate that mode choice is influenced by various subjective attitudes, habits, and experiences, which is important for informing policy and education programs to increase active transportation rates.

Various studies have also highlighted the demographic indicators of active travel. Unsurprisingly, a wide range of methods, study areas, and sample sizes have produced differential findings. Utilizing data from the 2009 National Household Travel Survey, Kuzmyak and Dill (2012) found that males were two to four times more likely to make a trip by bicycle than females. There are many potential explanations for this gender gap, but one of the most common found in the literature is that females have a higher concern for safety and tend to feel less comfortable while bicycling on certain facilities (Emond et al., 2009). In the Kuzmyak and Dill study, children and younger adults ( $<35$ years) were far more likely to walk and bicycle for transportation purposes than older adults. While bicycling rates were similar across income groups, lower income citizens were more likely to travel by foot. Other studies also have found the relationship between utilitarian bicycling and income to be murky (Dill and Voros, 2007). Other significant demographic indicators of active travel include race, BMI, education, and vehicle-to-adult ratios. Utilizing data from the Neighborhood Quality of Life Study, Sallis et al. (2013) found that there was a greater propensity to bicycle amongst White non-Hispanic bike owners and bike owners with lower BMIs. With respects to vehicle access, Kuzmyak and Dill (2012) found that individuals living in households with fewer vehicles than licensed drivers walk and bike nearly twice as much as their counterparts; however, contradictory findings show that those with higher vehicle-to-adult ratios are more likely to bike (Sallis 
et al., 2013). Various studies have found college education to be associated with greater propensity to utilize active modes (Plaut, 2005; Sallis et al., 2013). This research is critical to developing plans to increase overall active transportation rates within a community.

In order to plan specific transportation networks for active modes it is important to understand the factors which influence route choice decisions. Most of the research in this field has focused on objective measures of the built environment. While mode choice and route choice are often treated separately for obvious reasons, Broach (2016) found that for bicyclists and pedestrians the most important environmental route choice factors generally tend to impact mode choice. According to his findings important route choice factors for bicycling include directness, turn frequency, slope, traffic levels, intersection control, and transportation facilities. For pedestrians, subpar walking facilities, incomplete street environments, and the need to cross a busy arterial street without proper intersection control serve as significant barriers. Interestingly, Broach found that pedestrians were willing to walk out of their way to travel along smaller commercial streets, while similar streets with no commercial activity were often avoided. Agrawal et al. (2008) found that minimizing the distance of travel was the primary route choice consideration amongst pedestrians walking to transit stations. Survey respondents also considered safety from vehicles, safe street crossings, and low crime to be important aspects of a given route. Previous studies have also found distance to be a critical route choice factor for bicyclists (Broach et al., 2012). While some of these studies consider demographic characteristics, in the future a greater focus should be payed to the 
differences in route choice preferences across individuals of different genders, races, income levels, and ethnicities.

These studies reveal the complexity of route choice and mode choice factors considered by bicyclists and pedestrians. As expected, given the variance in study design and location, the actual effect of these factors differ substantially across studies.

However, there is consensus that objective, subjective, and demographic factors contribute significantly to both the propensity to travel by foot and bicycle and the route chosen for a given trip. The research presented in this section is essential to the successful promotion and enhancement of active transportation. However, while these studies contribute to the mounting evidence of the motivations and route preferences of bicyclist and pedestrians, other active modes such as skateboarding have been overlooked. The following section will introduce the physical, social, and legal measures that have been taken to regulate skateboarders' use of space.

\section{Urban Governance and Skateboarding}

Adjacent to the recent increase in active transportation over the past few decades, skateboarding has also grown considerably, with approximately 12 million recorded participants in 2005 (Howell, 2008). In the 1990s, "street skating" became the most popular form of skateboarding. Typically, street skating involves the use of stairways, handrails, embankments, street furniture, and even flat surfaces to perform stunts, which undermine the prescribed uses of the built environment. Often times, these stunts leave behind traces (e.g. paint residue on handrails and benches and chips on concrete ledges) which represent the contestation of societal norms and urban governance. Vivoni (2009) 
argues that, "Skateboard traces most often signal an unsanctioned engagement with the built environment that undermines prescribed uses, social norms, and legal mandates found on the sanctity of property value and intent on regulating social relation in public space" (p. 141). Their behavior outside the realm of the status quo engenders social stigmas which construe skateboarding as a nuisance to urban life and landscape. Local authorities often compare skateboarders to cockroaches, label them as "skate rats," and conflate their use of space with the presence of drug dealers, homelessness, and graffiti artists (Nemeth, 2006; Woolley and Johns, 2001).

In response to the rise in street skating, urban officials have implemented various strategies in attempt to control the presence and behavior of skateboarders. As such, these issues have received attention from scholars concerned with the exclusivity of public space (Howell, 2001; Nemeth 2006), urban governance (Stratford, 2002), land use (Vivoni, 2009), and urban youth (Woolley and Johns, 2001). These topics are not mutually exclusive and are often interconnected within the literature. This section will introduce a few of the strategies commonly used to regulate skateboarding, including exclusionary architecture, surveillance, and what I refer to as "isolate and criminalize." These strategies are presented here because they have a considerable impact on the use of space and may influence the ways in which someone travels by skateboard.

Exclusionary Architecture: Chui (2009) argues that "the ways people perceive and use public space are not only governed by social norms but also determined by rules and designated functions created by architects, landscape architects, and urban planners" (p. 25). A brief inventory of the ground-level architecture in the downtown of any 
contemporary city will quickly reveal the physical strategies utilized to control the behavior of skateboarders. It has become the norm for urban planners, developers, and architects to incorporate metal clips, or 'pig ears,' on benches and ledges to prevent skateboarders from sliding or grinding across the edge of the object (they have also been used as tool to deter homelessness) (Howell, 2001). Rough surface materials, such as cobblestone, are placed around street furniture to prevent skateboarders from maintaining efficient speed to perform stunts. Knobs are often times added to handrails to prevent sliding, and benches, trash bins, planters, and other objects are placed strategically to obstruct a smooth path for skateboarders. These techniques demonstrate the considerable levels of detail and effort put into urban design as a means of controlling the ways in which space is used by skateboarders (see Nemeth, 2006; Howell, 2001; and Woolley, Hazelwood, and Simkins, 2011). Woolley, Hazelwood, and Simkins (2011) identify that these "skate-proof" strategies can be applied either in the original design of the project, as a response to the presence of skateboarding during the project, or even after completion of the project. These physical designs are implemented so that skateboarders cannot navigate space comfortably without obstruction.

Surveillance: Increasingly, urban officials and business owners are utilizing closed circuit television (CCTV) within public and private spaces in order to monitor and regulate behavior (Howell, 2001). Planners, designers, and business owners anticipate that the constant presence of surveillance will prevent skateboarders from using the space for their activity and encourage them to act according to the social and legal norms of society. These cameras also allow urban officials to learn about the behaviors of 
skateboarders, so that they can predict potential movements and design strategies to better regulate their activity (Howell, 2001). Woolley, Hazlewood, and Simkins (2011) and Mitchell and Heynen (2009) argue that video cameras alone are rarely a sufficient means of regulating behavior. This has also been acknowledged by public and private entities; thus, security guards are often hired as a complimentary surveillance tactic to exclude skateboarders and other unwanted users from urban space. Surveillance has become a common strategy utilized in attempt to maintain the social norms of society within the urban fabric.

Isolate and Criminalize: The number of purpose built skateparks (spaces designated for the use of skateboarding) grew from approximately 165 in 1997 to more than 2,100 by 2008 (Howell, 2008). In many cases, cities will supply the land and/or a small donation to begin the construction process and rely on the community to raise the remaining funds through private donations (Nemeth, 2006; Howell, 2008). However, the land donated by municipalities is often outside of the downtown and away from transportation nodes, making it difficult for these spaces to be accessed by inner-city and lower income skateboarders (Nemeth, 2006; Howell 2001). Furthermore, the construction of a skatepark is often utilized to justify the municipalities' decision to criminalize skateboarding in other parts of the city (Owens, 2001). Thus, the seemingly wellintentioned process of providing a public skatepark has become a common strategy to further isolate skateboarders from the general public and criminalize their activity within the city center. Regardless of whether these by-laws restrict skateboarding in urban 
plazas, streets, or sidewalks they have a legally bound impact on the ways in which skateboarders can navigate the city and utilize space.

These strategies are demonstrative of Flusty's (1994) taxonomy of interdictory space: exclusionary architecture creates prickly spaces (or spaces that cannot be comfortably occupied), surveillance creates jittery spaces (or spaces which cannot be utilized unobserved), and, for some, isolation and criminalization creates slippery spaces (or spaces that cannot be reached). These systems of spatial control are complex networks that work to dictate who may use urban space and how urban space may be used. The fortification and control of space is a "socio-spatial strategy" (Davis, 2006), which creates spaces of "designed-and-contrived diversity" (Mitchell, 1995) where interaction is carefully planned to create a desirable image for some at the expense of others. The exclusion of certain individuals from public space to increase the experience of others questions the actual publicness of public space and citizenship of the excluded.

\section{Skateboarding Transportation}

As bicycling and walking were not too long ago, skateboarding is generally thought of as a recreational activity. However, like other active modes, the activity of skateboarding is inseparable from the notion of mobility; the recreational pursuit of street skateboarding and the common practice of "cruising" encompass the flow of skateboarders through the city streets. In recent years, studies have shown that skateboarding is being utilized as an effective means of transportation by individuals across the United States and Canada (Fang, 2015; Fang and Handy, 2017b; Walker, 2013). 
Federal, state, and local governments strongly advocate for the enhancement of active transportation; however, their focus is almost entirely on pedestrians and bicyclists. The FHWA defines a pedestrian as "a person moving from place to place on foot or with assistance, such as with a wheelchair or guide dog” (Biton et al., 2017, p. 3). While this definition appears to include skateboarders, cities tend to isolate skateboarding and employ a distinct set of traffic laws which regulate their use of transportation facilities. For example, Portland, OR's website distinguishes the two in stating, "Downtown sidewalks are for pedestrians. Skateboarders may use most streets but are required to stay off the sidewalks in the downtown core" (The City of Portland, 2018; italics added). In turn, government funded policies and programs designed to enhance bicycle and pedestrian transportation often neglect skateboarding, even though it provides many of the same benefits (i.e. physical activity, reduction of emissions, alternative choices, and access to employment).

Utilizing data from a variety of sources in California, Fang (2015) quantified the use of skateboarding transportation and provided anecdotal evidence that it has a large enough presence to be actively acknowledged by transportation planners. In this study Fang found that at the University of California, Santa Barbara there is share of college students who commute by skateboard (7\%) is larger than those who drive alone (6\%). The evidence provided in this study reveals importance of skateboarding as first- and last-mile mode and for and intercampus trips; while some college skateboard commuters ride for the entirety of their trip, it appears that skateboarding is more commonly used as a "secondary travel mode." Utilizing data from the California Household Travel Survey, 
Fang infers that skateboarders and users of other non-motorized modes (excluding walkers, bicyclists, and wheelchair users) travel more than 130,000 miles per day and approximately 48 million miles per year in California; the mode share for these modes is higher than other widely-recognized modes (i.e. taxis, ferry boats, paratransit, and streetcars). Fang's research shows that skateboarding is a rising mode of mobility and infers that skateboarding merits recognition from transportation planners and researchers.

Fang (2013) found that $90 \%$ of the Californian cities in his sample $(n=60)$ had regulations addressing the use of skateboarding within the city, particularly on transportation facilities. He argues that the regulations which have been set in place to mitigate the concerns of recreational skateboarding present serious legal barriers to utilizing skateboarding as a viable mode of transportation. Regulations range from bans on specific facilities such as sidewalks and streets to prohibitions within entire geographic areas, such as the central business district (CBD); the later prohibition makes it illegal for an individual who works or lives in the CBD to commute by skateboard. Interestingly, one city deemed it necessary to acknowledge that someone carrying a skateboard is not subject to the same restrictions as somebody riding a skateboard. In other cities, negative tones and language towards skateboarding were utilized in the writing of the regulations. Fang found that when reasons for the regulations were provided they commonly included safety and property damage concerns, complaints from the elderly, and inconveniences to business owners. The findings from Fang's research are in accordance with the vast literature on the social exclusion of skateboarders from 
the public realm for the benefit of the 'legitimate public' (Wooley et al., 2011; Howell, 2001; Owens, 2001; Chui, 2009; Vivoni, 2009).

In a study of skateboarders at UC Davis, Fang and Handy (2017b) find that fun and enjoyment is most fundamental reason individual choose commute by skateboard; however, the high values attributed to convenience, speed, and economic efficiency indicate that skateboarders also consider the practical qualities of mode choice and are not solely motivated by fun. The authors claim that being frequently exposed to skateboarding can facilitate an increase in ridership, as was found by Dill and Voros (2007) with bicycling. Fang and Handy show that skateboarders value the presence of bike lanes and paths separated from automobile traffic, quality surface conditions, minimal grade change, and dry climate. Results from his study suggest that the travel behavior of skateboarders can be explained by the same theory as other types of commuters, although they attribute higher values to enjoyment than they do convenience and safety (contrary to bicyclists). However, another study by Fang and Handy (2017a) revealed that the relatively low concern for safety is not necessarily representative of the potential risks of skateboarding; skateboarders have a relatively high fatality rate per distance traveled, when compared to bicyclists and motorists.

In a study of utilitarian skateboarders in the U.S. and Canada, Walker (2013) found that skateboarders value the enjoyment, exercise, and convenience derived from their mode choice. She identifies surface condition, vulnerability to wet conditions, and social stigmatization as key disadvantages of skateboarding. Similar to Broach's (2016) findings on pedestrian route choice indicators, her results indicate quality street 
environment, low traffic, and gentle grade change to be the most important features of a desired skate route. Both Walker (2013) and Fang and Handy (2017b) argue that the built environment can provide significant benefits as well as barriers to utilitarian skateboarding. Additionally, they reveal that, despite common perceptions, skateboarders are not irrational actors and consider various factors to make complex mode and route choice decisions. While research has shown bicyclist and pedestrians derive satisfaction from the routine activity of travel, which is often perceived as unenjoyable and stressful (Gatersleben and Uzzell, 2007), the studies presented in this section suggest that the positive utility of travel may be even greater for skateboard commuters. In the following section I will present my research questions, the objectives of this study, and the methodology utilized. 


\section{Methodology}

The Federal Highway Administration claims that a clear understanding of the barriers and motivations to pedestrian and bicycle travel is essential in designing infrastructure and developing policies meant to "tap latent demand for non-motorized travel" (National Bicycling and Walking Study, 1992, p. 9). The purpose of this research is to begin to examine these factors as they relate to skateboarding, and to provide insight into certain aspects of this unique and under-studied mode of transportation. The primary research questions investigated in this study include: 1) What are the key motivations and barriers to utilizing skateboarding as a mode of transportation?; 2) What are the social, legal, and environmental factors that impact route choice amongst utilitarian skateboarders?; 3) How do skateboarders utilize and value the existing transportation infrastructure?; and 4) Do the answers to these questions differ in accordance with the skateboarders' personal characteristics (i.e. gender, skill, and frequency of use), and if so why?

My pursuance of this research topic was inspired by four interconnected elements. First and foremost, was my own subjective connection to skateboarding; over the past 16 years skateboarding has contributed significantly to my well-being and identity and has been a critical component of my everyday travel routine. Second, I recognized a large gap in the active transportation literature which focused primarily on bicyclists and pedestrians and, in turn, noticed a lack of academic research addressing skateboarding as a mode of transportation. Third, I sought to provide research findings which could inform future transportation policy and promote more inclusive transportation networks by accommodating users not typically considered by decision makers. Finally, I was eager to 
understand and illuminate the ways in which social, legal, and physical barriers impact the way skateboarders navigate the city.

A mixed methods approach was utilized to investigate the questions presented above. As classified by Padgett (2012), this study follows a dominant/less-dominant design (QUAN\#qual). The dominant segment of this study is quantitative. An online survey was designed to capture the perceptions and experiences of a large sample of utilitarian skateboarders. The less-dominant, or qualitative, segment was utilized to enhance the ecological validity of the study (Padgett, 2012). Semi-structured interviews were conducted to provide further insight and clarification to the survey results. The data collection and analysis occurred sequentially, in order of priority.

The survey consisted of 34 questions which were separated into four primary sections. The survey questions addressed general information about skateboard use and experience, mode choice factors and barriers, route choice factors, comfort levels, and demographic information (Appendix A). The survey questions were informed by previous studies on skateboarding transportation (Fang and Handy, 2017b; Walker, 2013) and similar research focusing on bicycle and pedestrian transportation. I also included questions which address issues not commonly considered in transportation surveys (e.g. playful travel, lifestyle and self-identity, and perceived social acceptance); these questions were meant to highlight the unique attributes of this resourceful mode of mobility and were informed by my extensive personal experience traveling by skateboard. Multiple open-ended questions were utilized to collect supportive qualitative data about skateboarders' perceptions and experiences. Before distribution, the survey 
was reviewed by academic advisors and tested by peers; feedback was utilized to adjust and restructure the survey.

The online survey was open from October, 162017 until February, 20 2018. The survey was made available to skateboarders 18 years or older; each respondent who completed the survey had the option to enter a drawing for a $\$ 50$ gift certificate to Daddies Boardshop. Survey participants were recruited through a variety of methods. The online survey link was distributed through various social media platforms and e-mails to skateboard retailers, manufacturers, and organizations. Approximately 250 business cards were handed out during intercepts with local skateboarders and meetings with local skate shops. Potentially interested parties were identified within my personal network and through extensive web research on skateboarding and active transportation advocacy. Fliers were also distributed in select neighborhoods and businesses around Portland, OR. As a result of the outreach efforts, the survey was shared on various skateboarding- and transportation-oriented websites, blogs, and social media pages. Daddies Boardshop, NW Skate Coalition, Skate Like a Girl PDX, and Portland State University's Transportation Research and Education Center (TREC) were among the most active promoters of this study.

A total of 390 surveys were recorded for analysis. Only 28 of those respondents (7\%) did not complete the survey to entirety but were included because they had completed the survey past a point deemed acceptable (Progress $\geq 43 \%$ ). Figure 1 shows the spatial distribution of respondents within the United States (92\%), and Table 1 provides the number of responses per state as well as the breakdown of international 
responses $(8 \% ; n=362)$. There is a clear cluster of respondents surrounding Portland, OR. Other clusters appear around large cities such as San Francisco, CA, Los Angeles, CA, Seattle, WA, Denver, CO, and New York City, NY. These cities represent the vast majority of respondents.

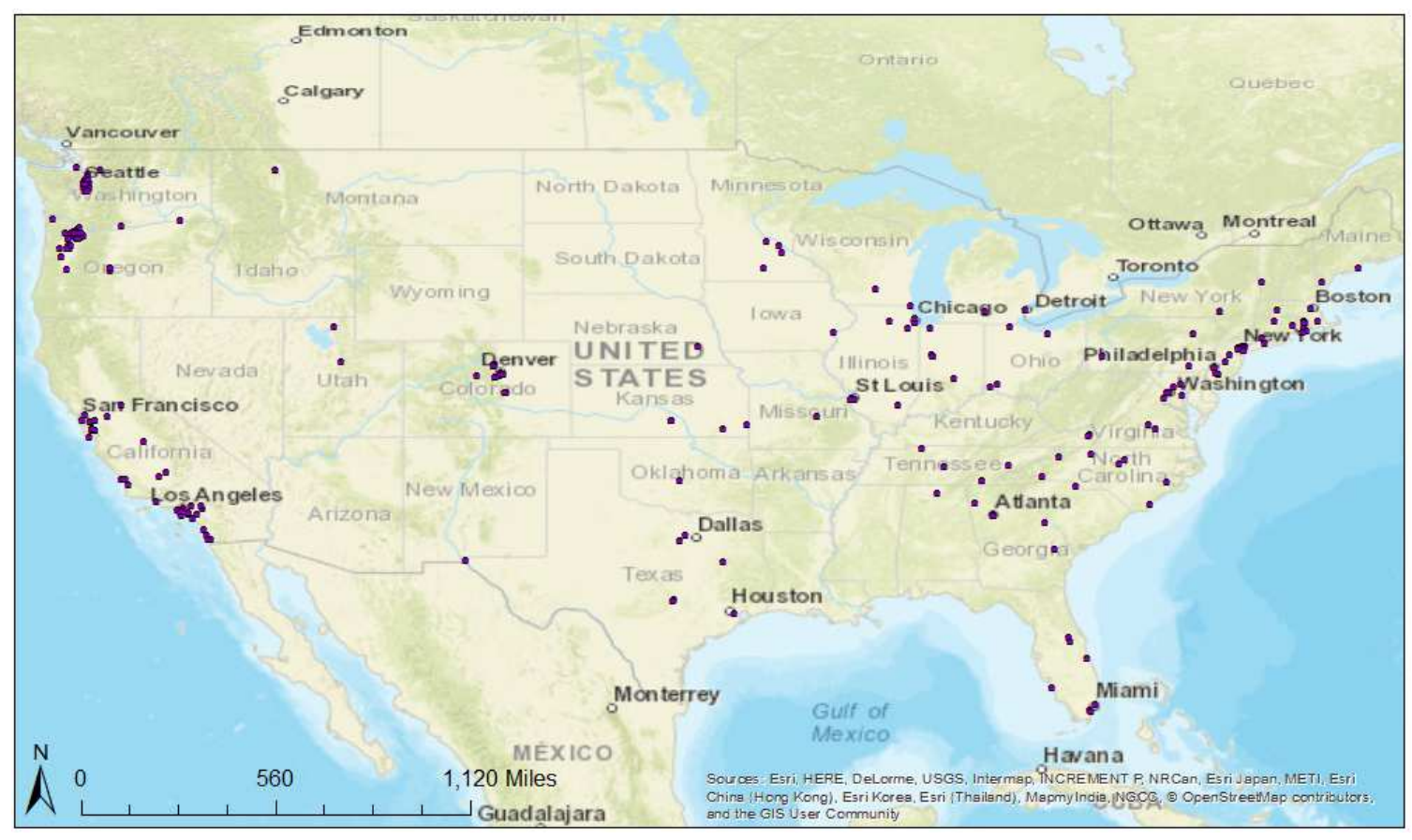

Figure 1: Distribution of US Respondents (Sources: Esri) 
Table 1: Responses by State \& Breakdown of International Responses

\begin{tabular}{|c|c|c|c|}
\hline United States $(n=334)$ & Count & United States Cont. & Count \\
\hline Oregon & 117 & Massachusetts & 3 \\
\hline California & 39 & Wisconsin & 2 \\
\hline Washington & 36 & Utah & 2 \\
\hline Colorado & 13 & Maine & 2 \\
\hline New York & 12 & Michigan & 2 \\
\hline Kansas & 9 & District of Columbia & 2 \\
\hline New Jersey & 8 & Vermont & 1 \\
\hline Florida & 7 & Nebraska & 1 \\
\hline Illinois & 7 & Alabama & 1 \\
\hline North Carolina & 7 & South Carolina & 1 \\
\hline Texas & 7 & Oklahoma & 1 \\
\hline Rhode Island & 6 & Hawaii & 1 \\
\hline Georgia & 6 & Montana & 1 \\
\hline Virginia & 6 & Puerto Rico & 1 \\
\hline Pennsylvania & 5 & International $(n=28)$ & Count \\
\hline Tennessee & 5 & Europe & 13 \\
\hline Indiana & 5 & Canada & 7 \\
\hline Minnesota & 4 & Africa & 3 \\
\hline Ohio & 4 & Asia & 3 \\
\hline Missouri & 4 & Australia & 1 \\
\hline Maryland & 3 & South America & 1 \\
\hline Connecticut & 3 & & \\
\hline
\end{tabular}

The exported survey responses were cleaned and coded to prepare the data for analysis. Data cleaning efforts included carefully editing write-in responses to match the desired variable type (e.g. convert written numbers to numeric values); coding Likert scale responses as numerical variables; examining write-in responses for text fields to see if they fall under a prescribed category; recoding variables to create groupings; and breaking apart "select all that apply" responses to create binary variables. Responses were then analyzed utilizing SPSS statistical software. Frequency reports were interpreted to identify trends and common perceptions amongst skateboarders. Bivariate analyses were executed and interpreted to highlight significant differences across various populations of skateboarders. Prior to the analysis, gender, skill level, and frequency of 
utilitarian skateboarding were identified as the explanatory variables to be used to disaggregate and compare responses. These groupings and subsequent hypotheses were informed by existing literature and personal experience. Depending on the structure of the variables in a given analysis, hypotheses were tested utilizing either a chi-squared test of independence (test for equality of proportions) or an independent samples t-test.

For simplicity's sake, the hypotheses were kept static through the entirety of the study. Chi-squared tests were utilized to identify similarities and differences in perceptions and experiences amongst groups. Independent sample t-tests were utilized to assess differences in attitudinal values and comfort levels; for each of the t-tests I expect to find the values to be higher for males, more skilled skateboarders, and frequent utilitarian skateboarders. In other words, it is expected that these groups attribute higher values to certain aspects of utilitarian skateboarding and feel more comfortable traveling by skateboard than their counterparts. Justification for each of the hypotheses will be provided in the corresponding sections.

To support the survey results, I conducted five semi-structured interviews with skateboarders who were living in Portland, OR at the time of the study; each interview participant received a $\$ 10$ gift certificate to Daddies Boardshop. Interviews typically lasted around 30 minutes. Again, these questions were inspired by existing skateboarding and active transportation literature as well as my past experiences. The interview guide was generated at the same time as the survey; however, analysis of the survey results led to minor revisions. Most of the questions were designed to provide further insight into the survey findings, while others were designed to provide nuances and address issues not 
easily captured by questionnaire responses (Appendix B). The interviews were transcribed and coded utilizing five identified themes, including "Advantages," "Barriers," "Route Choice," "Identity," and "Social Acceptance." These themes were identified as areas in need of further clarification given the explanatory limitations of the survey data.

This study, like most, consisted of various methodological limitations. First, it is important to acknowledge that this survey was not randomly distributed, and results may not accurately represent the overall population of utilitarian skateboarders; however, given the exploratory nature of the study and the nuance of the topic, this strategy was the most feasible and suitable option. Furthermore, the survey sample size greatly surpassed my initial expectations and those used in previous studies; Fang and Handy (2017b) examined a sample of 41 survey respondents, and while Walker (2013) collected a sample size of 464, many of the questions were skipped by 100 or more respondents. As skateboarding continues to grow as a mode of transportation, more rigorous sampling techniques can be applied.

Another important limitation was that the majority of participant recruitment for the survey portion took place online. Thus, individuals with limited access to a computer or smartphone may have been underrepresented. Future research should address this issue because skateboarding is a cost-effective mode of transportation and may have the capacity to serve the mobility needs of economically disadvantaged populations. This study was also limited to individuals over the age of 18 . By excluding younger individuals, a significant portion of the skateboarding population has been left out. Safe 
Routes to School and similar programs could greatly benefit on a study focused on younger skateboarders. Lastly, a more intimate analysis of the interview results may have supported a more meaningful use of the substantial amounts of data; however, due to time constraints, the qualitative analysis was limited, yet it provided a significant contribution to the study. 


\section{Study Findings}

\section{Respondent Characteristics}

\section{Demographics}

Demographic results presented in Table 2 show that respondents were predominately white $(76 \%)$, male $(86 \%)$, younger than 34 years old $(80 \%)$, and have attended or graduated from college (75\%). The results portray a fairly even distribution of the responding skateboarders across all income groups. The majority of respondents were employed (74\%), renters $(62 \%)$, licensed drivers $(88 \%)$, and lived in households with one or more vehicle per adult (61\%) and no children (71\%).

Skateboarding is most commonly thought of as a recreational activity embraced and performed by young individuals; however, a notable proportion of respondents were older than $35(20 \%)$. As an individual ages many things may deter them from skateboarding both recreationally and as form of transportation. These factors are not likely to be mutually exclusive to one use or the other. Such factors include actual and perceived risk, changing priorities (i.e. work and family), changes in physical health and stamina, and social norms and public perception. However, the results indicate that there is a moderate presence of adults 35 years and older within the skateboarding world and that the transportation choice is not only viable for children and young adults. 
Table 2: Individual and Household Demographic Characteristics

\begin{tabular}{|c|c|c|c|c|c|}
\hline Characteristics (n) & Survey & $\begin{array}{c}\text { U.S. } \\
\text { Census }\end{array}$ & Characteristics (n) & Survey & $\begin{array}{c}\text { U.S. } \\
\text { Census }\end{array}$ \\
\hline Gender (362) & & & Education (360) & & \\
\hline Male & $86 \%$ & $49 \%$ & Some high school or less & $6 \%$ & $13 \%$ \\
\hline Female & $13 \%$ & $51 \%$ & High school diploma or GED & $19 \%$ & $28 \%$ \\
\hline Non-Binary & $1 \%$ & $\mathrm{~N} / \mathrm{A}$ & Some college or Associate's & $39 \%$ & $31 \%$ \\
\hline Race/Ethnicity (359) & & & $\begin{array}{l}\text { Four-year college degree or } \\
\text { higher }\end{array}$ & $36 \%$ & $28 \%$ \\
\hline Asian & $4 \%$ & $5 \%$ & Employment (359) & & \\
\hline $\begin{array}{l}\text { Black or African } \\
\text { American }\end{array}$ & $1 \%$ & $13 \%$ & $\begin{array}{l}\text { Employed full-time or part- } \\
\text { time }\end{array}$ & $74 \%$ & $58 \%$ \\
\hline Hispanic or Latino/a & $8 \%$ & N/A & School only & $19 \%$ & $\mathrm{~N} / \mathrm{A}$ \\
\hline White or Caucasian & $76 \%$ & $73 \%$ & Neither & $7 \%$ & $7 \%$ \\
\hline Other & $11 \%$ & $9 \%$ & Vehicles in Household (359) & & \\
\hline Age (361)* & & & One or more vehicle per adult & $61 \%$ & $55 \%$ \\
\hline $18-24$ & $52 \%$ & $10 \%$ & More adults than vehicles & $39 \%$ & $45 \%$ \\
\hline $25-34$ & $28 \%$ & $14 \%$ & Children in Household (353) & & \\
\hline $35-44$ & $9 \%$ & $13 \%$ & No children & $71 \%$ & $32 \%$ \\
\hline $45-54$ & $9 \%$ & $14 \%$ & One or more child & $29 \%$ & $68 \%$ \\
\hline $55+$ & $2 \%$ & $27 \%$ & Tenure (359) & & \\
\hline Income (358) & & & Rent & $62 \%$ & $36 \%$ \\
\hline Less than $\$ 25,000$ & $15 \%$ & $22 \%$ & Own & $33 \%$ & $64 \%$ \\
\hline$\$ 25,000-\$ 49,999$ & $20 \%$ & $23 \%$ & Other & $5 \%$ & $\mathrm{~N} / \mathrm{A}$ \\
\hline$\$ 50,000-\$ 74,999$ & $16 \%$ & $18 \%$ & Driver's License (360) & & \\
\hline$\$ 75,000$ - \$99,999 & $11 \%$ & $12 \%$ & Yes & $88 \%$ & $85 \% * *$ \\
\hline More than $\$ 100,000$ & $15 \%$ & $24 \%$ & & & \\
\hline I prefer not to say & $23 \%$ & $\mathrm{~N} / \mathrm{A}$ & & & \\
\hline
\end{tabular}

Note: US Census data gathered from 2016 ACS 5-year estimates

* US estimates do not add up to $100 \%$ due to missing age groups

** USDOT Bureau of Transportation Statistics (2013)

Females account for $13 \%$ of the sample, which is higher than figures found in other studies; in both Beal (1996) and Walker's (2013) studies females accounted for $10 \%$ and $8 \%$ of the sample, respectively. Skateboarding is often, and justifiably, defined as a male-dominated activity with considerable gender bias. Beal (1996) found that female skateboarders tend to face additional barriers to entry, which are shaped and reinforced by their male counterparts; female participants in Beal's study felt unwelcome until they were able to prove their masculinity, because male assumptions of femininity 
were not accepted in the subculture of skateboarding. Assumptions of sex differences (female appearance, natural aptitudes, and social roles) create social barriers that have the capacity to inhibit female participation in recreational skateboarding. Furthermore, Hart (1979) found that, during childhood, boys have less restricted spatial boundaries than do girls; these boundaries can potentially impact physical activity and roaming as adults. These obstacles can have notable impact on the future of skateboarding transportation, because individuals who utilize skateboarding as a form of transportation often start recreationally at a younger age (Fang and Handy, 2017b; Walker, 2013). During this period of time skateboarders are able to acquire the fundamental skills required to get from place to place. Thus, addressing the gender bias in skateboarding will be an essential component of enhancing skateboarding transportation, and it will likely be most successful if done in the realm of recreation.

As discussed in previous sections, skateboarders are often conflated with individuals of lower socioeconomic class; however, the survey results indicate that skateboarders come from households with varying incomes and cannot be defined as a low income population. Furthermore, the vast majority of respondents were currently attending school or employed (93\%) and had some college experience $(73 \%)$ at the time they took the survey. While skateboarding as a form of recreation and transportation may question societal norms, skateboarders have and continue to contribute to the social and economic vitality of cities.

The possession of a valid driver's license, access to a vehicle, and the presence of children may impact an individual's propensity to utilize skateboarding as a mode of 
transportation. Having the option to drive instead of skateboard may influence individuals' mode choices for various trips. While the majority of respondents have a valid driver's license and access to one or more vehicle, there remains a notable portion who do not (13\% and 39\%, respectively). Lastly, having the responsibility to transport children and additional cargo is likely to make skateboarding a less viable mode for certain trips.

\section{Skill and Experience}

Respondents' self-assessed their skill level utilizing four prescribed categories, beginner, intermediate, advanced, and expert. Only $8 \%$ of the respondents identified as beginner, $51 \%$ identified as intermediate, $34 \%$ as advanced, and $7 \%$ as expert $(\mathrm{n}=390)$. According to results from a chi-squared test of independence, female respondents were significantly more likely to identify as a beginner or intermediate skateboarder (83\%) when compared to males $(56 \%)(\mathrm{n}=311 ; \mathrm{df}=1 ; \mathrm{p}<.000)$.

Respondents were also asked to report the age at which they started skateboarding for recreation and transportation purposes; the minimum of the respondents' answers to both questions was used to calculate the age they started skateboarding in general. The average age respondents started skateboarding was approximately 14 years old $(n=390)$, which was also the average age respondents started skateboarding for recreation $(n=389)$. The vast majority of respondents did not start utilizing skateboarding as a form of transportation until a year or more after they had been skateboarding recreationally $(60 \%$; $\mathrm{n}=380$ ). Consequentially, the average age respondents started skateboarding for transportation was $18(\mathrm{n}=381)$. 
Table 3 shows at what stage in their life respondents started skateboarding for each purpose. For both purposes, the majority of respondents started skateboarding as a child. However, the proportion of respondents who started skateboarding as an adult is greater for transportation (36\%) than it is recreation (19\%). Again, this is representative of the gap in time between recreation and transportation. The proportions for "age started" and "age started for recreation" columns vary by only one percent in two of the age groups. Although small, these differences portray how the adoption process of skateboarding may differ between various age groups. In fact, respondents who started later in their life (25 years or older) were far more likely to start skateboarding for recreation and transportation in the same year (80\%) compared to those who started earlier in life $(36 \%)(n=380)$. Conversely, individuals who start skateboarding at a younger age were significantly more likely to start skateboarding for recreational purposes before using it as a mode of transportation.

Table 3: Age Started Skateboarding for Recreational and Transpotation Purposes

\begin{tabular}{lccc}
\hline Age Group & $\begin{array}{c}\text { Age Started } \\
\text { Skateboarding }\end{array}$ & $\begin{array}{c}\text { Age Started } \\
\text { skateboarding } \\
\text { for recreation }\end{array}$ & $\begin{array}{c}\text { Age Started } \\
\text { skateboarding for } \\
\text { transportation }\end{array}$ \\
\hline Less than 10 years old & $22 \%$ & $22 \%$ & $5 \%$ \\
10-17 years old & $60 \%$ & $59 \%$ & $59 \%$ \\
18-24 years old & $10 \%$ & $10 \%$ & $22 \%$ \\
25-30 years old & $3 \%$ & $3 \%$ & $6 \%$ \\
Greater than 31 years old & $5 \%$ & $6 \%$ & $8 \%$ \\
\hline $\mathrm{n}$ & 390 & 389 & 381 \\
\hline Mean & 14 & 14 & 18 \\
Median & 13 & 13 & 15 \\
Std. Deviation & 8.4 & 9.0 & 8.3 \\
\hline
\end{tabular}




\section{Frequency and Primary Use}

Figure 2 shows how often respondents reported skateboarding for recreational and transportation purposes. The majority of respondents reported that they currently skateboard at least one time per week; 75 percent were skateboarding once a week or more for recreation and 66 percent for transportation. Respondents were more likely to report skateboarding five or more days a week for transportation (22\%) than they were recreation $(17 \%)$.

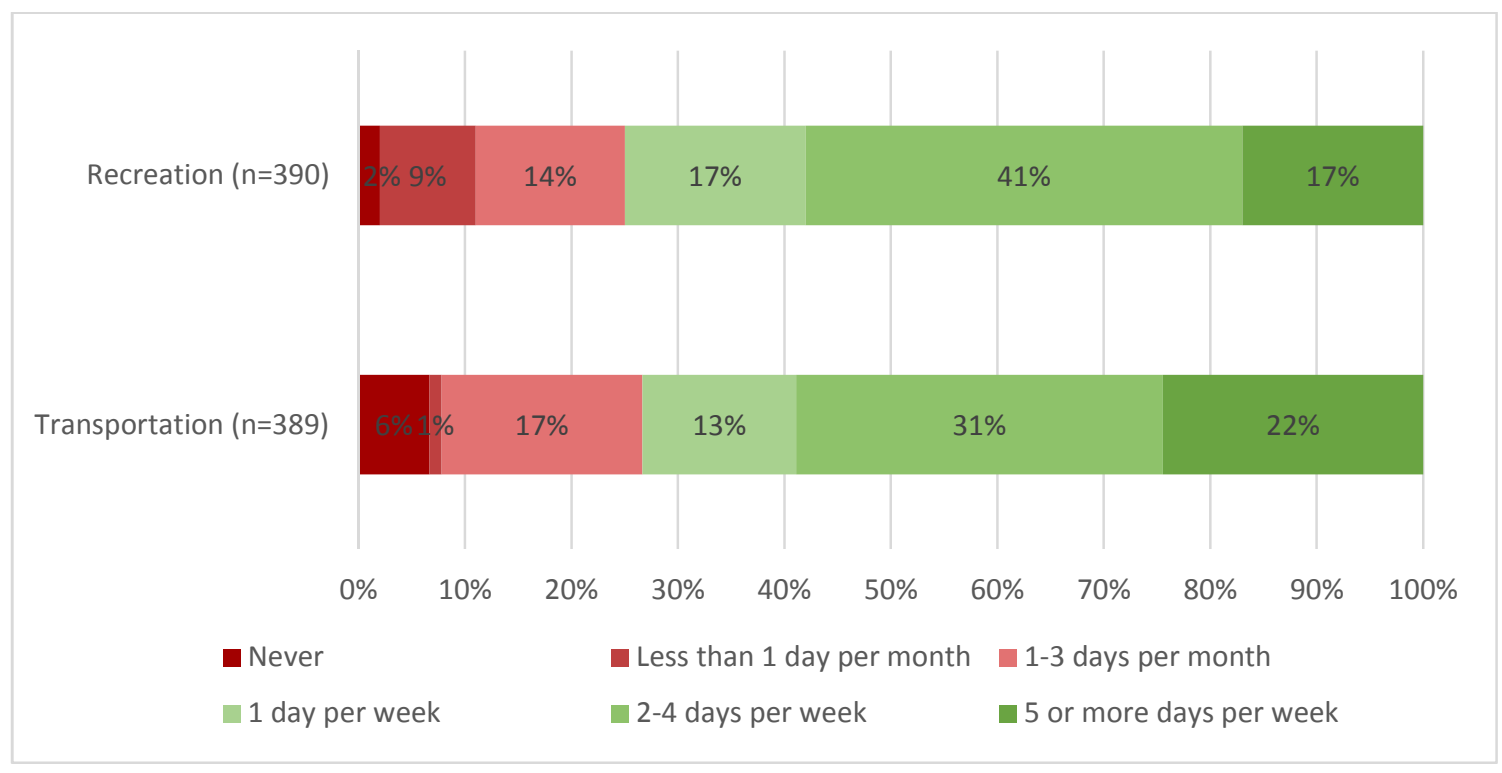

Figure 2: Frequency of Use

Two groups were created to categorize respondents by the frequency that they reported skateboarding for transportation. Respondents who reported skateboarding for transportation less than once a week were categorized as 'infrequent users' and those who reported skateboarding for transportation once a week or more were categorized as 'frequent users' (these categories will be used for the remainder of the paper). Disaggregating demographic characteristics utilizing these groups highlighted significant 
differences in use between populations (Table 4). Chi-squared results indicated that males, younger adults, and less educated respondents were significantly more likely than their counterparts to be frequent skateboarders. Respondents without a valid driver's license were also far more likely to skateboard for transportation once a week or more (78\%) than respondents with a license (65\%). This finding is supported by an open-ended response from one of the skateboarders who stated, "up until about a year ago I didn't have a license, so skateboarding and using public transportation was all I had" (Anonymous Respondent).

Table 4: Frequency of Transportation-Oriented Skateboarding by Demographics

\begin{tabular}{|c|c|c|c|c|}
\hline Characteristics & $\begin{array}{c}\text { Infrequent } \\
\text { Users }\end{array}$ & $\begin{array}{c}\text { Frequent } \\
\text { Users }\end{array}$ & $\mathrm{n}$ & $\chi^{2}$ \\
\hline \multicolumn{5}{|l|}{ Individual } \\
\hline Male & $30 \%$ & $70 \%$ & 310 & \multirow{2}{*}{$11.773 * *$} \\
\hline Female & $55 \%$ & $45 \%$ & 47 & \\
\hline Younger than 25 & $25 \%$ & $75 \%$ & 189 & \multirow{2}{*}{$12.832 * *$} \\
\hline Older than 25 & $43 \%$ & $57 \%$ & 171 & \\
\hline White Only & $33 \%$ & $68 \%$ & 271 & \multirow{2}{*}{0.022} \\
\hline Non-White & $33 \%$ & $67 \%$ & 87 & \\
\hline No Valid Driver's License & $22 \%$ & $78 \%$ & 45 & \multirow{2}{*}{$2.902 *$} \\
\hline Valid Driver's License & $35 \%$ & $65 \%$ & 314 & \\
\hline No College Experience & $18 \%$ & $82 \%$ & 89 & \multirow{2}{*}{$12.289 * *$} \\
\hline College Experience & $38 \%$ & $62 \%$ & 270 & \\
\hline \multicolumn{5}{|l|}{ Household } \\
\hline No Children & $32 \%$ & $69 \%$ & 251 & \multirow{2}{*}{1.647} \\
\hline Children & $39 \%$ & $61 \%$ & 101 & \\
\hline More Adults than Cars & $31 \%$ & $69 \%$ & 140 & \multirow{2}{*}{0.244} \\
\hline One or More Cars per Adult & $34 \%$ & $66 \%$ & 218 & \\
\hline Lower Income $(<\$ 55,000 \mathrm{AHI})$ & $32 \%$ & $68 \%$ & 126 & \multirow{2}{*}{1.534} \\
\hline Higher Income $(>\$ 55,000 \mathrm{AHI})$ & $39 \%$ & $61 \%$ & 149 & \\
\hline
\end{tabular}

Furthermore, these questions were used determine respondents' primary use of skateboarding. Most respondents rode for both purposes equally (40\%), followed by 
recreation more frequently (36\%), and transportation more frequently (24\%). Given the playful nature of skateboarding and its inherent relationship with mobility there is a thin line between recreation- and transportation-oriented skateboarding. For example, various researchers have observed what may be considered a "recreational pursuit" in street skateboarding, in which skateboarders travel from one skate spot to another through the urban fabric. While this is likely to be considered a recreational activity by skateboarders, the individuals are reliant on the various transportation facilities which connect them to their destinations. Additionally, the common skateboarding practice of "cruising" involves continuous movement down the street, sidewalk, or path, but is not necessarily a destination-oriented trip. Cruising could be compared to "taking the car out for a spin."

Two groups were created to categorize respondents by their primary use (see Table 5). Again, these groups were disaggregated by various demographic characteristics to highlight differences in use. Chi-squared results indicated that respondents' primary use for skateboarding is dependent on their access to a motor vehicle; respondents living in households with less than one vehicle per adult were more likely to skateboard equally or more frequently for transportation and less likely to primarily skateboard for recreation. Lower income respondents were also more likely to skateboard for transportation purposes equally or more frequently than for recreation. These results indicate that skateboarding transportation may play an important role in socioeconomically disadvantaged households. Future research should explore this relationship in detail. Interestingly, individual characteristics, such as gender, race, and age were not significant. 
Table 5: Primary Use by Demographic Characteristics

\begin{tabular}{|c|c|c|c|c|}
\hline Characteristics & $\begin{array}{l}\text { Recreation } \\
\text { More } \\
\text { Frequently }\end{array}$ & $\begin{array}{c}\text { Transportation } \\
\text { Equally or More } \\
\text { Frequently }\end{array}$ & $\mathrm{n}$ & $\chi^{2}$ \\
\hline \multicolumn{5}{|l|}{ Individual } \\
\hline Male & $36 \%$ & $64 \%$ & 310 & \multirow{2}{*}{0.316} \\
\hline Female & $32 \%$ & $68 \%$ & 47 & \\
\hline Younger than 25 & $35 \%$ & $65 \%$ & 189 & \multirow{2}{*}{0.002} \\
\hline Older than 25 & $36 \%$ & $64 \%$ & 171 & \\
\hline White Only & $34 \%$ & $66 \%$ & 271 & \multirow{2}{*}{1.750} \\
\hline Non-White & $41 \%$ & $59 \%$ & 87 & \\
\hline No Valid Driver's License & $27 \%$ & $73 \%$ & 45 & \multirow{2}{*}{1.812} \\
\hline Valid Driver's License & $37 \%$ & $63 \%$ & 314 & \\
\hline No College Experience & $38 \%$ & $62 \%$ & 89 & \multirow{2}{*}{0.335} \\
\hline College Experience & $35 \%$ & $65 \%$ & 270 & \\
\hline \multicolumn{5}{|l|}{ Household } \\
\hline No Children & $34 \%$ & $67 \%$ & 251 & \multirow{2}{*}{1.598} \\
\hline Children & $41 \%$ & $59 \%$ & 101 & \\
\hline More Adults than Cars & $29 \%$ & $71 \%$ & 140 & \multirow{2}{*}{$4.787 * *$} \\
\hline One or More Cars per Adult & $40 \%$ & $60 \%$ & 218 & \\
\hline Lower Income $(<\$ 55,000$ AHI) & $31 \%$ & $69 \%$ & 126 & \multirow{2}{*}{$3.337 *$} \\
\hline Higher Income $(>\$ 55,000 \mathrm{AHI})$ & $42 \%$ & $58 \%$ & 149 & \\
\hline
\end{tabular}

Note: $\mathrm{df}=1 ;{ }^{*} \mathrm{p}<.10 ; * * \mathrm{p}<.05$

\section{Types of Skateboard}

The types of skateboard that respondents reported using for transportation purposes varied (Table 6). Those who rode a longboard only accounted for the largest proportion of respondents (42\%), followed by those who rode multiple types of skateboard $(37 \%)$, skateboard only (15\%), and those who rode a cruiser only (6\%). Table 6 also shows the breakdown of the types of skateboard selected by those who chose more than one option. Each type of skateboard offers a different set of benefits and drawbacks (see Figure 3 for visual reference of the types of skateboards). Skateboards and cruisers are smaller and can be easily stored on the bus or train or at an individual's destination. The small wheels of a skateboard make them more vulnerable to rough surfaces and are generally slower, 
which can make longer distances a challenge. Longboards and cruisers generally have larger wheels which can help minimize the impact of cracks and road debris and make traveling long distances much easier. Longboards also tend to be faster which may make them more appealing for transportation purposes; however, the design and weight of longboards can limit the user's ability to maneuver through tight spaces and over larger obstacles without dismounting. It is likely that if respondents have access to multiple types of skateboards, the purpose, distance, and physical environment of the trip will likely impact which board they choose.

Table 6: Types of Skateboards Used

\begin{tabular}{|c|c|c|}
\hline Skateboard Type & Count & Percent \\
\hline Longboard Only & 160 & $42 \%$ \\
\hline Multiple Types & 145 & $37 \%$ \\
\hline Skateboard Only & 59 & $15 \%$ \\
\hline Cruiser Only & 22 & $6 \%$ \\
\hline Total & 386 & $100 \%$ \\
\hline \multicolumn{3}{|c|}{ Breakdown of Multiple Types $(n=145$} \\
\hline Longboard + & 118 & $81 \%$ \\
\hline Cruiser + & 100 & $69 \%$ \\
\hline Skateboard + & 95 & $66 \%$ \\
\hline Electric + & 8 & $6 \%$ \\
\hline
\end{tabular}

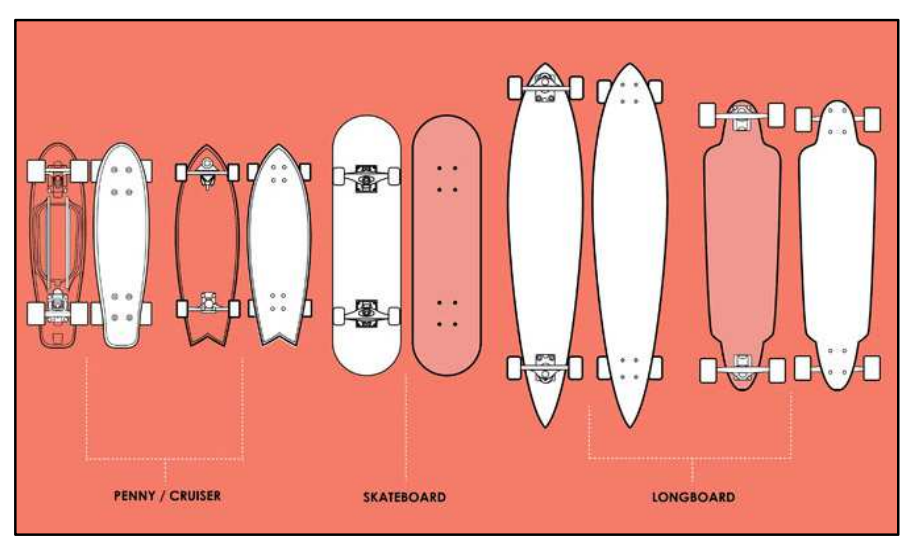

Figure 3: Types of Skateboards (image from www.boardriding.com)

\section{General Travel Behavior}

\section{Trip Characteristics}

Results presented in Table 7 show that skateboards are used for numerous types of destination-oriented trips; $62 \%$ of the respondents reported utilizing their skateboards for commuting to work and school, $71 \%$ for personal errands, $55 \%$ to reach destinations for entertainment, dining out, or socializing, and 55\% to get to skateparks and skate spots. While recreational trips were the most commonly selected choice (81\%), it is evident that 
skateboarding fulfills the needs for various utilitarian trips for the majority of respondents.

Table 7: Types of Trip Made by Skateboard by Selected Characteristics

\begin{tabular}{lc|cc|cc|cc}
\hline & \multicolumn{7}{c}{ Percent of Responses by Group } \\
\cline { 2 - 8 } Trip Type & All & Female & Male & $\begin{array}{c}\text { Less } \\
\text { Experienced }\end{array}$ & $\begin{array}{c}\text { More } \\
\text { Experienced }\end{array}$ & $\begin{array}{c}\text { Infrequent } \\
\text { Users }\end{array}$ & $\begin{array}{c}\text { Frequent } \\
\text { Users }\end{array}$ \\
\hline Commuting & $62 \%$ & $\underline{51 \%}$ & $\underline{64 \%}$ & $\mathbf{5 8 \%}$ & $\mathbf{6 8 \%}$ & $\mathbf{3 0 \%}$ & $\mathbf{7 8 \%}$ \\
Personal Errands & $71 \%$ & $66 \%$ & $73 \%$ & $69 \%$ & $74 \%$ & $\mathbf{5 5 \%}$ & $\mathbf{8 0 \%}$ \\
Entertainment & $55 \%$ & $\underline{68 \%}$ & $\underline{54 \%}$ & $\underline{51 \%}$ & $\underline{60 \%}$ & $\mathbf{3 9 \%}$ & $\mathbf{6 3 \%}$ \\
Exercise/recreation & $81 \%$ & $83 \%$ & $82 \%$ & $\underline{79 \%}$ & $\underline{86 \%}$ & $\underline{77 \%}$ & $\underline{84 \%}$ \\
Get to skatepark/ & $55 \%$ & $\mathbf{4 3 \%}$ & $\mathbf{5 9 \%}$ & $\mathbf{4 7 \%}$ & $\mathbf{6 8 \%}$ & $\mathbf{4 4 \%}$ & $\mathbf{6 1 \%}$ \\
skate spots & 388 & 47 & 309 & 228 & 160 & 132 & 255 \\
\hline $\mathrm{n}$ & \multicolumn{7}{c|}{ Note: Underline $(p<.10)$ and bold $p<.05)$ indicate a significant difference based on a chi-squared test }
\end{tabular}

Table 7 also shows the types of trips made disaggregated by gender, experience, and frequency of use for transportation purposes. Self-reported skill levels were utilized to categorize experience; those who identified as beginner or intermediate will be referred to as "less experienced" and those who identified as advanced or expert will be referred to as "more experienced." Males and more experienced respondents were significantly more likely than their counterparts to utilize their skateboard to get to skateparks and skate spots. These groups were also more likely to utilize their skateboards for commuting to work and school. As expected, those who more frequently skateboard for transportation purposes were significantly more likely than their counterparts to select each of the destination-oriented trips. Discomfort on transportation facilities during peak hours and the fear of falling and tearing one's clothes are both potential factors that may be more discerning for commute trips than they are for other trips. These and other factors are likely to decline with more experience, and as such may become less of a deterrent as a skateboarder's skill increases. 
The average distance respondents were willing to travel by skateboard in a typical day was approximately five and a half miles (all responses were recoded with a maximum of 10 miles; $\mathrm{n}=355$ ). The majority of respondents were willing to travel up to five miles by skateboard in a typical day (63\%). The proportion of respondents willing to travel 10 or more miles by skateboard was a surprising $28 \%$. The vast majority of these respondents reported that they rode a longboard only or multiple types of skateboards including a longboard (93\%). These results indicate that longboards tend to be more suitable for longer trips, while skateboards and cruisers may be most useful for short local trips and multimodal trips.

In response to the question "Are there any destinations you are not willing to travel to by skateboard?" $60 \%$ of respondents answered "Yes" ( $\mathrm{n}=380)$. Respondents were asked to explain the type of trip and describe why they were not willing to take it. Open-ended answers were coded utilizing a set of codes determined by the author. The codes represent two themes, destinations and environmental factors. Figure 4 is a weighted word cloud representing the number of times each code was mentioned; multiple codes could be utilized for a single response. The most commonly cited destination themed codes were "Work or other formal event" (9\%), "Shopping" (6\%), "Places where skateboards are prohibited" (5\%), and "Social events" $(4 \%)(\mathrm{n}=228)$. Public perception was a common deterrent for those not willing to skateboard to work, as one respondent puts it, "I do not skate to work because it could possibly be seen as unprofessional" (Anonymous Respondent). 


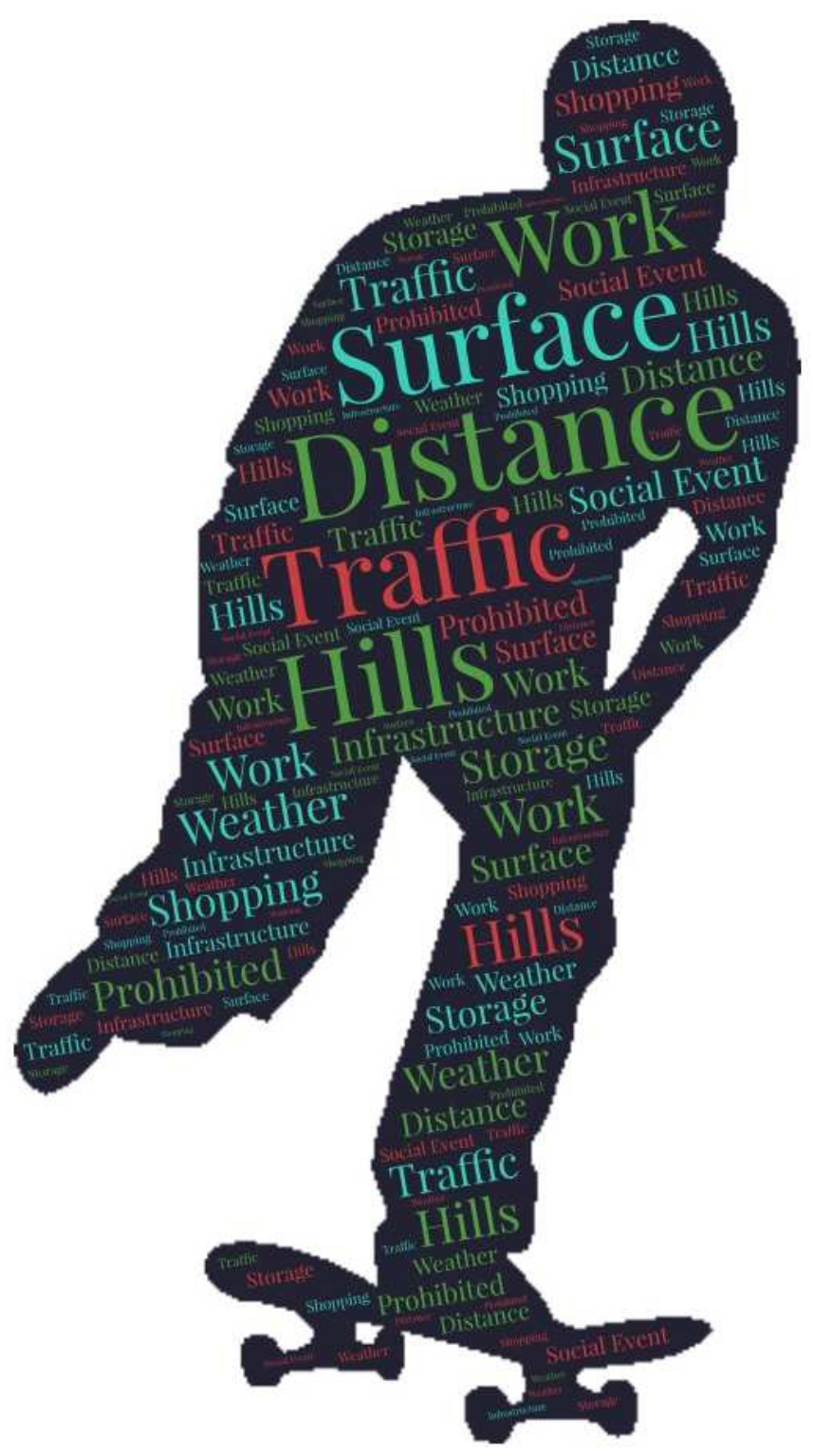

Figure 4: Destination and Environmental Trip Deterrents for Skateboarding

Respondents were more likely to cite environmental factors that would deter them from skateboarding for any given trip than they were to cite specific destinations. The most commonly cited environmental factors were "Distance" (44\%), "Surface Conditions" (17\%), "Traffic" (14\%), and "Hills" $(12 \%)(n=229)$. The lack of safe infrastructure and weather were also important factors. One respondent sums it up by simply by stating "Up 
hills, over poor quality surface, very long distances, [and] high exposure to cars" (Anonymous Respondent). These factors will be explored further in later sections. It is important to note that numerous respondents who cited distance mentioned the significance of other modes in their travels. For example, one respondent stated "you just hold it like a purse when you are not riding it, or set it down next to you... Why not take a bus and a skateboard when you are going somewhere further than the corner story" (Anonymous Respondent). This is depictive of the multi-modal nature of skateboarding travel.

\section{Other Modes of Transportation}

Respondents who travel by skateboard tend to rely on a variety of other modes (Figure 5). Within the last month from when the survey was taken $85 \%$ of the respondents had traveled by personal vehicle, $83 \%$ by foot, $56 \%$ by bike, $54 \%$ by public transit, and more than a third of the sample utilized rideshare (e.g. Uber, Lyft, etc.). Respondents were least likely to cite traveling by motorcycle and carshare (e.g. Zipcar, Car2Go, etc.) $(7 \%$ each). Despite a month being a fairly long period of time, these statistics are very high and are representative of the multi-modal ease of skateboarding as well as the various limitations. Fang and Handy (2017b) found that skateboarding can serve as a viable secondary mode of transportation; skateboarders value the ability to drive or take transit for long distance trips and rely on their skateboard for first- and last-mile access. Skateboarders also have the flexibility to quickly dismount their board and travel by foot if conditions are not conducive for skateboarding. On the other hand, various limitations of skateboarding can make other modes more appealing for certain trips. In an open-ended response one skateboarder stated that, "Sometimes lots of steep hills may be a deterrent if I need to go 
somewhere that is 10 miles away or more. In this case I might prefer to bike" (Anonymous Respondent). As with other active modes the physical exertion may deter its use for commute trips and other types of trips where one would not like to arrive sweaty or exhausted; thus, other modes may be more suitable.

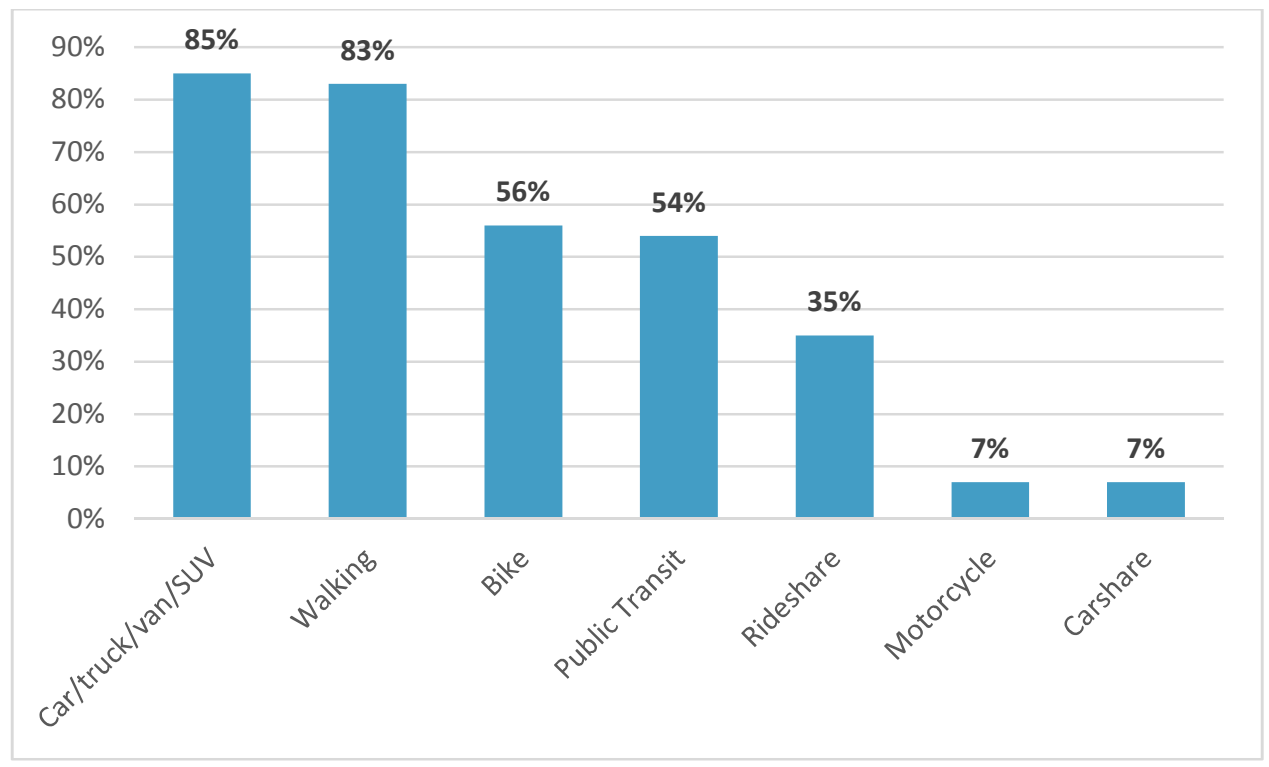

Figure 5: Other types of Modes Used by Respondents in the Past Month $(n=388)$

\section{Perceptions}

To assess how skateboarders perceive skateboarding as a mode of travel respondents were asked to report whether they agree or disagree with 11 statements (two of which were excluded from the analysis). The results to these questions are presented in Figure 6.

Nearly all of the respondents were in agreement that skateboarding is a fun way to travel $(98 \%)$ and that it is a cost effective mode of transportation (95\%). The strikingly high value attributed to fun demonstrates that, for most skateboarders, travel is not a disutility to be minimized, but rather traveling by skateboard provides a positive utility not necessarily related to reaching a destination (Mokhtarian and Saloman, 2001). This 
was commonly expressed by both survey respondents in open-ended responses and interviewees. When asked why skateboarding transportation is important to him, one interviewee stated, "I actually just find it fun. Especially when I'm going down a hill or even chasing a train. Just going that fast is kind of really impressive to me, and really fun" (Anonymous Interviewee). Another respondent wrote, "I love skateboarding for transportation, it's so easy for me, and faster and more fun and cooler!! I rarely walk anywhere and the people who mostly do are really missing out" (Anonymous Respondent).

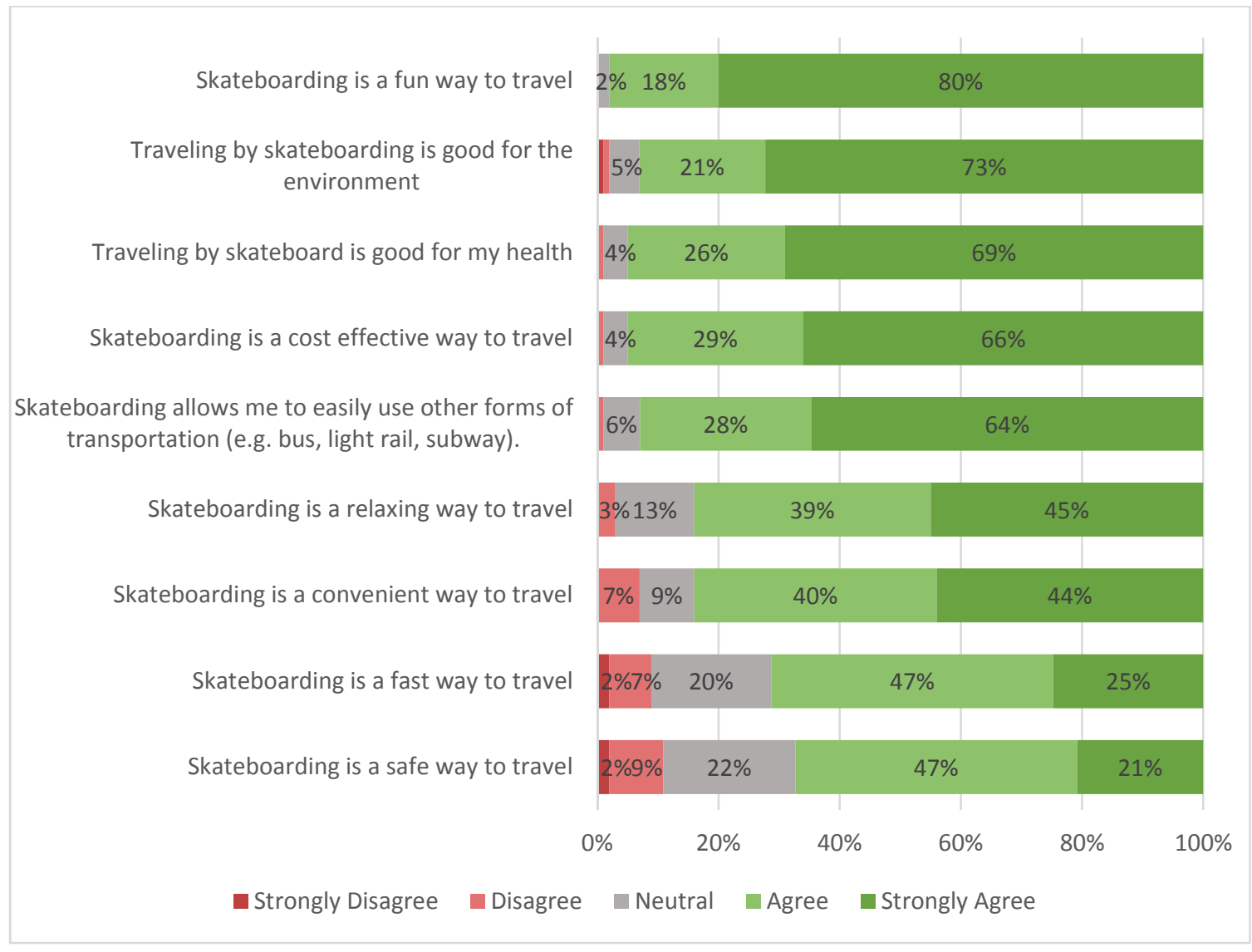

Figure 6: Perceptions of Skateboard Transportation $(n=390)^{1}$

\footnotetext{
${ }^{1}$ Note: Values $\leq 1 \%$ not shown
} 
Environmental and physical health benefits of skateboarding transportation were rated very highly by respondents. More than $80 \%$ of respondents also displayed value for the relaxation of travel, ease of multi-modal trips, and overall convenience. With respect to relaxation, this finding contributes to the work of Gatersleben and Uzzell (2007) on the positive utility of active travel; skateboarders appear to value the relaxation of travel, in comparison to motorists who tend to find their commutes to be stressful. One respondent stated, "I do it because it's the most fun way to get around town. It is similar to meditation, applying deep focus and relaxation" (Anonymous Respondent). In terms of the later topics, it could be expected that the ease of combining skateboards with public transportation is a component of convenience; for example, one interviewee stated they first began skateboarding because "It was so much more versatile for navigating the city and it could be combined with bus and with transit" (Anonymous Interviewee). However, qualitative results revealed additional components of convenience valued by utilitarian skateboarders, such as the benefit of not having to lock up a skateboard like you do a bicycle, the ease of getting around campus, the flexibility for short urban trips, and the ability to avoid traffic.

Just under two- thirds of respondents agreed or strongly agreed that skateboarding is a fast way to travel. With no reference to other modes this is a rather ambiguous measure; however, it is evident that respondents value the speed efficiency of skateboards. Each of the interviewees stated that their speed is faster than walking, yet slower than bicycling; however, for some, this was dependent on the cyclist. One of the interviewees stated, "Definitely faster than somebody walking. Probably not as fast as 
somebody who would be on a bike that is focused. I'd compare it to the speed of somebody who is on a leisurely ride on a bicycle" (Anonymous Interviewee). This excerpt is in accordance with the observations made by Fang and Handy (2017a); they found skateboarders and bicyclists to have nearly identical minimum speeds and the average speed for bicyclists was only about two mph faster. Lastly, the statement "skateboarding is a safe way to travel" received a relatively lower rate of agreement and higher rate of disagreement, which supports findings from previous studies (Fang and Handy, 2017b).

Independent sample t-tests were run to test the hypotheses that perceptions differ between populations groups based on gender, skill, and frequency of use for transportation purposes. The value attributed to each statement represents the respondents' attitudinal score; these scores range from 1 to 5 , or strongly disagree to strongly agree with 3 being neutral. The assumption was made that male skateboarders, more experienced skateboarders, and those who utilize skateboarding for transportation more frequently will have, on average, higher attitudinal scores. A summary of the results is presented in Table 8 (See Appendix E for significant t-test results). 
Table 8: Summary of Independent Samples T-Test Results

\begin{tabular}{|c|c|c|c|}
\hline \multirow[b]{2}{*}{ Attribute of Skateboarding Transportation } & \multicolumn{3}{|c|}{$\begin{array}{l}\text { Significant Difference in Means } \\
\text { Found within Grouping }\end{array}$} \\
\hline & Gender & $\begin{array}{c}\text { Skill } \\
\text { Level }\end{array}$ & $\begin{array}{c}\text { Frequency } \\
\text { of Use }\end{array}$ \\
\hline Skateboarding is a fun way to travel & Yes (-) & Yes (-) & Yes (-) \\
\hline $\begin{array}{l}\text { Traveling by skateboarding is good for the } \\
\text { environment }\end{array}$ & No $(+)$ & No (-) & Yes (-) \\
\hline Traveling by skateboard is good for my health & No (-) & Yes (-) & Yes (-) \\
\hline Skateboarding is a cost effective way to travel & No $(-)$ & No $(-)$ & Yes $(-)$ \\
\hline $\begin{array}{l}\text { Skateboarding allows me to easily use other } \\
\text { forms of transportation }\end{array}$ & No $(=)$ & No $(-)$ & No (-) \\
\hline Skateboarding is a relaxing way to travel & No $(-)$ & Yes (-) & Yes (-) \\
\hline Skateboarding is a convenient way to travel & Yes (-) & Yes (-) & Yes (-) \\
\hline Skateboarding is a fast way to travel & Yes (-) & Yes $(-)$ & Yes $(-)$ \\
\hline Skateboarding is a safe way to travel & Yes (-) & Yes (-) & Yes (-) \\
\hline $\begin{array}{l}(-)=\text { Female/Less Experienced/Infrequent User } \\
(+)=\text { Female/Less Experienced/Infrequent Use } \\
(=)=\text { Female/Less Experienced/Infrequent Use }\end{array}$ & $\begin{array}{l}\overline{\mathrm{x}}<\text { counte } \\
\overline{\mathrm{X}}>\text { count }\end{array}$ & $\begin{array}{l}\operatorname{arts}^{\prime} \overline{\mathrm{x}} \\
\text { parts' } \overline{\mathrm{x}} \\
\text { parts' } \overline{\mathrm{x}}\end{array}$ & \\
\hline
\end{tabular}

With regards to gender, significant differences in mean attitudinal scores were found in four of the nine statements. Both males and females attributed a very high value to the statement "skateboarding is a fun way to travel." This was expected given the playful nature of skateboarding transportation and its inherent connection to fun and enjoyment. However, males, on average, attributed a higher attitudinal value to the fun of skateboarding transportation. This difference may be partially explained by internal motivations for utilizing skateboarding as a mode of transportation; perhaps, males tend to travel by skateboard for the playful benefits, while females utilize it more strictly for utilitarian means.

Males also had significantly higher mean attitudinal values for the statements regarding convenience, speed, and safety. The overall convenience that skateboarding offers to an individual is likely to consist of many components and be highly contextual, 
which can make it a challenging concept to compare; however, the findings suggest that, on average, males associate a higher value to a subjective measure of convenience than females do. The significant difference between males' and females' perceptions about speed may portray actual differences in average travel speeds or it could simply represent a difference in what respondents believe to be "fast." Fang and Handy (2017a) studied the speed of skateboard commuters on the UC Davis campus, although they were unable to make meaningful comparisons with respects to gender due to a lack of observed females. Lastly, the significant difference in perceptions about safety indicate that, on average, males more strongly believe that skateboarding is a safe way to travel. Similar findings in utilitarian bicycling literature suggest that females tend to show a greater concern for safety and traffic risks than males. Safety is another complex concept that may involve numerous objective and subjective factors; the degree to which an individual feels safe traveling by skateboard may be spatially and temporally specific and dependent on factors such as automobile traffic, comfort and familiarity with the area, time of day, surface material, physical capabilities, and topography.

Comparing mean scores by respondents' experience generated significant differences in six of the nine statements, all of which support the hypothesis that less experienced skateboarders, on average and for these statements, have lower attitudinal scores than more experienced skateboarders. These outcomes were hypothesized because skateboarding has a relatively steep learning curve and, like most physical activities, requires practice and experience. This is especially important for individuals navigating public transportation facilities such as roadways, bike lanes, and sidewalks. Having a 
more robust set of skills may allow a skateboarder to be less concerned with the requirements of the trip itself and permit a more playful and enjoyable trip; this assumption is supported by the significant difference in mean attitudinal values attributed to the statement "skateboarding is a fun way to travel." Skateboarders lacking these fundamental skills are likely to be less comfortable navigating the numerous obstacles and risks associated with traveling by skateboard. These individuals may also find it more difficult to carry cargo. Again, support for these assumptions are found in the significant differences in perceptions towards the relaxing nature, convenience, and safety of skateboarding transportation. Furthermore, more experience is likely to permit faster travel and higher comfort levels at faster speeds.

Interestingly, results indicate a significant difference in mean attitudinal values associated with the health benefits of traveling by skateboard; one possible explanation may be that less experienced skateboarders have a greater concern of physical injury. Educational and skill development programs could be an effective way to enhance skateboarders' commuting capabilities and comfort. It is important to recall that the less experienced category accounts for $83 \%$ of all female respondents; thus, these programs should prioritize female participation.

Finally, comparing mean attitudinal values between infrequent and frequent utilitarian skateboarders produced significant t-test results for eight of the nine statements. For each of the statements, frequent utilitarian skateboarders had significantly higher mean attitudinal scores, indicating a positive association between the frequency of utilitarian skateboarding and the values attributed to various aspects of skateboarding 
transportation. The most significant t-test results were produced by the differences in mean attitudinal values for the statements regarding convenience, speed, relaxation, and safety.

These findings suggest that individuals who travel by skateboard more frequently tend to perceive their capabilities on transportation facilities more confidently and attribute higher values to the potential benefits of skateboarding transportation (e.g. convenience and cost-effectiveness). Interestingly, the frequent users group is made up of nearly an even split of less experienced (49\%) and more experienced skateboarders $(51 \%)$, so these findings are not necessarily a depiction of skill level; instead, they are suggestive of the familiarity with and the endorsement of skateboarding as a viable mode of transportation. Frequent utilitarian skateboarders also had a significantly higher mean attitudinal score for the statement "traveling by skateboard is good for the environment." This is potentially representative of a stronger concern for environmental issues which drives their more frequent use of a zero-emission mode; however, further research is needed to explore this relationship.

Each of the statistically significant t-test results were in support of the original hypotheses; when compared to their counterparts, male skateboarders, more experienced skateboarders, and more frequent utilitarian skateboarders tend to attribute higher attitudinal values to statements regarding skateboarding transportation. Differences in attitudes towards the statements regarding fun, convenience, speed, and safety produced significant results for each of the groupings. Perceptions of what these concepts mean may differ; however, it is more likely that these findings are suggestive of differential 
skill and comfort levels as well as differential valuations of concerns (e.g. safety concerns for females relative to males).

The comparison of attitudinal values attributed to the statements, "skateboarding is good for my health," and "skateboarding is a relaxing way to travel" produced significant results for the experience and frequency of use groupings. The results from the former statement are likely a product of differential levels of actual and perceived risks of physical injury due to skill and comfort, rather than a difference in attitudes regarding the health benefits of the physical activity. Attitudes towards environmental benefits and cost benefits were only significantly different between infrequent and frequent utilitarian skateboarders. The difference in mean attitudinal values towards the statement "skateboarding allows me to easily use other forms of transportation" was no greater than $|0.1|$ in any of the groupings. Respondents attributed a high attitudinal value to this statement and it was the only statement to not produce a significant result, which indicates that between these groups of skateboarders the multi-modal ease of skateboarding is highly and universally valued.

\section{Mode Choice}

\section{Motivations}

To evaluate motivations behind utilizing skateboarding as a mode of transportation respondents were asked to select and rank the top-three reasons they choose to travel by skateboard. They were provided with 11 prescribed motivations (one of which was excluded from the analysis) and the option to select "other" and write in a response. 
Figure 7 shows the proportion of respondents who selected and prioritized each motivation.

"Fun and enjoyment" was selected by $81 \%$ of the respondents and was nearly two times more likely to be selected than the second most commonly reported motivation. These results support previous findings that suggest enjoyment is the most fundamental motivation for traveling by skateboard (Fang and Handy, 2017b; Walker, 2013). While respondents were far more likely to rank enjoyment over all other modes, convenience was selected by $41 \%$ of the sample and appears to play a critical role in the decision to travel by skateboard. Furthermore, convenience was reported as the second-most important motivation by the largest proportion of respondents. This finding is complemented by the selection of other motivations which represent various aspects of convenience, including "fast travel" (23\%), "I can easily take it on the train, bus, etc." (22\%), and "it's cost effective" (17\%). Thus, utilitarian skateboarders base their decision to travel by skateboard on various practical characteristics and are not solely motivated by pleasure. 


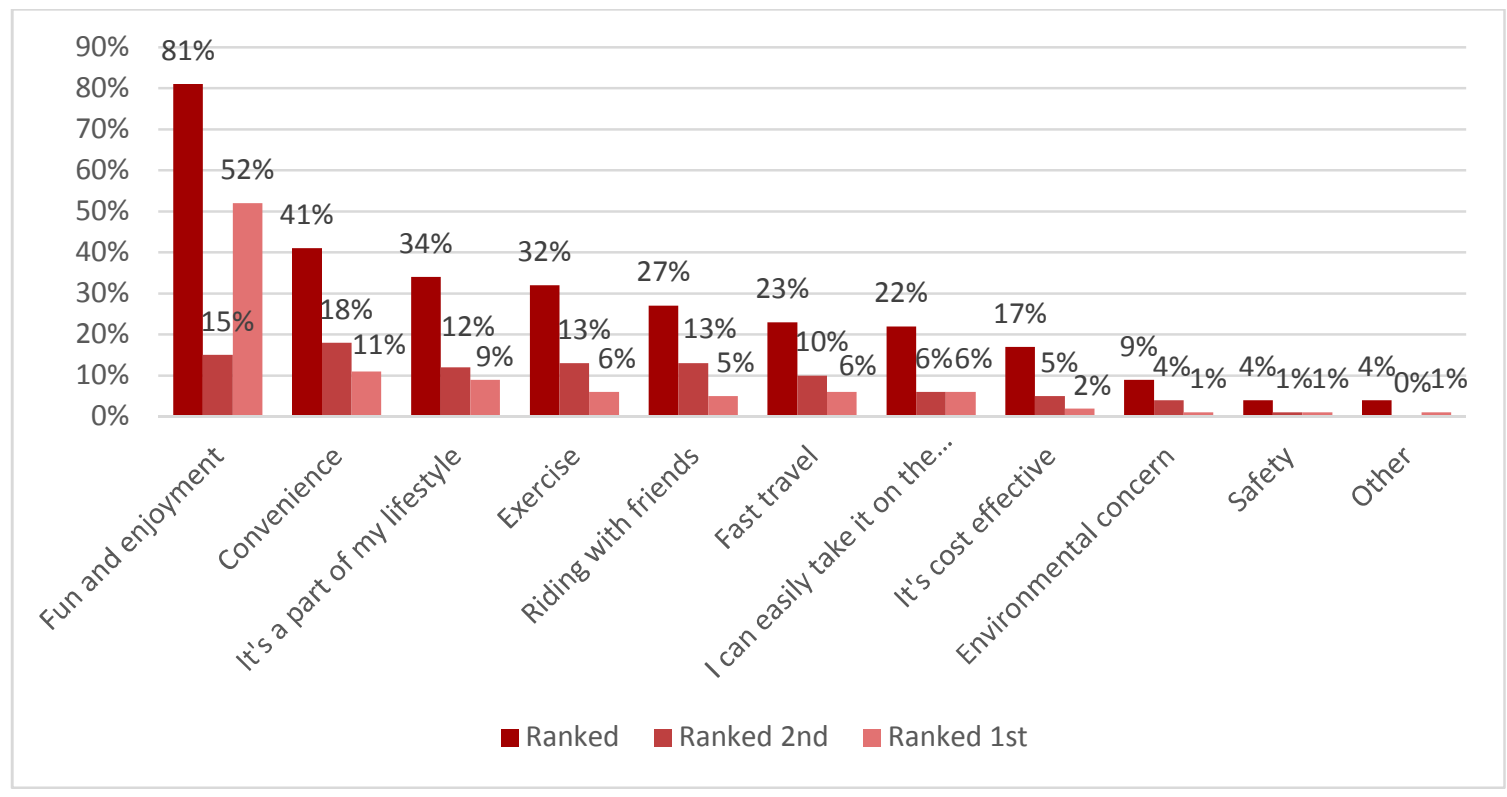

Figure 7: Important Motivations $(n=381)$

In a study of street skateboarding in New York City, Chui (2009) asserts that "skateboarding is not just a sport or a leisure activity; it is considered the origin and oasis of a lifestyle" (p. 39). Consistent with that, one interviewee in my study stated that, "skateboarding pretty much let me become the person that I wanted to become" (Anonymous Interviewee). The results presented in Figure 7 indicate that the lifestyle associated with skateboarding can have a significant influence on an individual's decision to travel by skateboard; more than one-third of the respondents reported that they travel by skateboard because it is a part of their lifestyle. This finding is representative of the cultural implications of mode choice decisions. Furthermore, the culture of skateboarding can have a significant influence on the formation of an individual's identity (Beal, 1996). Skateboarding and even the skateboard itself can become representations of self-identity. Thus, it can be expected that an individual who identifies with the skateboarding culture is likely to attempt to incorporate skateboarding into their daily lifestyle choices, 
including travel. This was illuminated by another interviewee who stated, "I mean, I didn't need to bring [my skateboard] today. I maybe only rode it for about five minutes... but it's like a part of me that I carry with me now" (Anonymous Interviewee). Social interaction and a collective identity are also important components of skateboarding (Wooley and Johns, 2001); "riding with friends" was selected by $27 \%$ of the respondents as a primary reason for choosing to travel by skateboard. Together, these findings suggest that, for skateboarders, social benefits and self-identity are essential components of mode choice.

The proportion of respondents who reported environmental concerns as a motivator was $9 \%$. This was surprisingly low considering a previous study had found environmental concerns to be a primary motivator among bicycle commuters (Stinson and Bhat, 2004). However, this small proportion is higher than figures found in previous studies on skateboarders; Walker (2013) reported that only $7 \%$ of respondents listed sustainability as one of their top three reasons for skateboarding. The least commonly reported prescribed motivation was "safety" (4\%). This result is not suggestive of a lack of concern for safety, rather it indicates that there are a number of respondents who choose skateboarding as a mode of travel because they perceive it as a safe option. While only $4 \%$ of respondents selected "other" and provided a response, $50 \%$ of those who did $(n=14)$ cited the mental benefits of skateboarding. For example, one respondent stated that they commute by skateboard for "mental clarity before and after work" (Anonymous Respondent). Future research should place a greater focus on the mental health benefits of skateboarding transportation. 
Disaggregating these results by gender, experience, and frequency of use for transportation purposes revealed that motivations are fairly similar across populations. However, it also highlighted some significant differences (Table 9). Females were more than two times less likely than males to report that they travel by skateboard because it is a part of their lifestyle; females were significantly more likely to cite the multimodal benefits of skateboarding (33\%) than males (20\%). Skateboarders with less experience were less likely to select lifestyle as a primary motivator $(30 \%)$ than more experienced skateboarders $(42 \%)$ but were more likely to be motivated by the cost-effective nature of skateboarding (21\%, compared to $10 \%)$. Those who skateboard for transportation once or more a week were significantly more likely to report being motivated by lifestyle (39\%), fast travel (27\%), and convenience (44\%), when compared to infrequent utilitarian skateboarders $(23 \%, 17 \%$, and $36 \%$, respectively). On the other hand, they were less likely to cite fun and enjoyment, exercise, and cost effectiveness. Thus, regular utilitarian skateboarders tend to be more strongly motivated by the practicality of skateboarding transportation than they are by attributes of enjoyment. 
Table 9: Motivations by Gender, Skill Level, and Frequency of Use

\begin{tabular}{|c|c|c|c|c|c|c|}
\hline \multirow[b]{2}{*}{ Reason Selected } & \multicolumn{6}{|c|}{ Percentage of Responses by Group } \\
\hline & Female & Male & $\begin{array}{c}\text { Less } \\
\text { Experienced }\end{array}$ & $\begin{array}{c}\text { More } \\
\text { Experienced }\end{array}$ & $\begin{array}{c}\text { Infrequent } \\
\text { Users }\end{array}$ & $\begin{array}{c}\text { Frequent } \\
\text { Users }\end{array}$ \\
\hline Fun and enjoyment & $82 \%$ & $80 \%$ & $80 \%$ & $83 \%$ & $\underline{86 \%}$ & $78 \%$ \\
\hline Convenience & $40 \%$ & $43 \%$ & $43 \%$ & $38 \%$ & $\overline{36 \%}$ & $\overline{44 \%}$ \\
\hline It's a part of my lifestyle & $16 \%$ & $38 \%$ & $30 \%$ & $42 \%$ & $23 \%$ & $39 \%$ \\
\hline Exercise & $40 \%$ & $30 \%$ & $31 \%$ & $33 \%$ & $41 \%$ & $27 \%$ \\
\hline Riding with friends & $27 \%$ & $27 \%$ & $28 \%$ & $25 \%$ & $29 \%$ & $26 \%$ \\
\hline Fast travel & $33 \%$ & $23 \%$ & $22 \%$ & $26 \%$ & $17 \%$ & $27 \%$ \\
\hline $\begin{array}{l}\text { I can easily take it on the } \\
\text { train, bus, etc. }\end{array}$ & $33 \%$ & $20 \%$ & $21 \%$ & $22 \%$ & $23 \%$ & $21 \%$ \\
\hline It's cost effective & $9 \%$ & $17 \%$ & $21 \%$ & $10 \%$ & $22 \%$ & $14 \%$ \\
\hline Environmental concern & $4 \%$ & $10 \%$ & $10 \%$ & $8 \%$ & $9 \%$ & $9 \%$ \\
\hline Safety & $7 \%$ & $3 \%$ & $4 \%$ & $4 \%$ & $3 \%$ & $4 \%$ \\
\hline Other & $4 \%$ & $4 \%$ & $40 \%$ & $30 \%$ & $3 \%$ & $4 \%$ \\
\hline $\mathrm{n}$ & 45 & 308 & 226 & 155 & 130 & 250 \\
\hline
\end{tabular}

Fang and Handy (2017b) and Walker (2013) highlighted some of the social motivations to utilizing skateboarding as a mode of transportation, such as skateboarding with friends, the influence of being surrounded by others who commute by skateboard, and the perception of "coolness." However, neither of these studies identified the important role of lifestyle and how that role differs between populations. The results presented in Table 9 portray significant differences in the influence of lifestyle on mode choice. For male skateboarders, more experienced skateboarders, and frequent utilitarian skateboarders lifestyle was among the top-three most commonly selected motivations. For females it was the $7^{\text {th }}$ most commonly selected motivation, for less experienced skateboarders it was $4^{\text {th }}$, and for infrequent utilitarian skateboarders it was tied for $5^{\text {th }}$.

These differences may exist for a variety of reasons; however, it is likely that they are rooted within certain attributes of recreational skateboarding. As mentioned previously, recreational skateboarding is a male dominated activity, and as such, skateboarding spaces (skateparks and skate spots) are male dominated. One female 
interviewee highlighted some of challenges women face navigating these spaces, "I got asked if I was a boy a lot at the skatepark especially by little kids that are like 'but you skateboard' and I'm like 'yeah but yeah I'm a girl' and they're like 'but girls can't skateboard,' and [they] just can't comprehend that. And then yeah, [I] just like never really felt like I was included in the culture" (Anonymous Interviewee). These social barriers can inhibit female participation and the likelihood to identify with the culture; thus, what may be considered a skateboarding lifestyle is not as easily attainable for some.

\section{Barriers}

Respondents were also asked to report the barriers which would reduce their propensity to skateboard for any given trip. They were presented with 10 prescribed barriers and the option to select other and provide a response; there was no limit on the number of options respondents could choose and they were encouraged to select all that apply. Given that this survey targeted people who already skateboard, the prescribed barriers primarily considered environmental characteristics and situational attributes rather than personal barriers such as physical health and a lack of awareness or desire. Responses to this question are presented in Figure 8.

In aggregate, the most commonly reported barriers were poor road and sidewalk conditions (73\%), wet and slick conditions (72\%), and distance to destination (61\%). Each of these factors have been found to be significant indicators of non-motorized mode choice, specifically walking and biking (Broach, 2016; Dill and Carr, 2003). Poor road and sidewalk conditions are likely such a significant concern for skateboarders because of 
the small wheel size, which make them vulnerable to even subtle cracks in the pavement and small pebbles and road debris. During interviews each respondent cited the challenges of traveling on poor surface conditions and reported an incident where they had crashed due to a rock or crack. Wet and slick conditions impose the risk of sliding and losing control and may jeopardize the durability of the wooden and metal components of the skateboard. As mentioned in previous sections, distance can be a significant mode choice factor, and depending on the type of skateboard being utilized it may only be viable for short urban or neighborhood trips. However, if skateboarding is used as a secondary mode of transportation in pair with public transit, rideshare, personal vehicle, or even bicycle, longer distance trips can be satisfied.

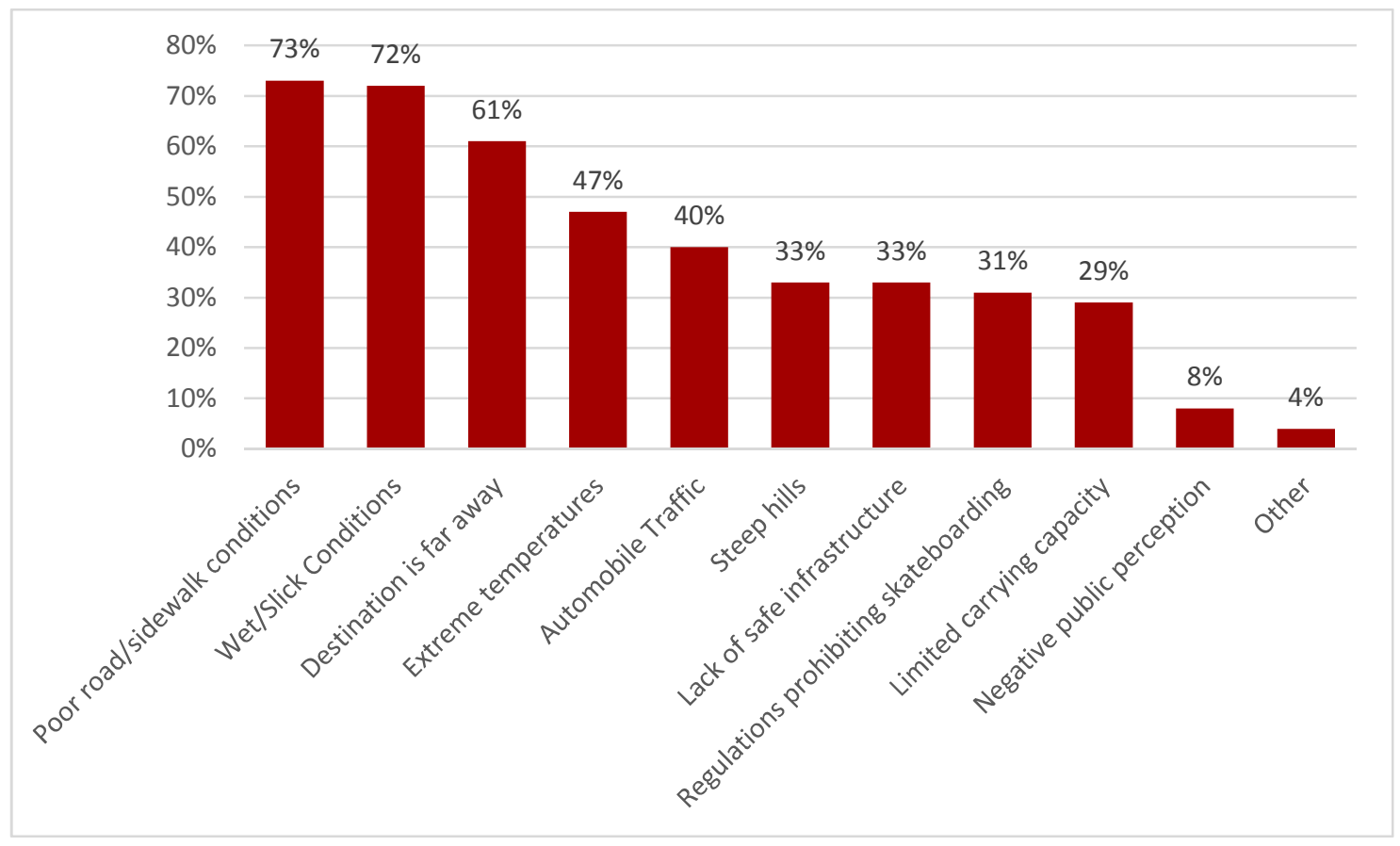

Figure 8: Selected Barriers $(n=386)$ 
After the third most common barrier, there was a drop in consensus. Extreme temperatures was selected by $47 \%$ of respondents and automobile traffic by $40 \%$. In terms of weather, this may be due to the distribution of respondents in different climate regions. Surprisingly, steep hills and a lack of safe infrastructure were only cited by onethird of the respondents. Limited carrying capacity and regulations prohibiting skateboarding where both cited by approximately $30 \%$ of the sample. Although among the least selected prescribed options, the fact that nearly one-third of respondents cited skateboarding regulations as an important mode choice barrier is substantial; legal barriers are not considered when assessing mode choice factors for almost all other motorized or non-motorized modes. The least commonly cited prescribed barrier was negative public perception. While skateboarding is fraught with negative social stigmas they do not appear to have a significant impact on utilitarian skateboarders' mode choice decision; public perception and acceptance will be discussed in further detail in a later section. "Other" was selected by $4 \%$ of the respondents. The most common write-in responses regarded injury and pedestrian traffic.

These results suggest that skateboarders consider a wide variety of factors when deciding whether or not skateboarding is a viable mode choice, and many of the factors they consider reflect those found to be significant indicators of the propensity to walk and bike. Thus, policies and programs to enhance conditions and opportunities for pedestrians and bicyclists may also increase the propensity to skateboard, such as complete streets policies, educational programs, non-motorized infrastructure investment, and mixed land use development. However, the unique needs of skateboarding should be actively 
considered when implementing these policies and programs, and special attention should be payed to reducing the impact regulations and prohibitions have on the viability of skateboarding transportation.

The disaggregated results presented in Table 10 demonstrate that these barriers are not equally perceived across populations. Female skateboarders were more likely to report all but two of the prescribed barriers, distance and extreme temperatures. They were significantly more likely to select poor road and sidewalk conditions (87\%), steep hills $(60 \%)$, and automobile traffic $(51 \%)$ than males $(71 \%, 28 \%$, and $38 \%$, respectively). Less experienced skateboarders were also more likely to select all but two of the prescribed barriers, poor road and sidewalk conditions and lack of safe infrastructure. In terms of statistical significance, less experienced skateboarders more frequently cited steep hills (41\%), distance (65\%), and limited carrying capacity (33\%) than more experienced skateboarders $(21 \%, 56 \%$, and $23 \%$, respectively). Lastly, infrequent utilitarian skateboarders were more likely than their counterparts to select 10 out of the 11 barriers, including "other." Poor infrastructure conditions, wet or slick conditions, automobile traffic, steep hills, and negative public perception were selected as mode choice deterrents by a significantly greater proportion of infrequent utilitarian skateboarders when compared to frequent utilitarian skateboarders. 
Table 10: Barriers Selected by Gender, Skill Level, and Frequency of Use

\begin{tabular}{lcc|cc|cc}
\hline & \multicolumn{7}{l}{ Percent of Responses by Group } & & & \\
\cline { 2 - 7 } Barrier Selected & Female & Male & $\begin{array}{c}\text { Less } \\
\text { Experienced }\end{array}$ & $\begin{array}{c}\text { More } \\
\text { Experienced }\end{array}$ & $\begin{array}{c}\text { Infrequent } \\
\text { Users }\end{array}$ & $\begin{array}{c}\text { Frequent } \\
\text { Users }\end{array}$ \\
\hline Poor road/sidewalk & $\mathbf{8 7 \%}$ & $\mathbf{7 1 \%}$ & $74 \%$ & $70 \%$ & $\underline{78 \%}$ & $\underline{70 \%}$ \\
conditions & $77 \%$ & $70 \%$ & $70 \%$ & $74 \%$ & $\mathbf{8 1 \%}$ & $\mathbf{6 8 \%}$ \\
Wet/Slick Conditions & $57 \%$ & $62 \%$ & $\underline{65 \%}$ & $\underline{56 \%}$ & $66 \%$ & $59 \%$ \\
Destination is far away & $45 \%$ & $49 \%$ & $48 \%$ & $47 \%$ & $51 \%$ & $45 \%$ \\
Extreme temperatures & $\underline{51 \%}$ & $\underline{38 \%}$ & $43 \%$ & $36 \%$ & $\underline{46 \%}$ & $\underline{\mathbf{3 7 \%}}$ \\
Automobile Traffic & $\mathbf{6 0 \%}$ & $\mathbf{2 8 \%}$ & $\mathbf{4 1 \%}$ & $\mathbf{2 1 \%}$ & $\mathbf{4 8 \%}$ & $\mathbf{2 5 \%}$ \\
Steep hills & $40 \%$ & $33 \%$ & $33 \%$ & $33 \%$ & $37 \%$ & $31 \%$ \\
Lack of safe infrastructure & $38 \%$ & $30 \%$ & $33 \%$ & $28 \%$ & $31 \%$ & $31 \%$ \\
Regulations prohibiting & $38 \%$ & $28 \%$ & $\mathbf{3 3 \%}$ & $\mathbf{2 3 \%}$ & $34 \%$ & $27 \%$ \\
skateboarding & $11 \%$ & $9 \%$ & $9 \%$ & $7 \%$ & $\underline{12 \%}$ & $\underline{6 \%}$ \\
Limited carrying capacity & $2 \%$ & $4 \%$ & $3 \%$ & $4 \%$ & $5 \%$ & $3 \%$ \\
Negative public perception & 47 & 307 & 227 & 159 & 133 & 252 \\
Other & & &
\end{tabular}

Note: Underline $(p<.10)$ and bold $(p<.05)$ indicate a significant difference based on a chi-squared test

Furthermore, females, less experienced skateboarders, and infrequent utilitarian skateboarders, on average, cited more barriers than their counterparts; according to an independent samples t-test, the mean number of barriers selected for these groups were significantly higher than they were for male skateboarders, more experienced skateboarders, and frequent utilitarian skateboarders $(\mathrm{p}<.005$ for each test). Together, these results indicate that different populations of skateboarders perceive different mode choice barriers and some populations are deterred by greater number of factors. It is evident that enhanced skill and familiarity with skateboard commuting can reduce the impact of some of these barriers; however, others require additional attention from urban planners and decision makers. 


\section{Route Choice}

The Built Environment

Survey respondents were presented with 15 different environmental characteristics and asked to indicate whether they are desired or avoided features of any given skateboarding route. For the sake of simplicity, each feature was characterized as 'desired' or 'avoided' based on response consensus; the results are presented in Figure 9 and Figure 10, which will be discussed in turn. It is important to acknowledge that an individual's perception of these features is subjective, so these categories do not speak for all utilitarian skateboarders.

Figure 9 displays each of the environmental characteristics that were more commonly reported as a desired feature than they were an avoided feature. The three most desired environmental factors were smooth surface conditions (97\%), gentle downhill slopes (83\%), and wide sidewalks (77\%). The former two were also the most common strongly desired factors; however, the presence of various fun features to skate, referred to here as "micro-features," replaced wide sidewalks as the third. Micro-features consist of structures or objects that a recreational skateboarder might interact with, such as staircases, curbs, ledges, and embankments. Micro-features are not commonly evaluated as a route choice factor in the pedestrian and bicycle literature but given the playful nature of skateboarding it was included, and it demonstrated a significant level of importance. 


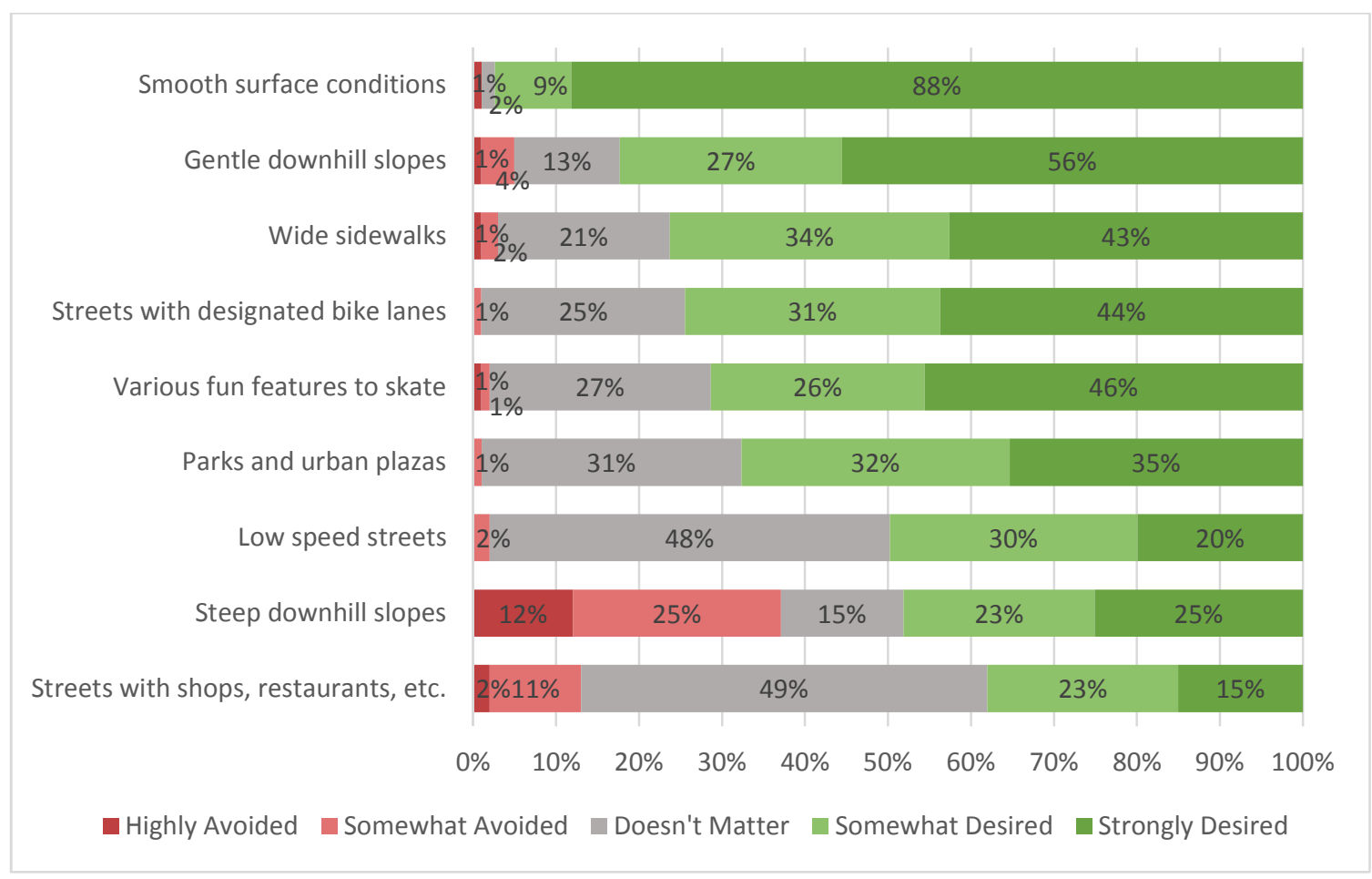

Figure 9: Desired Route Features ( $n=368)$

While Fang and Handy (2017a) claim that individuals traveling by skateboard tend to travel in a straight line and refrain from engaging in playful activity (i.e. performing tricks), the evidence provided here suggests that skateboarders attribute value to the possibility of playful interaction with the built environment. When traveling for utilitarian purposes these interactions are not likely to be ostentatious or risky, but rather quick and subtle with the goal of continuous forward movement. One interviewee expressed his enjoyment of playful travel in stating, "I can jump off the sidewalk, jump back on the sidewalk, if there's like a three-stair I can still keep riding over it and do a little trick for fun" (Anonymous Interviewee). He goes on to discuss that, while traveling by skateboard, he is unlikely to engage in activities which jeopardize the safety of others or cause property damage, two concerns which are commonly used to argue for the 
regulation of skateboarding. This interviewee also highlights some of the utilitarian values of skateboarding tricks, such as maneuvering down and over obstacles that may otherwise hinder continuous mobility. However, on facilities such as bike lanes, separated paths, and traffic lanes where there are fewer micro-features or in spaces heavily trafficked, the type of travel behavior observed by Fang and Handy should be expected. For example, one interviewee stated, "yeah, we jump around a little bit, but if you're using it for a mode of transportation, and you're in those [bike] lanes just going to where you gotta go, we're gonna be moving at the same flow as cyclists" (Anonymous Interviewee). Furthermore, the type of skateboarder and skateboard being utilized are likely to influence travel behavior; Fang and Handy (2017a) reported in their study that the majority of observed skateboarders were traveling by longboard, the design of which "make tricks more difficult if not impossible" (p. 9).

Streets with designated bike lanes were desired by $75 \%$ of the sample. Walker (2013) also found bike lanes to be an advantageous feature for utilitarian skateboarders. It is evident that bicycle and pedestrian infrastructure play an important role in skateboarding transportation, which should be expected as the spaces skateboarders are expected to navigate are often ill defined and inconsistent. Over two-thirds of respondents reported that parks and urban plazas made a route desirable, which is indicative of the role visual aesthetics play in route choice. Low-speed streets and streets with shops and restaurants were also desired features; however, nearly half of the respondents reported that they do not matter. Broach (2016) found streets with ground level retail and restaurants to be a significant route choice factor for pedestrians; for 
skateboarders it does not seem to have such a large influence, yet the fact that nearly $40 \%$ rated the feature as somewhat desired or strongly desired suggests a moderate level of importance. The rating of steep downhill slopes was unique. While $48 \%$ of respondents rated it as desired, $37 \%$ rated it either highly avoided or somewhat avoided. This split is likely representative of differential skill levels and the proportion of skateboarders who practice downhill longboarding and/or value the exhilaration of speed.

Figure 10 displays each of the environmental characteristics that were more commonly reported as an avoided feature than they were a desired feature. As we saw with desired features, the infrastructural condition is at the top of the list. Rough surface conditions was rated as an avoided feature by $84 \%$ of the respondents. Surface conditions and infrastructure maintenance were cited by numerous survey respondents when they were asked to share any final thoughts, and each of the interviewees mentioned infrastructural conditions as a key disadvantage and/or route choice factor. One interviewee stated, "as soon as you hit something rough it will slow you down drastically and you have to push that much harder or it just becomes uncomfortable to ride, so I'm always looking for the smoothest route" (Anonymous Interviewee). In alignment with previous findings steep uphill slopes (80\%) and high volume traffic (56\%) were perceived by the majority as adverse route features (Walker, 2013). 


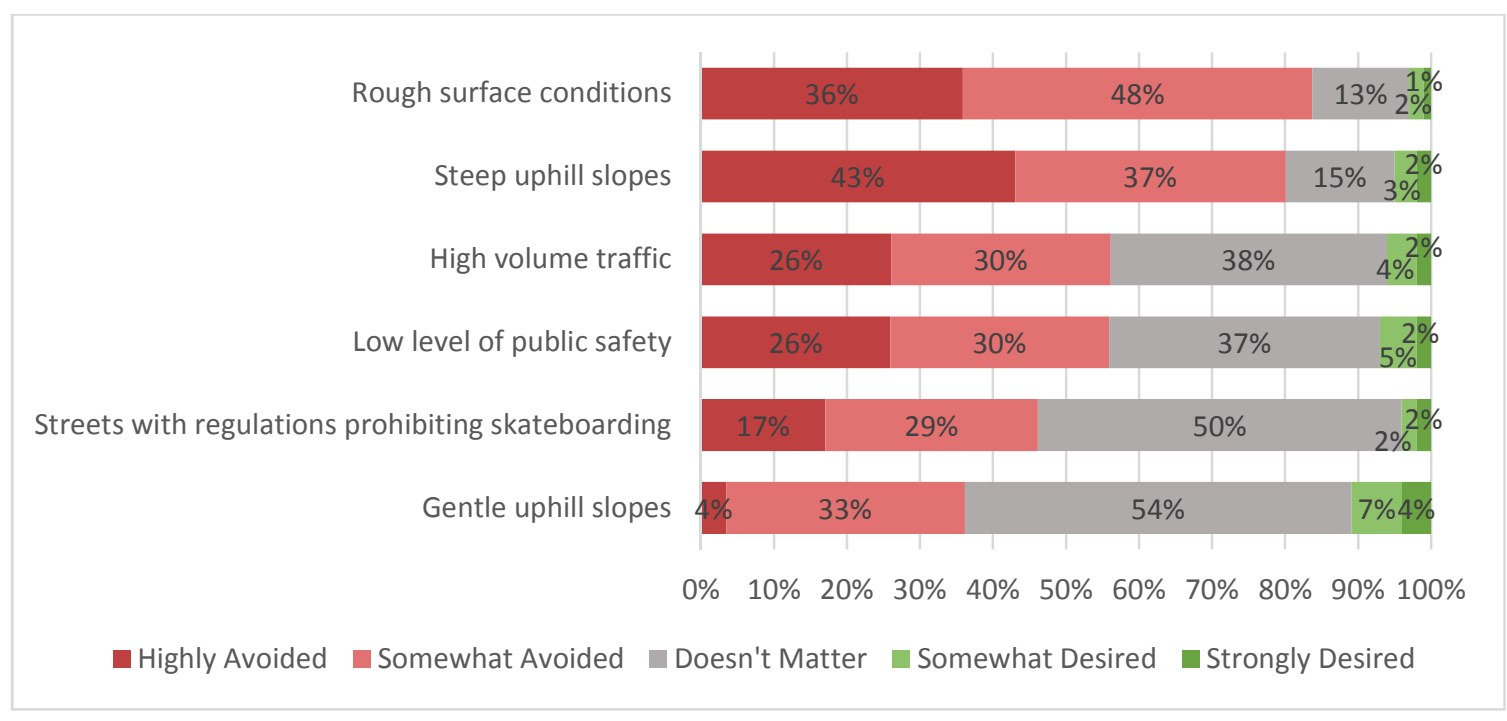

Figure 10: Avoided Route Features (n=368)

Unsurprisingly, low levels of public safety (e.g. high crime) was selected as an avoided feature by the majority of respondents. A recent study at the University of Michigan-Flint found crime to be among the highest ranked barriers to bicycling for students, faculty, and staff (Rybarczyk and Gallagher, 2014). Half of the respondents in my study stated it does not matter if a proposed route consisted of areas where skateboarding was prohibited. Fang and Handy (2017b) found that regulations do not tend to inhibit skateboard travel at the University of California-Davis, and conclude that it is "perhaps not surprising given that when traveling, individuals do not usually have to consider whether their modes of travel are legal." Furthermore, the spaces where skateboarding is prohibited often permit travel by pedestrians, bicyclists, or motorists. The inconsistency of regulations and enforcement across various facilities and within certain geographies can be confusing. In an open-ended response one survey respondent wrote, "I find in [New York City] that the authorities make up rules about skateboarding to best fit the situation to their liking. I've been told I can't ride on the sidewalk and also 
that I'm not allowed in the street. I've been told I was going to fast in the street after being illegally cut off by a police officer. It doesn't seem like the rules are very clear for skateboarders" (Anonymous Respondent).

Chi-squared tests were utilized to compare perceptions of route choice factors across populations. Table 11 shows the proportion of respondents who selected "somewhat desired" or "strongly desired" for each of the 'desired' route features. Smooth surface conditions was universally desired by all respondents in each group. Males, more experienced skateboarders, and frequent utilitarian skateboarders were all significantly more likely than their counterparts to rate gentle and steep downhill slopes as a desired feature. A binary logistic regression model revealed that gender was a significant indicator of the likelihood to rate steep downhill slopes as a desired feature, even when controlling for experience (see Appendix E for model results). This suggests that males are more likely to seek out the thrill of downhill skateboarding and engage in risk-taking behavior, as observed by Atencio et al. (2009) in their study on gender relations and identities in urban skateboarding. Furthermore, males and more experienced skateboarders were significantly more likely than their counterparts to desire routes with a variety of micro-features to engage with. On the other hand, female skateboarders, less experienced skateboarders, and infrequent utilitarian skateboarders desired features that could enhance safety, such as low-speed streets, wide sidewalks, and bike lanes. 
Table 11: 'Desired' Route Features by Gender, Skill Level, and Frequency of Use

\begin{tabular}{|c|c|c|c|c|c|c|}
\hline \multirow[b]{2}{*}{ Desired Feature } & \multicolumn{6}{|c|}{$\begin{array}{l}\text { Percent of Respondents who Selected Somewhat Desired or Strongly } \\
\text { Desired }\end{array}$} \\
\hline & Female & Male & $\begin{array}{c}\text { Less } \\
\text { Experienced }\end{array}$ & $\begin{array}{c}\text { More } \\
\text { Experienced }\end{array}$ & $\begin{array}{c}\text { Infrequent } \\
\text { Users }\end{array}$ & $\begin{array}{c}\text { Frequent } \\
\text { Users }\end{array}$ \\
\hline Smooth surface conditions & $100 \%$ & $97 \%$ & $97 \%$ & $99 \%$ & $99 \%$ & $97 \%$ \\
\hline Gentle downhill slopes & $70 \%$ & $85 \%$ & $80 \%$ & $88 \%$ & $77 \%$ & $86 \%$ \\
\hline Wide sidewalks & $94 \%$ & $74 \%$ & $81 \%$ & $72 \%$ & $85 \%$ & $73 \%$ \\
\hline Streets with bike lanes & $\underline{85 \%}$ & $72 \%$ & $75 \%$ & $74 \%$ & $76 \%$ & $74 \%$ \\
\hline Various fun features to skate & $\overline{62 \%}$ & $\overline{74 \%}$ & $68 \%$ & $78 \%$ & $69 \%$ & $73 \%$ \\
\hline Parks and urban plazas & $\overline{70 \%}$ & $\overline{68 \%}$ & $70 \%$ & $64 \%$ & $70 \%$ & $66 \%$ \\
\hline Low speed streets & $66 \%$ & $47 \%$ & $54 \%$ & $45 \%$ & $59 \%$ & $46 \%$ \\
\hline Steep downhill slopes & $15 \%$ & $54 \%$ & $36 \%$ & $67 \%$ & $32 \%$ & $57 \%$ \\
\hline $\begin{array}{l}\text { Streets with shops, } \\
\text { restaurants, etc. }\end{array}$ & $40 \%$ & $38 \%$ & $43 \%$ & $32 \%$ & $37 \%$ & $39 \%$ \\
\hline $\mathrm{n}$ & 47 & 311 & 217 & 151 & 123 & 244 \\
\hline
\end{tabular}

Note: Underline $(p<.10)$ and bold $(p<.05)$ indicate a significant difference based on a chi-squared test

The proportion of respondents who selected "somewhat avoided" or "highly avoided" for each of the 'avoided' features was disaggregated by gender, skill level, and frequency of use (Table 12). For the most part, males, more experienced skateboarders, and more frequent utilitarian skateboarders were less likely to report these features as avoided. Chi-squared results indicate that males and frequent utilitarian skateboarders are significantly less likely to avoid rough surface conditions, steep uphill slopes, and areas with low levels of public safety. Frequent utilitarian skateboarders were also significantly less likely to report high volume traffic as an avoided feature. Surprisingly, there were no significant differences between groups of different experience levels. If individuals actively avoid and seek out different features in the built environment, as suggested in these findings, it could be expected that route choice would differ significantly across populations. Further research should investigate how these preferences influence routine trips for different types of utilitarian skateboarders. 
Table 12: 'Avoided' Route Features by Gender, Skill Level, and Frequency of Use

\begin{tabular}{|c|c|c|c|c|c|c|}
\hline \multirow[b]{2}{*}{ Avoided Feature } & \multicolumn{6}{|c|}{$\begin{array}{l}\text { Percent of Respondents who Selected Somewhat Avoided or Highly } \\
\text { Avoided }\end{array}$} \\
\hline & Female & Male & $\begin{array}{c}\text { Less } \\
\text { Experienced }\end{array}$ & $\begin{array}{c}\text { More } \\
\text { Experienced }\end{array}$ & $\begin{array}{l}\text { Infrequent } \\
\text { Users }\end{array}$ & $\begin{array}{l}\text { Frequent } \\
\text { Users }\end{array}$ \\
\hline Rough surface conditions & $98 \%$ & $82 \%$ & $84 \%$ & $84 \%$ & $90 \%$ & $81 \%$ \\
\hline Steep uphill slopes & $94 \%$ & $79 \%$ & $82 \%$ & $78 \%$ & $90 \%$ & $75 \%$ \\
\hline High volume traffic & $60 \%$ & $55 \%$ & $59 \%$ & $52 \%$ & $\underline{63 \%}$ & $53 \%$ \\
\hline Low level of public safety & $75 \%$ & $53 \%$ & $59 \%$ & $52 \%$ & $\underline{63 \%}$ & $\underline{53 \%}$ \\
\hline $\begin{array}{l}\text { Streets with regulations } \\
\text { prohibiting skateboarding }\end{array}$ & $55 \%$ & $45 \%$ & $48 \%$ & $43 \%$ & $48 \%$ & $45 \%$ \\
\hline Gentle uphill slopes & $43 \%$ & $36 \%$ & $37 \%$ & $35 \%$ & $38 \%$ & $35 \%$ \\
\hline $\mathrm{n}$ & 47 & 311 & 217 & 151 & 123 & 244 \\
\hline
\end{tabular}

\section{Route Consistency}

Interviewees often mentioned how the flexibility of skateboarding allowed them to be highly mobile and referred to the ability to swiftly maneuver from the sidewalk to the road or make sudden changes in their route to save time on a trip. Some also noted how their routine routes may be disrupted by things such as development projects, but their flexibility allowed them to easily adapt. These sorts of experiences are supported by survey respondents' answers to the question, "For everyday trips by skateboard, how often do you utilize the same route?" (Figure 11). For routine trips, the majority of respondents most commonly reported that their route is often the same $(61 \%)$. Another $18 \%$ reported that their route is sometimes the same, $3 \%$ said rarely, and $1 \%$ said never. Only $17 \%$ of respondents felt that they rely on the same route all of the time for everyday trips they make by skateboard. Given the flexibility of skateboarding and skateboarders' vulnerability to traffic and surface conditions, it is not surprising that various environmental factors could quickly redirect their route. For instance, one interviewee noted, "I have a general idea of the way that I usually go, especially if I'm heading into downtown. But I give myself a couple-block radius, all depending on the lights... nine 
times out of 10, it's just whatever the patterns of the lights are at that time" (Anonymous Interviewee).

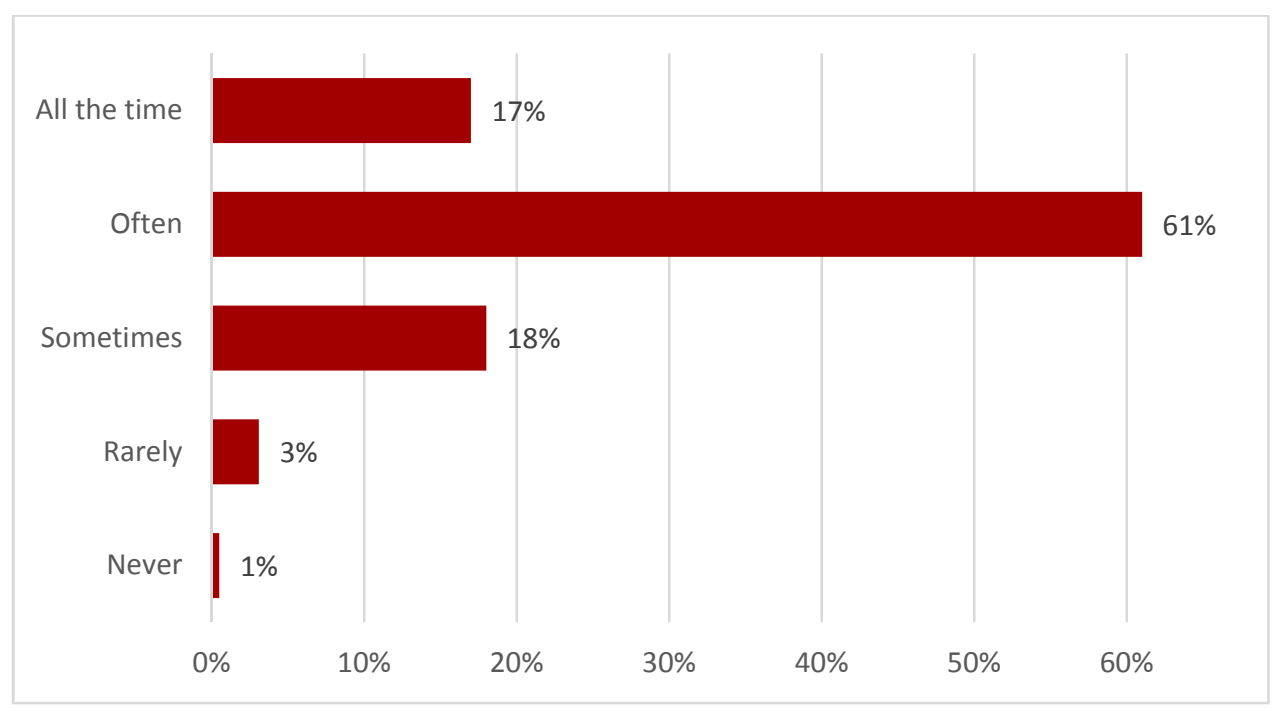

Figure 11: Route Consistency for Routine Trips $(n=365)$

\section{Facility Use}

The spaces in which skateboarders legally belong and those in which they feel comfortable (physically and socially) can be rather ambiguous and are often contradictory. Traffic laws for skateboarding can differ within and across political boundaries. In some areas skateboarders may be prohibited from riding in the roadway, in others they may be prohibited from riding on the sidewalk, and in others skateboarding may be prohibited entirely (e.g. central business districts and urban plazas). The spaces where skateboarders are legally allowed to ride may also change from day to night. The slower speed of skateboards, in relation to motor vehicles and bicycles, can make riding in roadways and bike lanes intimidating if the other users are not aware or tolerant. On the other hand, their speed in relation to pedestrians can cause discomfort among 
skateboarders and other users if there is lack of communication and acceptance. With this ambiguity in mind, survey respondents were asked which transportation facilities they use most often. Respondents were able to choose one of four prescribed options or select "other" and write in a response. The results are presented in Figure 12.

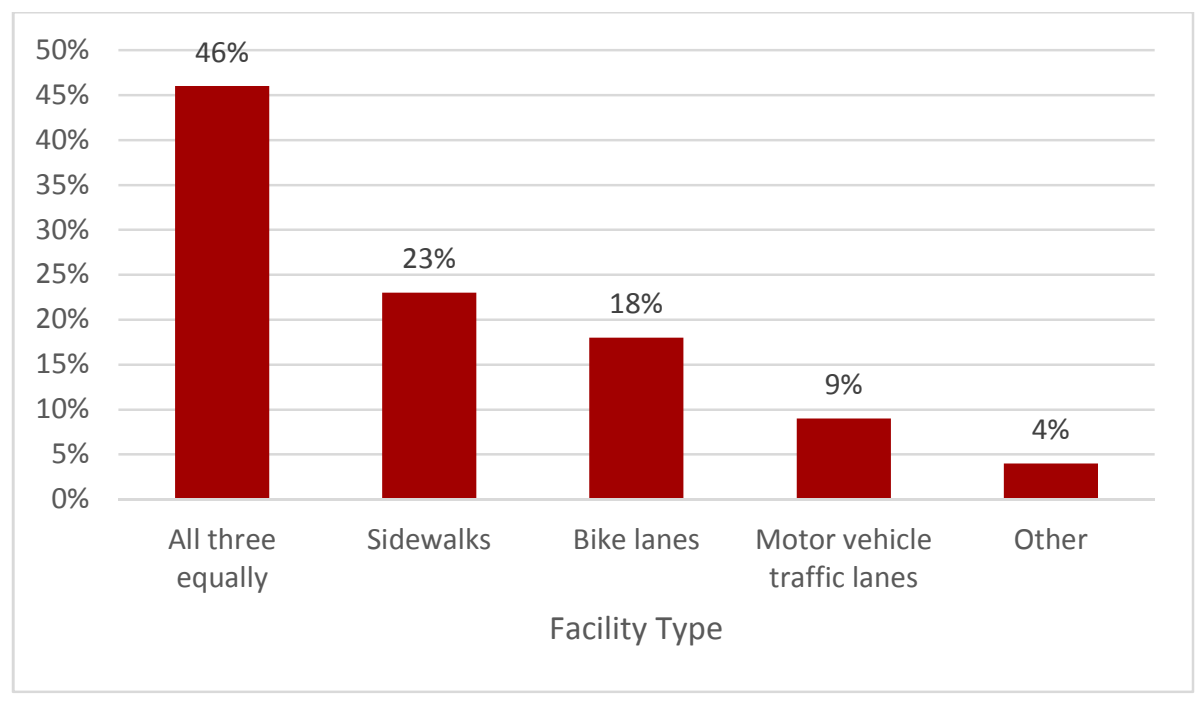

Figure 12: Transportation Facility Use by Skateboarders ( $n=368$ )

The greatest portion of respondents reported that when skateboarding on the street they travel on the sidewalk, bike lanes, and motor vehicle traffic lanes equally (46\%). Interviews with utilitarian skateboarders suggest that facility choice is often situational. For example, one interviewee stated, "it really depends on the surface of the sidewalk. If the sidewalk is good that's where I would prefer. If not then I'll usually use the street, and whether it's in a bike lane or [in] the street depends on whether there is a bike lane, but I think I'd prefer to use a bike lane than an actual lane" (Anonymous Interviewee). Additional data collected from interviews support three potential explanations for the use of various facilities. Each explanation is presented with a supporting excerpt. First, the 
variance in surface conditions and traffic levels could encourage skateboarders to select the facility which best accommodates comfortable travel: "if I know a sidewalk's broken, I can pop off, and just go onto the road, and then go around that block, and get back on" (Anonymous Interviewee). Second, skateboarders are aware of the prohibitions and abide by the traffic laws, resulting in a shift between facilities: "Yeah, I follow the downtown prohibition of skating on the sidewalk. Hoyt to Market to $13^{\text {th }}$, or whatever it is, to Naito. I don't skate on the sidewalks in that area" (Anonymous Interviewee). Lastly, the presence of different facilities varies from street to street, requiring skateboarders to rely on the facilities available: "I know certain places in Portland you're able to skateboard in the bike lane, but you don't always have that option on every street" (Anonymous Interviewee).

Respondents were less likely to report that a single facility accommodates most of their skateboarding travel; 23\% selected sidewalks, 18\% selected bike lanes, and 9\% selected motor vehicle traffic lanes. Some of the respondents who selected "other" (4\%), mentioned that they utilize a combination of bike lanes and sidewalks. It is expected that a skateboarder's skill and comfort level impact their decision on which facility to use. When disaggregated, the survey results suggest that females, less experienced skateboarders, and infrequent utilitarian skateboarders are more likely to rely on sidewalks for the majority of their trips than their counterparts. These findings are likely indicative of differential levels of perceived safety. 


\section{Comfort Levels and the Role of Bike Lanes}

Findings in previous sections have provided evidence that bike lanes and other pedestrian and bicycle facilities play an important role in skateboarding transportation. In order to assess the influence of bike lanes on comfort, respondents were asked to report their comfort levels on various roadway types with and without the presence of designated bicycle spaces. They were also asked to report their comfort on a path or trail separated from traffic. The scale ranged from 1 to 4 , or "very uncomfortable" to "very comfortable." Figure 13 displays the mean comfort levels in each hypothetical situation and the relative effect of designated bike lanes or markings. "Paths or trails separated from traffic" was not included in this figure because there was no alternative option; however, the results will be discussed.

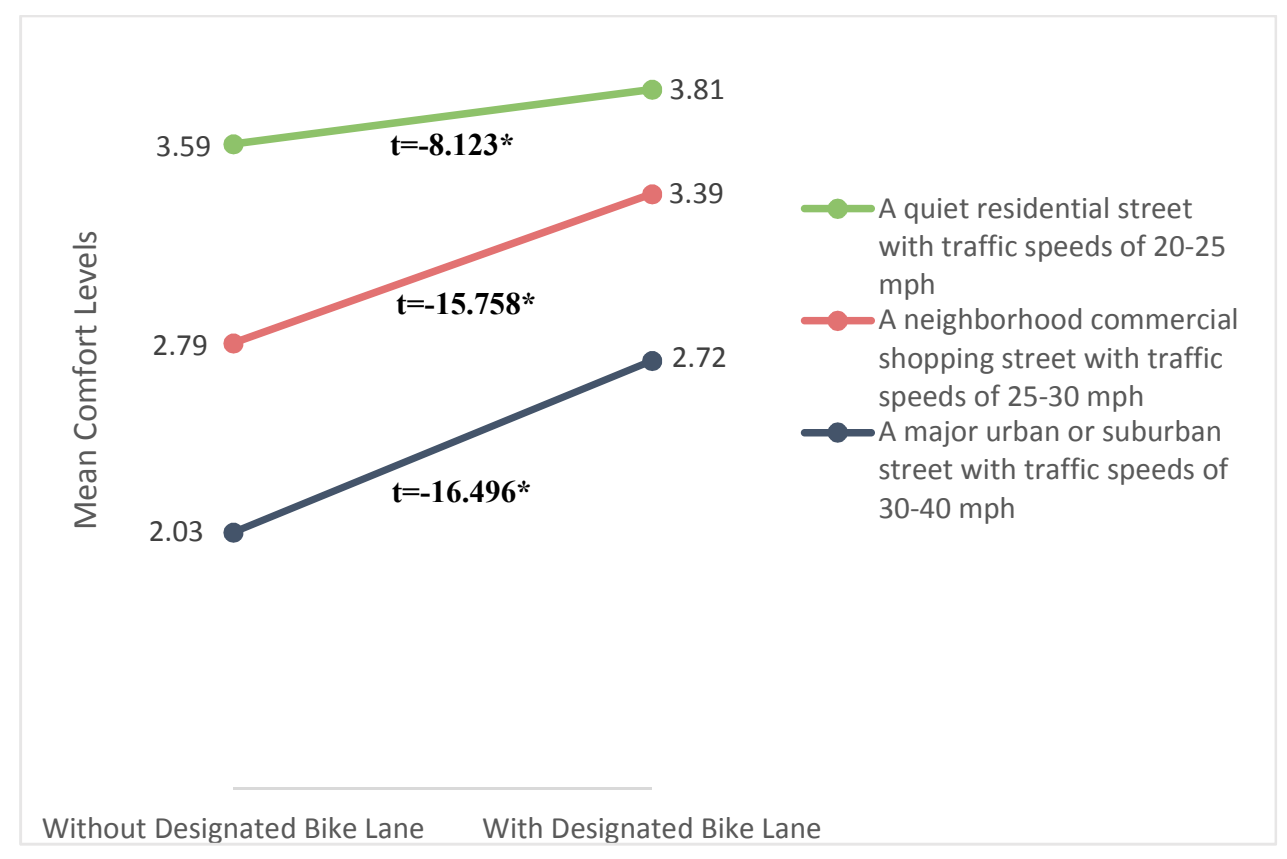

Figure 13: Bike Lanes and Comfort: Paired Samples T-Tests $(n=368)^{2}$

${ }^{2}$ Note: $\mathrm{df}=367 ;{ }^{*} \mathrm{p}<.000$ 
As expected, skateboarders tend to feel most comfortable on paths or trails separated from traffic; the mean comfort level for this situation was 3.83, which is very close to the maximum possible mean of 4.0. This suggests that enhancement of pedestrian and bicycle trail systems could also benefit the perceived safety of skateboarders. The mean comfort level on quite residential streets was fairly high even without bicycle route markings $(\overline{\mathrm{x}}=3.59)$; however, on average, comfort levels decreased considerably with an increase in speed. On neighborhood commercial shopping streets with speeds of 25-30 mph the mean comfort level was 2.79 and on major urban and suburban streets with speeds of 30-40 mph the mean comfort level was 2.03. When bicycle markings were added to the hypothetical residential street, comfort levels increased almost to the level of a separated trail or path $(\overline{\mathrm{x}}=3.81)$. As the speed of traffic increased the added comfort of bike lanes grew significantly. The mean projected increase in comfort when bicycle markings were added to neighborhood commercial streets (0.60) and major urban or suburban streets (0.69) were approximately three times higher than it was for quite residential streets $(0.22)$. While comfort levels were extremely low for major urban and suburban streets, adding a bike lane brought the mean comfort level to a near comfortable situation $(\overline{\mathrm{x}}=2.72)$.

These findings suggest that bike lanes and other infrastructure designed primarily for bicyclists positively impact the comfort levels of utilitarian skateboarders. These results are also representative of the value interviewees attributed to bike lanes. One interviewee said, "When I grew up I was skateboarding on the side of the highway to get to the nearest grocery store a couple miles away... So, when I got to the suburbs and then 
the city, it was like 'holy geez, bike lanes, this is great!'” (Anonymous Interviewee). Another interviewee said, "and since I'm comfortable riding with cyclists, generally what ends up going into place for them works for me" (Anonymous Interviewee).

Independent samples t-tests were utilized to identify differences in comfort across populations based on gender, experience, and frequency of use. Table 13 shows mean comfort levels by group for each situation and highlights significant results. The assumption was made that females, less experienced skateboarders, and infrequent utilitarian skateboarders would feel less comfortable traveling by skateboard in these hypothetical situations.

Table 13: Differences in Mean Comfort Levels: Independent Samples T-Test

\begin{tabular}{|c|c|c|c|c|c|c|}
\hline & \multicolumn{6}{|c|}{ Mean Comfort by Group } \\
\hline & Female & Male & $\begin{array}{c}\text { Less } \\
\text { Experienced } \\
\end{array}$ & $\begin{array}{c}\text { More } \\
\text { Experienced }\end{array}$ & $\begin{array}{c}\text { Infrequent } \\
\text { Users }\end{array}$ & $\begin{array}{c}\text { Frequent } \\
\text { Users }\end{array}$ \\
\hline $\begin{array}{l}\text { A path or trail separated } \\
\text { from traffic }\end{array}$ & 3.83 & 3.83 & 3.82 & 3.85 & 3.86 & 3.81 \\
\hline $\begin{array}{l}\text { A quiet residential street } \\
\text { with traffic speeds of } 20-25 \\
\text { mph and no bicycle route } \\
\text { markings }\end{array}$ & 3.57 & 3.61 & 3.57 & 3.63 & 3.56 & 3.61 \\
\hline ....add a bicycle route & 3.87 & 3.81 & 3.80 & 3.83 & 3.79 & 3.82 \\
\hline $\begin{array}{l}\text { A neighborhood } \\
\text { commercial shopping street } \\
\text { with traffic speeds of } 25-30 \\
\text { mph and no designated bike } \\
\text { lanes }\end{array}$ & 2.36 & 2.88 & 2.74 & 2.87 & 2.58 & 2.9 \\
\hline$\ldots$ add a bike lane & 3.15 & 3.42 & 3.35 & 3.44 & 3.17 & 3.49 \\
\hline $\begin{array}{l}\text { A major urban or suburban } \\
\text { street with traffic speeds of } \\
30-40 \mathrm{mph} \text { and no } \\
\text { designated bike lanes }\end{array}$ & 1.47 & 2.12 & $\underline{1.94}$ & $\underline{2.15}$ & 1.79 & 2.15 \\
\hline ... add a bike lane & 2.3 & 2.79 & $\underline{2.63}$ & $\underline{2.85}$ & 2.41 & 2.89 \\
\hline $\mathrm{n}$ & 47 & 311 & 217 & $\overline{151}$ & 123 & 244 \\
\hline
\end{tabular}


Respondents' comfort levels on separated facilities and on quiet residential streets (with or without bike lanes) were fairly high for all groups and were not significantly different. However, as the speed of traffic increased comfort levels decreased at a faster rate for some groups. On average, females and infrequent utilitarian skateboarders felt less comfortable than their counterparts on neighborhood commercial shopping streets and major urban or suburban streets, with or without a bike lane. Surprisingly, comfort levels on neighborhood commercial streets were not significantly different between skateboarders of different experience levels; however, less experienced skateboarder, on average, felt less comfortable on major urban or suburban streets (with or without bike lanes). In terms of gender, these findings align with those of Emond, Tang, and Handy (2009), who found that female bicyclists tend to feel less comfortable than males on two-

and four-lane streets (with and without bike lanes). These results reinforce the importance of infrastructure, especially as a means of enhancing levels of perceived safety for those who tend to feel less comfortable traveling in the street; low levels of perceived safety could inhibit their choice to travel by skateboard and potentially encourage less sustainable modes. Furthermore, if skateboarders react to improved safety conditions in a similar way to bicyclists, it could be expected that infrastructural improvements could greatly increase the propensity to skateboard (Sallis et al., 2013).

\section{Regulations and Perceived Acceptance}

Considering the negative social perceptions often associated with skateboarding and the prevalence of local skateboarding prohibitions, it was assumed that skateboarders may feel as though their mobility needs are marginalized by local regulations and policies as 
well as other users of the transportation network. To assess the validity of this assumption, respondents were asked whether they agree or disagree with various statements regarding these matters (Figure 14).

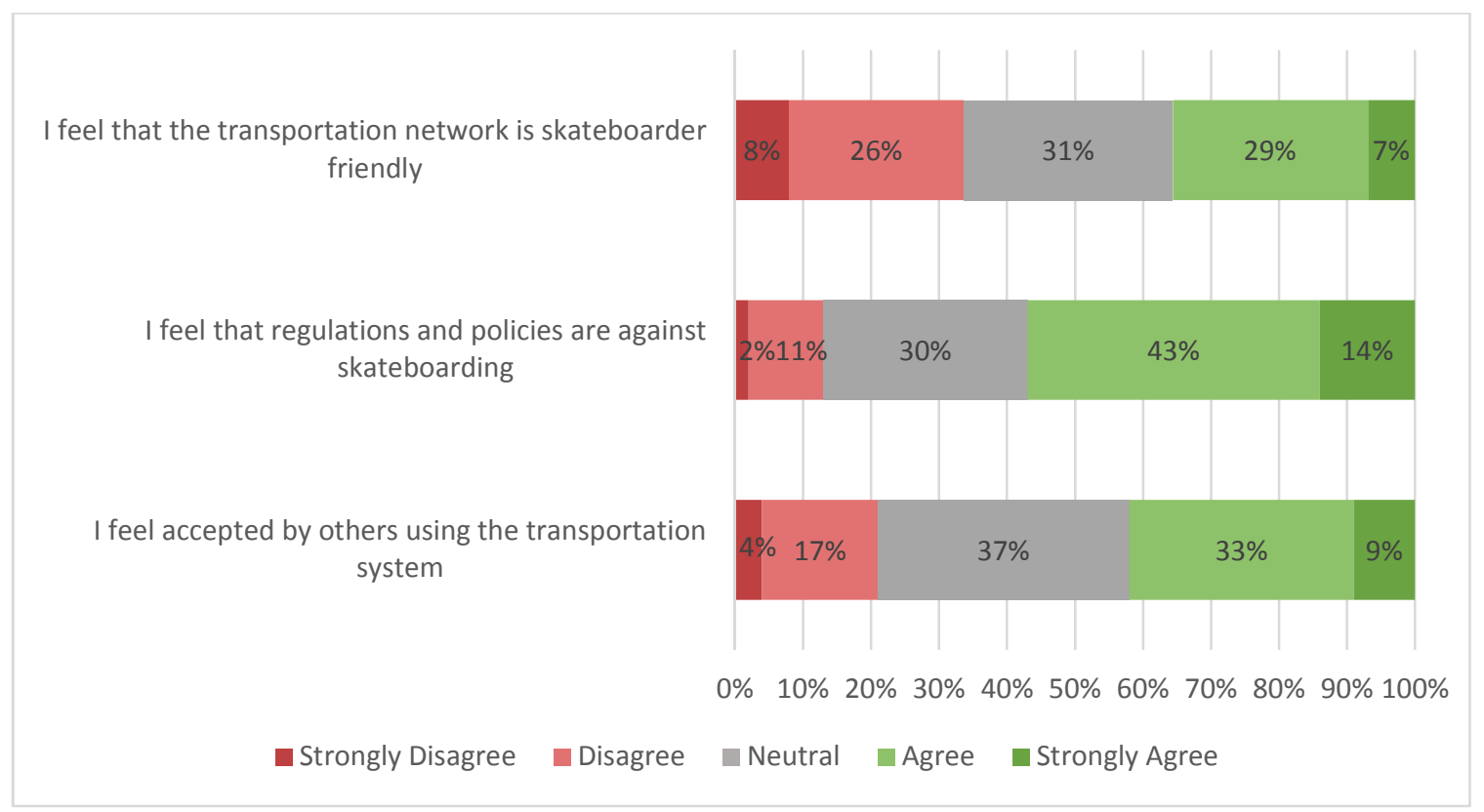

Figure 14: Attitudes towards Regulations and Acceptance ( $n=368)$

There was a near even split of respondents who disagreed (34\%), were neutral $(31 \%)$, or agreed $(36 \%)$ that the transportation network is skateboarder friendly. Many of the factors considered in this paper can influence an individual's level of agreement with this statement, such as the presence and conditions of infrastructure, public perception, traffic laws and enforcement, and traffic speeds and volume. Thus, attitudes will differ in accordance with the environmental characteristics and regulations of the neighborhood and jurisdiction in which a skateboarder commutes. Subjective factors will also influence their opinion. When asked about their experiences commuting by skateboard in Portland, most of the interviewees made comparisons to other cities to highlight how Portland's 
bicycle infrastructure, social environment, and political climate make it a friendlier place to skateboard than others. One interviewee stated, "Currently there aren't rules about taking skateboards on the bus or Max, whereas I know that in some places there are. So, I think Portland is at least a little bit better about it" (Anonymous Interviewee). Another interviewee stated, "I really appreciate that it's legal to skate in the street here. I have been pulled over in other jurisdictions for skating in the street" (Anonymous Interviewee). This interviewee went on to state that Portland's transportation system is "aspirational" when it comes to skateboarding (Anonymous Interviewee). These excerpts highlight how the jurisdictional context can impact a skateboarder's perception of the transportation network.

The majority of respondents agreed or strongly agreed that regulations and policies are against skateboarding (57\%). Given the prevalence of skateboarding regulations within the United States and Canada, this was not surprising. While many of these regulations were set in place to control recreational skateboarding in the public realm, they affect all skateboarders (Fang, 2013). Most interviewees were able to recall a time where they had been approached by law enforcement while skateboarding. One interviewee stated that she had been approached by a police officer while dismounted from her skateboard. Numerous survey respondents also made reference to skateboarding regulations and enforcement in open-ended responses. One respondent stated, "Until archaic anti-skateboard laws are changed, I hope police will make good judgments and tolerate people who are obviously commuting by skateboard" (Anonymous Respondent). Even in Portland where skateboarding has been recognized as a "legitimate mode of 
transportation" and skateboarders "have a legal status similar to bicyclists" there are still limitations which limit the mobility of skateboarders (The City of Portland, 2018). These limitations include the prohibition of skateboarding on numerous streets and all sidewalks in the downtown core. While this is certainly a step in the right direction, these prohibitions are especially limiting for individuals who do not feel comfortable traveling in the motor vehicle traffic lanes. As Fang (2013) has claimed, regulations in geographic areas such as the central business districts make skateboarding to commercial destinations and work essentially illegal for many individuals.

More than one-fifth of the respondents disagreed that they feel accepted by other users of the transportation system, and another $37 \%$ reported that they were neutral. In an open-ended response, one skateboarder stated "I feel that skateboarding and longboarding have a bad face to the name. Boarding should be accepted as a fun and creative way to get around, it shouldn't be shunned" (Anonymous Respondent). Skateboarders tend to rely on various transportation facilities and those facilities are generally provided for a specific mode other than skateboarding. One respondent felt that the status quo of the transportation system ensures that "The street is for vehicles, not skateboards, but the sidewalk is for pedestrians, not vehicles (skateboards)...and bike lanes are for bikes only" (Anonymous Respondent). Without a space provided for them, skateboarders are constantly a guest in someone else's space, which can generate a sense of physical and social discomfort; however, interviewed skateboarders demonstrated a high level of respect for others' space and acknowledge that they are guests. Defining spaces for a specific mode can also generate a sense of ownership in those for whom the space is 
provided, which can potentially sanction negative attitudes and actions towards those who are seen as interlopers. In open-ended responses, numerous skateboarders reported the desire for skateboarding to be accepted as a mode of transportation and for fair treatment from motorists and bicyclists. For example, one respondent stated, "I wish car drivers would understand we are equal to cyclists and respect us a little more on roadways" (Anonymous Respondent).

On the other hand, a notable portion of respondents felt as though they are accepted by other users of the transportation system (42\%). Each of the interviewees felt a general sense of acceptance within Portland, although some had experienced slight resistance from pedestrians. Interviewees and survey respondents acknowledge that often times acceptance towards skateboarding is acquired with competence and courtesy. For example, one interviewee said, 'I feel like most people don't really care if you're being courteous and not running into them." Furthermore, they demonstrated a desire to be courteous to others, with hopes of challenging the stigmas associated with skateboarding. One skateboarder described it as wanting to be a "steward of the skateboarding community" (Anonymous Interviewee). These findings suggest perceived acceptance is dependent on the social tolerance of other users. While skateboarders may not always feel accepted, it appears that they tend to pay respect to others within the spaces they are utilizing. One respondent stated, "I am polite when I skate and always let cars and pedestrians go first because they still think we are reckless. I like to prove them wrong" (Anonymous Respondent). This excerpt and others like it are contradictory to the social constructs which have portrayed skateboarders as nuisances and illogical users of space. 


\section{Conclusions}

In this study, the perceptions and experiences of utilitarian skateboarders were evaluated to provide insight into the characteristics of an under-studied mode of transportation. My primary goal for this study was to explore the following questions with the hopes of providing empirical evidence which can inform more inclusive transportation policy decisions in the future: 1) What are the key motivations and barriers to utilizing skateboarding as a mode of transportation?; 2) What are the social, legal, and environmental factors that impact route choice amongst utilitarian skateboarders?; 3) How do skateboarders utilize and value the existing transportation infrastructure?; and 4) Do the answers to these questions differ in accordance with the skateboarders' personal characteristics (i.e. gender, skill, and frequency of use), and if so why? In this section I will revisit these questions and address the key findings of this study. I will also make suggestions on how cities can begin to open their doors to new and beneficial mobilities, especially skateboarding. Lastly, I will discuss future research avenues which could expand our understanding of the role skateboarding plays in our urban transportation systems.

With respect to mode choice, the results of this study are in partial accordance with previous research on utilitarian skateboarding. Similarly to Fang and Handy (2017b) and Walker (2013), this study identifies fun as the most fundamental mode choice factor. Convenience, which is made up of multiple components such as flexibility and the ease short urban trips also plays a crucial motivational role. In convergence from previous work, this study suggests that the skateboarding culture and lifestyle has a significant 
influence on the decision to travel by skateboard - riding a skateboard for transportation purposes becomes an opportunity for an individual to represent one's self-identity. However, the role of lifestyle differs significantly between populations; males were two times more likely to report that they travel by skateboard because it is a part of their lifestyle. It is likely that this is an outcome of the gendered barriers constructed within the skateboarding culture which disenfranchise females and femininity (Beal, 1996).

Like pedestrians and bicyclists, individuals are deterred from skateboarding by the conditions of the transportation facilities, wet and extreme weather conditions, distance, slope, and automobile traffic (Broach et al. 2012, Dill and Voros, 2007). What separates skateboarding from these other active modes is the role of traffic regulations. The survey results suggest that skateboarders commonly believe that the traffic laws within their city discourage skateboarding and are often ambiguous and contradictory. This is not necessarily surprising given that the spaces that skateboarders are legally allowed to occupy differ within and across boundaries and are often ill-defined (Fang, 2013). Furthermore, it is not uncommon for skateboarders to feel ostracized by other users of the transportation network and some feel as though they are perceived as ingenuous, unprofessional, and disorderly. These negative perceptions limit the use of skateboarding as a mode of transportation, especially amongst adults.

The attributes of the physical environment which deter individuals from skateboarding also play a significant role in route choice. Similar claims have been made for bicyclists and pedestrians (Broach, 2016). Skateboarders in this study claimed that their route choices are sensitive to surface conditions, existing infrastructure, safety, 
traffic, and slope. Females, less experienced skateboarders, and infrequent utilitarian skateboarders attributed a higher value to features that might enhance their safety, such as wide sidewalks, designated bike lanes, and low speed streets. On the other hand, their counterparts placed a higher value on features that pertain more to fun, enjoyment, and thrill, such as micro-features ad steep downhill slopes. Even when controlling for skill, gender was a significant indicator of the desire for hills, which is consistent with previous research on the gender differences of risk taking behavior within the skateboarding culture (Atencio et al., 2009).

The high value attributed to micro-features (i.e. ledges, staircases, embankments) is interesting. Fang and Handy (2017a) observe that individuals traveling by skateboard tend to move in a straight line and refrain from performing stunts. I believe that this behavior should be expected on facilities such as narrow bike lanes, heavily trafficked roads or sidewalks, and/or environments with few micro-features; however, interview excerpts and survey findings from this study are suggestive of the playful interaction between skateboarders and the built environment during travel. It is my contention that the discrepancies in findings are a result of methodological differences. Fang and Handy's conclusions are likely heavily influenced by the use of a single observation point, as the built environment and a host of other factors (e.g. skill, trip purpose, and mood) will contribute to the likelihood of playful behavior.

Skateboarders in this study highlighted the importance of the existing transportation facilities in their travels; respondents were more likely to report that they use sidewalks, bike lanes, and motor vehicle lanes equally over any single facility. This 
does not come as a surprise as the spaces that skateboarders are legally allowed to use and those they feel comfortable using are often contradictory and constantly in flux. The sensitivity to surface quality and traffic, the presence of regulations, and the lack of safe infrastructure in some neighborhoods can cause a shift in the use of facilities. While this may not be ideal, skateboarders valued the flexibility of their mode and ability to maneuver between facilities or simply dismount their skateboard and walk. Skateboarders do not require their own spaces within the transportation network, yet they desire to be accepted and recognized as legitimate users of the existing spaces (i.e. motor vehicle traffic lanes, bike lanes, off-street paths, and sidewalks). It is evident that skateboarders value these spaces for reasons of convenience and safety; bike lanes and bike routes had a significant positive impact on the comfort levels of skateboarders regardless of the speed of traffic, and as speed increased the value attributed to the bike lanes increased. However, reported comfort levels on these facilities portray differential levels in perceived safety across populations; on roadways with speeds over 25 miles per hour, females and infrequent utilitarian skateboarders reported significantly lower comfort levels than their counterparts, even with the presence of a bike lane. In terms of gender, these findings align with a study which evaluated the perceived comfort levels of bicyclists on similar facilities (Emond et al. 2009). While this study shows that skateboarders travel in unique ways, it is apparent that they value many of the same attributes and transportation facilities as bicyclists and pedestrians.

The first step to enhancing the conditions and opportunities for utilitarian skateboarders would be to acknowledge skateboarding as a legitimate mode of 
transportation. While many respondents reported that they were unsatisfied with the regulations and policies against skateboarding, Portland residents often attributed a high value of appreciation to the decriminalization of skateboarding on most of the city's streets. Another important aspect of acknowledging skateboarding would be to include it as a mode in travel surveys (e.g. campus travel surveys, on-board transit surveys, national travel surveys, etc.) and bicycle and pedestrian counts. This is applicable at the local, regional, state, and federal level. Acquiring data on utilitarian skateboarding will allow cities to better understand how it is used and address the mode's unique needs.

It is unlikely that the spatial anti-skateboarding regulations will be completely lifted anytime in the near future; however, it could be beneficial for cities to revisit those regulations and attempt to disentangle them, and to do so with a consideration for how they might impact individuals who rely on skateboarding for transportation purposes. This could help cities redefine the areas where skateboarding should and should not be accepted. Setting clear and consistent spatial regulations would benefit both the city and skateboarders and could significantly decrease the tension between skateboarders and law enforcement. In addition to educating law enforcement on these regulations, the cities should also focus on informing the general public of where skateboarders can and cannot ride to help prevent conflicts between skateboarders and other road users. In a paper on the spatial politics of skateboarding, geographer Elaine Stratford asks us to think about the benefits of permitting and accommodating the use of new and playful mobilities: "Imagine how enchanting it might be to radically shift the ways in which we move through the armatures of the city, foster sensory civility toward one another, respect 
difference, and recognize that 'giving up' is not always about loss but about opening spaces for new ways of being” (2016, p. 355).

The vast differences in perceived barriers and comfort levels suggest that, like bicyclists, there various types of skateboarders, some who are risk-adverse and some who will skateboard regardless of the environmental conditions (Dill and McNeil, 2013). It is critical for cities to consider these differences when deciding where skateboarders are permitted; for example, limiting skateboarding to the roadway in some areas could deter risk-adverse skateboarders. These differences also present a unique opportunity for cities to deploy safety education and training courses for skateboarders. These courses could be used to train individuals on the skills necessary to safely and comfortably navigate urban transportation facilities by skateboard. They could also be used by cities and non-profits to encourage the use of skateboarding as a mode of travel, while building awareness amongst the general public. I recommend that these courses be taught within both recreational- and transportation-oriented settings (i.e. public skateparks and public streets, respectively). While many skateboarders start off recreationally, it is essential to introduce inexperienced and potential utilitarian skateboarders to the unique challenges of navigating the streets.

The findings in this study suggest that enhancements made to improve conditions for other active modes (i.e. biking and walking) could ultimately benefit skateboarders in the context of supportive regulations; however, a greater effort is needed to actively consider and include skateboarders in the planning and design process for non-motorized infrastructure. This could be done by considering the barriers presented in this study, 
especially surface conditions, traffic conditions, and regulations. In recent years, policies like Complete Streets have opened the door to accommodating the needs of diverse users, yet the projects are overwhelmingly geared towards improving the conditions for pedestrians, bicyclists, motorists, and transit riders. It is my contention that skateboarders will react to infrastructural improvements in similar ways to pedestrians and bicyclists (Dill and Carr, 2003), and if so, creating inviting and accommodating spaces for skateboarders could tap latent demand for utilitarian skateboarding.

This study has begun to fill numerous knowledge gaps regarding the use of skateboarding as a mode of transportation, but it was not without its limitations. The survey that was utilized in this study was not randomly distributed, which limits the generalizability of the study findings; however, given the relative nuance of the topic and the exploratory nature of this research, a snowball sampling method seemed most appropriate for collecting a reasonably sized sample. In future studies and as utilitarian skateboarding becomes more popular, more rigorous sampling methods can be utilized. The survey was also limited to individuals over the age of 18 and to those who had access to a computer or smart phone. By excluding children from the study I left out a significant portion of the skateboarding population, and that data could be beneficial for programs like Safe Routes to School. Lastly, a larger sample of interview participants and a more robust analysis of the qualitative data could have contributed significantly to the study, yet, as is, this component greatly enhanced the ecological validity of the survey findings. 
Throughout the course of this research I have identified numerous avenues for future research. The following questions arose through the explanatory limitations of this survey data as well as the methodological limitations mentioned above:

1) Does skateboarding transportation serve a more integral purpose in lower income and carless households? Findings presented in this study suggest that skateboarding is utilized more for transportation than recreational purposes by individuals living in households with lower annual incomes and without access to a motor vehicle. Future research should look at the economic benefits of skateboarding especially in socioeconomically disadvantaged households.

2) What are the perceived benefits and barriers of utilitarian skateboarding amongst younger populations (K-12) and what are the implications for safe routes to school? Future research should address the age limitation in this study. Given the high participation rate in skateboarding amongst urban youth, it is pivotal to understand the perceived benefits and barriers of utilitarian skateboarding for these populations. The findings could contribute significantly to Safe Routes to School programs across the United States.

3) How is skateboarding currently perceived within public planning agencies and the general public, and are skateboarders being considered in transportation policy decisions? Understanding how skateboarding is currently perceived within public planning agencies and the general public could provide insight into the social and political barriers to skateboard transportation and potential ways to overcome those challenges. 
4) How does the presence of skateboarding impact the use of other modes? Addressing this question could inform cities on how to best encourage diverse uses on transportation facilities originally designed for a specific user (e.g. bike lanes and sidewalks).

The academic field could also benefit from studies on the use of electric skateboards, route choice modeling, the barriers to entry for non-skateboarders, and the political process of legalizing skateboarding. I believe that addressing these questions will help local governments understand how to accommodate the needs and desires of those who utilize this emergent mode of transportation through the development of supportive and protective policies and projects. 


\section{References}

Agrawal, Asha Weinstein, Marc Schlossberg, and Katja Irvin. "How far, by which route and why? A spatial analysis of pedestrian preference." Journal of urban design 13, no. 1 (2008): 81-98.

Atencio, Matthew, Becky Beal, and Charlene Wilson. "The distinction of risk: Urban skateboarding, street habitus and the construction of hierarchical gender relations." Qualitative research in sport and exercise 1, no. 1 (2009): 3-20.

Bartholomew, Keith, and Reid Ewing. "Hedonic price effects of pedestrian-and transitoriented development." Journal of Planning Literature 26, no. 1 (2011): 18-34.

Beal, Becky. "Alternative masculinity and its effects on gender relations in the subculture of skateboarding." Journal of Sport Behavior 19, no. 3 (1996): 204.

Biton, Anna, James Andrew, and Jessica Baas. "Metropolitan pedestrian and bicycle planning handbook.” No. DOT-VNTSC-OSTR-17-02. John A. Volpe National Transportation Systems Center (US), 2017.

Broach, Joseph Paul. "Travel Mode Choice Framework Incorporating Realistic Bike and Walk Routes." PhD diss., Portland State University, 2016.

Broach, Joseph, Jennifer Dill, and John Gliebe. "Where do cyclists ride? A route choice model developed with revealed preference GPS data." Transportation Research Part A: Policy and Practice 46, no. 10 (2012): 1730-1740.

Chiu, C. "Contestation and Conformity: Street and Park Skateboarding in New York City Public Space.” Space and Culture 12, no. 1 (February 1, 2009): 25-42.

Clifton, Kelly, Kristina M. Currans, Christopher D. Muhs, Chloe Ritter, Sara Morrissey, and Collin Roughton. "Consumer Behavior and Travel Choices: A Focus on Cyclists and Pedestrians." In 92nd Annual Meeting of the Transportation Research Board.

Washington, DC, Vol. 14, 2012.

Coughenour, Courtney, Sheila Clark, Ashok Singh, Eudora Claw, James Abelar, and Joshua Huebner. "Examining racial bias as a potential factor in pedestrian crashes." Accident Analysis \& Prevention 98 (2017): 96-100.

Davis, Mike. "Fortress L.A." In City of Quartz: Excavating the Future in Los Angeles, 223-63. Verso Books, 2006. 
Dill, Jennifer, and Nathan McNeil. "Four types of cyclists? Examination of typology for better understanding of bicycling behavior and potential." Transportation Research

Record: Journal of the Transportation Research Board 2387 (2013): 129-138.

Dill, Jennifer, and Kim Voros. "Factors affecting bicycling demand: initial survey findings from the Portland, Oregon, region." Transportation Research Record: Journal of the Transportation Research Board 2031 (2007): 9-17.

Dill, Jennifer, and Theresa Carr. "Bicycle Commuting and Facilities in Major US Cities: If You Build Them, Commuters Will Use Them." Transportation Research Record: Journal of the Transportation Research Board, no. 1828 (2003): 116-123.

Emond, Catherine, Wei Tang, and Susan Handy. "Explaining gender difference in bicycling behavior." Transportation Research Record: Journal of the Transportation Research Board 2125 (2009): 16-25.

Fang, Kevin, and Susan Handy. "Skate and die? The safety performance of skateboard travel: A look at injury data, fatality data, and rider behavior." Journal of Transport \& Health (2017a).

Fang, Kevin, and Susan Handy. "Skateboarding for transportation: exploring the factors behind an unconventional mode choice among university skateboard commuters." Transportation (2017b): 1-21.

Fang, Kevin. "Skateboarding as a mode of transportation: Review of regulations in California cities and college campuses." In Transportation Research Board 92nd Annual Meeting, No. 13-3500. 2013.

Fang, Kevin. "Skateboarding for Transportation by the Numbers: Quantitative Indications of the Use of Skateboards as an Active Travel Mode." In Transportation Research Board 94 ${ }^{\text {th }}$ Annual Meeting, No. 15-3770. 2015.

Flanagan, Elizabeth, Ugo Lachapelle, and Ahmed El-Geneidy. "Riding tandem: Does cycling infrastructure investment mirror gentrification and privilege in Portland, OR and Chicago, IL?." Research in Transportation Economics 60 (2016): 14-24.

Flusty, Steven. Building Paranoia: The Proliferation of Interdictory Space and the Erosion of Spatial Justice. Los Angeles Forum for Architecture and Urban Design, 1994.

Flusty, Steven. "Thrashing Downtown: Play as Resistance to the Spatial and Representational Regulation of Los Angeles." Cities 17, no. 2 (2000): 149-158.

Frank, Lawrence D., James F. Sallis, Terry Conway, J. Chapman, Brian Saelens, and William Bachman. "Multiple pathways from land use to health: walkability associations 
with active transportation, body mass index, and air quality." Journal of the American Planning Association 72, no. 1 (2006): 75-87.

Garrett-Peltier, Heidi. "Pedestrian and bicycle infrastructure: A national study of employment impacts." Amherst, MA: Political Economy Research Institute (2011).

Gatersleben, Birgitta, and David Uzzell. "Affective appraisals of the daily commute: Comparing perceptions of drivers, cyclists, walkers, and users of public transport." Environment and behavior 39, no. 3 (2007): 416-431.

Hart, Roger. Children's experience of place. New York: Irvington, 1979.

Howell, Ocean. "The Poetics of Security: Skateboarding, Urban Design, and the New Public Space.” Urban Action, 2001.

Kuzmyak, J. Richard, and Jennifer Dill. "Walking and Bicycling in the United States: The Who, What, Where, and Why." TR News 280 (2012): 4-7.

Litman, Todd. "Evaluating active transport benefits and costs: guide to valuing walking and cycling improvements and encouragement programs." Victoria Transport Policy Institute (2017).

Lyons, William, Benjamin Rasmussen, David Daddio, Jared Fijalkowski, and Erica Simmons. "Nonmotorized Transportation Pilot Program.” Final Report. Washington, D.C.: U.S. Department of Transportation, May 2014.

Mitchell, Don, and Nik Heynen. "The Geography of Survival and the Right to the City: Speculations on Surveillance, Legal Innovation, and the Criminalization of Intervention." Urban Geography 30, no. 6 (August 2009): 611-32.

Mitchell, Don. "The End of Public Space? People's Park, Definitions of the Public, and Democracy." Annals of the Association of American Geographers 85, no. 1 (1995): 10833.

Mokhtarian, Patricia L., and Ilan Salomon. "How derived is the demand for travel? Some conceptual and measurement considerations." Transportation research part A: Policy and practice 35 , no. 8 (2001): 695-719.

National Bicycling and Walking Study. "Case Study No. 1: Reasons Why Bicycling and Walking Are Not Being Used More Extensively as Travel Modes.” FHWA, U.S. Department of Transportation, 1992.

Owens, Patsy Eubanks. "Recreation and Restrictions: Community Skateboard Parks in the United States. Urban Geography 22, no. 8 (November 2001): 782-97. 
Padgett, Deborah K. "Mixed Methods." In Qualitative and Mixed Methods in Public Health. Thousand Oaks: Sage publications, 2012.

Plaut, Pnina O. "Non-motorized commuting in the US." Transportation Research Part D: Transport and Environment 10, no. 5 (2005): 347-356.

Pucher, John, Jennifer Dill, and Susan Handy. "Infrastructure, programs, and policies to increase bicycling: an international review." Preventive Medicine 50 (2010): S106-S125.

Pucher, John, Ralph Buehler, David R. Bassett, and Andrew L. Dannenberg. "Walking and cycling to health: a comparative analysis of city, state, and international data." American Journal of Public Health 100, no. 10 (2010): 1986-1992.

Pucher, John, and Ralph Buehler. "Walking and cycling for healthy cities." Built Environment 36, no. 4 (2010): 391-414.

Rodríguez, Daniel A., and Joonwon Joo. "The relationship between non-motorized mode choice and the local physical environment." Transportation Research Part D: Transport and Environment 9, no. 2 (2004): 151-173.

Rogers, Shannon H., John M. Halstead, Kevin H. Gardner, and Cynthia H. Carlson. "Examining walkability and social capital as indicators of quality of life at the municipal and neighborhood scales." Applied Research in Quality of Life 6, no. 2 (2011): 201-213.

Rybarczyk, Greg, and Laura Gallagher. "Measuring the potential for bicycling and walking at a metropolitan commuter university." Journal of Transport Geography 39 (2014): 1-10.

Sallis, James F., Lawrence D. Frank, Brian E. Saelens, and M. Katherine Kraft. "Active transportation and physical activity: opportunities for collaboration on transportation and public health research." Transportation Research Part A: Policy and Practice 38, no. 4 (2004): 249-268.

Sallis, James F., Terry L. Conway, Lianne I. Dillon, Lawrence D. Frank, Marc A. Adams, Kelli L. Cain, and Brian E. Saelens. "Environmental and demographic correlates of bicycling." Preventive medicine 57, no. 5 (2013): 456-460.

Smith, Oliver. "Commute well-being differences by mode: Evidence from Portland, Oregon, USA." Journal of Transport \& Health 4 (2017): 246-254.

Stratford, Elaine. "Mobilizing a spatial politics of street skating: Thinking about the geographies of generosity." Annals of the American Association of Geographers 106, no. 2 (2016): 350-357. 
Stratford, Elaine. "On the edge: A tale of skaters and urban governance." Social \& Cultural Geography 3, no. 2 (2002): 193-206.

The City of Portland. "Guide to skateboarding in Portland, Oregon." https://www.portlandoregon.gov/transportation/article/594869. Accessed March, 2018.

Vivoni, F. "Spots of Spatial Desire: Skateparks, Skateplazas, and Urban Politics." Journal of Sport \& Social Issues 33, no. 2 (May 1, 2009): 130-49.

Walker, Tessa. "Skateboarding as Transportation: Findings from an Exploratory Study." Thesis, Portland State University, 2013.

Woolley, Helen, and Ralph Johns. "Skateboarding: The City as a Playground." Journal of Urban Design 6, no. 2 (June 2001): 211-30.

Woolley, Helen, Teresa Hazelwood, and Ian Simkins. "Don't Skate Here: Exclusion of Skateboarders from Urban Civic Spaces in Three Northern Cities in England." Journal of Urban Design 16, no. 4 (November 2011): 471-87. 


\section{Appendix A: Online Survey Questionnaire}

\section{Start of Block: Introduction}

\section{Skateboarding Transportation}

The purpose of this survey is to get a better understanding of how and why individuals travel by skateboard. Greater knowledge of specific forms of transportation makes it easier for urban decision makers to improve conditions and enhance opportunities for these users. The information gathered from these surveys will provide important data for a study being conducted at Portland State University.

Each participant will be entered to win a $\$ 50$ gift card to Daddies Boardshop (good online or in person). Survey will close on February 20, 2018.

Are you a Portland skateboarder and interested in participating in a 30 minute interview on the topic? Interviewees will receive a $\$ 10$ gift card to Daddies Boardshop.

Contact Michael Harpool at mjh22@pdx.edu with any questions or for more information.

Q43 Are you 18 years or older?

No (1)

Yes (2)

\section{End of Block: Introduction}

\section{Start of Block: General Skateboarding Information}

General Skateboarding Information

Q1 How old where you when you started skateboarding for recreation (fun and enjoyment)?

Q2 At what age did you start using your skateboard for transportation (to get places)? 
Q3 Have you been skateboarding regularly since you started?

Yes (1)

No (2)

Q4 Which of the following best describes your skill level on a skateboard?

Beginner (1)

Intermediate (2)

Advanced (3)

Expert (4)

Q5 What type of skateboard do you currently ride for transportation purposes? (Check all that apply)

Skateboard (1)

Longboard (2)

Cruiser (3)

Electric (4)

Other (Please Describe): (5)

Q6 How often do you currently use your skateboard for transportation?

Never (1)

Less than 1 day per month (2)

1-3 days per month (3)

1 day per week (4)

2-4 days per week (5)

5 or more days per week (6) 
Q7 How often do you currently use your skateboard for recreation/fun?

Never (1)

Less than 1 day per month (2)

1-3 days per month (3)

1 day per week (4)

2-4 days per week (5)

5 or more days per week (6)

End of Block: General Skateboarding Information

Start of Block: Getting Around by Skateboard.

Getting Around by Skateboard

Q8 Please indicate if you agree or disagree with the following statements. 
Strongly

Disagree (1)

Disagree (2)

Neutral (3)

Agree (4)

Strongly

Agree (5)

Skateboarding

is a safe way to

get around. (1)

Skateboarding

is a fun way to

get around. (2)

Skateboarding

is a fast way to

get around. (3)

Skateboarding

is a cool way to

get around. (4)

Skateboarding

is a convenient way to get around. (5)

Skateboarding is a cost-

effective way to get around.

(6)

Skateboarding is a relaxing way to get around. (7)

Skateboarding is good for the environment.

Traveling by skateboard is good for my health. (9)

Skateboarding allows me to easily use other forms of transportation (e.g. bus, light rail, subway).

(10) 
I travel by skateboard because it is a part of my lifestyle (11)

Q9 Why do you choose to use your skateboard to get places? From this list of potential skateboarding benefits please choose which three are most important to you and rank them as 1, 2, and 3 ( 1 being the most important). Note: Assign the values of 1, 2, and 3 to three of the available options. Values may not be repeated.

Safety (1)

Fun and enjoyment (2)

Fast travel (3)

Cool factor (4)

Convenience (5)

It's cost effective (6)

Environmental concern (7)

It is a part of my lifestyle (8)

Exercise (9)

Riding with friends (10)

I can easily take it on the train, bus, etc. (11)

Other (Please Describe): (12)

Q10 What other forms of transportation have you used in the past month? (Check all that apply)

Bike (1)

Car/truck/van/suv (2)

Rideshare (e.g. Uber, Lyft, etc.) (3)

Transit (e.g. bus, streetcar, subway) (4)

Walking (5)

Motorcycle/scooter (6)

Carshare (e.g. Zipcar, Car2Go, etc.) (7)

Other (Please Describe): (8) 
Q11 What sort of trips do you make on your skateboard? (Check all that apply) Commuting (work or school) (1)

Personal errands (e.g. groceries) (2)

Entertainment, dining out, socializing (3)

Exercise/recreation (4)

Get to skatepark/skate spots (5)

Other (Please Describe): (6)

Q12 Are there any destinations you are not willing to travel to by skateboard?

No (1)

Yes (Please explain the type of trip and why you are not willing to make it by skateboard) (2) 
Q13 Which of the following barriers would make you less likely to skateboard for any given trip? (Check all that apply)

Wet/slick conditions (1)

Poor road/sidewalk conditions (2)

Destination is far away (3)

Steep hills (4)

Automobile traffic (5)

Regulations prohibiting skateboarding (6)

Lack of safe infrastructure (7)

Limited carrying capacity (8)

Negative public perception (9)

Extreme temperatures (10)

Other (Please Describe): (11)

End of Block: Getting Around by Skateboard

\section{Start of Block: Choosing a Route}

\section{Choosing a Route}

Q14 For everyday travel, what is the longest distance (in miles) you are willing to go by skateboard? 
Q15 For everyday trips by skateboard, how often do you utilize the same route?

Never (1)

Rarely (2)

Sometimes

Often (4)

All the time (5)

Q16 Please indicate whether the following factors are desired or avoided features of any given skate route. 
Q17 Please indicate how comfortable you would be skateboarding in the following situations.

\begin{tabular}{|c|c|c|c|c|}
\hline & $\begin{array}{c}\text { Very } \\
\text { Uncomfortable (1) }\end{array}$ & $\begin{array}{c}\text { Somewhat } \\
\text { Uncomfortable (2) }\end{array}$ & $\begin{array}{c}\text { Somewhat } \\
\text { Comfortable (3) }\end{array}$ & $\begin{array}{c}\text { Very } \\
\text { Comfortable } \\
\text { (4) }\end{array}$ \\
\hline $\begin{array}{l}\text { A path or trail } \\
\text { separated from } \\
\text { traffic (1) }\end{array}$ & $?$ & ( & 0 & \\
\hline $\begin{array}{l}\text { A quiet residential } \\
\text { street with traffic } \\
\text { speeds of } 20-25 \\
\text { mph and no bicycle } \\
\text { route markings (2) }\end{array}$ & $\cap$ & & & \\
\hline $\begin{array}{l}\text { A quiet residential } \\
\text { street with traffic } \\
\text { speeds of } 20-25 \\
\text { mph and bicycle } \\
\text { route markings (3) }\end{array}$ & & & 0 & \\
\hline $\begin{array}{c}\text { A neighborhood } \\
\text { commercial } \\
\text { shopping street } \\
\text { with traffic speeds } \\
\text { of } 25-30 \mathrm{mph} \text { and } \\
\text { no designated bike } \\
\text { lanes (4) }\end{array}$ & & & & \\
\hline $\begin{array}{l}\text { A neighborhood } \\
\text { commercial } \\
\text { shopping street } \\
\text { with traffic speeds } \\
\text { of } 25-30 \mathrm{mph} \text { and } \\
\text { designated bike } \\
\text { lanes }(5)\end{array}$ & & & 0 & \\
\hline $\begin{array}{c}\text { A major urban or } \\
\text { suburban street } \\
\text { with traffic speeds } \\
\text { of } 30-40 \mathrm{mph} \text { and } \\
\text { no designated bike } \\
\text { lanes (6) }\end{array}$ & & & 0 & \\
\hline $\begin{array}{l}\text { A major urban or } \\
\text { suburban street } \\
\text { with traffic speeds } \\
\text { of } 30-40 \mathrm{mph} \text { and } \\
\text { designated bike } \\
\text { lanes (7) }\end{array}$ & & 0 & 0 & D \\
\hline
\end{tabular}


Q18 When riding on the street where do you skate most often?

Motor vehicle traffic lanes (1)

Sidewalks (2)

Bike lanes (3)

All three equally (4)

Other (Please Describe): (5)

Q19 Please indicate whether you agree or disagree with the following statements.

\begin{tabular}{c|ccccc} 
& $\begin{array}{c}\text { Strongly } \\
\text { Disagree (1) }\end{array}$ & Disagree (2) & Neutral (3) & Agree (4) & $\begin{array}{c}\text { Strongly } \\
\text { Agree (5) }\end{array}$ \\
\hline $\begin{array}{c}\text { I feel accepted } \\
\text { by others using } \\
\text { the }\end{array}$ & & & & \\
transportation \\
system (1)
\end{tabular}

\section{End of Block: Choosing a Route}

\section{Start of Block: Demographic Information}

Demographic Information - This information will be used understand the characteristics of the survey respondents. It will remain confidential and will not be tied to you in any way.

Q20 What is your age (in years)? 
Q21 What is your current 5-digit zip code

Q22 What gender are you?

Male (1)

Female (2)

Other (3)

Q23 Do you consider yourself (check all that apply):

American Indian or Alaskan Native (1)

Asian (2)

Black or African American (3)

Hispanic or Latino/a (4)

White or Caucasian (5)

Other (6)

Q24A Including yourself, how many adults live in your household?

Q24B How many children live in your household?

Q25 Do you rent or own your home?

Rent (1)

Own (2)

Other (3)

Q26 Do you have a valid driver's license?

Yes (1)

No (2) 
Q27 How many working motor vehicles are currently in your household?

Q28 What is your employment status? (Check all that apply)

I'm employed full time (1)

I'm employed part time (2)

I'm currently not employed (3)

I go to school full time (4)

I go to school part time (5)

Other (6)

Q29 What is your household's annual income

Less than $\$ 25,000(1)$

$\$ 25,000$ - $\$ 49,999(2)$

$\$ 50,000$ - $\$ 74,999(3)$

$\$ 75,000$ - $\$ 99,999$

More than $\$ 100,000(5)$

I prefer not to say (6)

Q30 What is the highest level of school you have completed?

Some high school or less (1)

High school diploma or GED (2)

Some college (3)

Trade/vocational school (4)

Associate degree (5)

Four-year college degree or higher (6) 


\section{Wrap-up}

Q31 Is there anything else you would like to tell me about your experiences traveling by skateboard?

Q42 How did you hear about this survey?

Social media (Facebook, Twitter, Instagram) (1)

Online blog (2)

Local skate shop (4)

Skateboard advocacy group (e.g. NW Skate Coalition) (5)

Friend or family member (8)

From the researcher directly (9)

Flyer (7)

Other (Please Explain): (6)

Q46 Click the $>>$ tab below to complete the survey! If you wish to be entered for the chance to win a $\$ 50$ gift card to Daddies Board Shop, please follow the link on the following page. For your protection, the contact information you provide cannot be linked to this survey in any way. Thank you for your time!

\section{End of Block: Wrap-up}




\section{Appendix B: Interview Guide}

\section{Some general questions about how you started skateboarding.}

1. How old were you when you started skateboarding?

2. What was it about skateboarding that made you want to try it?

3. When you first started was it more a means of recreation or was it a way to get places?

4. Do you remember if your parents or guardians encouraged it or were against it?

5. Where did you learn to skateboard?

a. What was your neighborhood like?

ii. Was there a skateboard scene?

iii. Were there any skateparks nearby?

iv. Was skateboarding frowned upon?

\section{Some general questions about your use of your skateboard now.}

6. What is the primary reason you skateboard now?

a. You stated that when you began skateboarding it was primarily for (insert "recreation" or "transportation"), has that changed? If so, why do you think that is?

8. Do you think where you grew up has any impact on how and why you skateboard today? If so, why?

9. What type or types of skateboard do you currently ride?

a. Do you have different skateboards for different purposes?

b. How much does a skateboard like that generally cost with all parts included?

c. How much would you say you spend a year replace or maintaining your skateboard?

\section{Some questions geared towards your recreational use of skateboarding (If only transportation skip this section).}

10. How is recreational skateboarding important to you?

10. Can you explain the style of recreational skateboarding you participate in?

a. Downhill, street skating, park skating, bowls, etc.?

11. How would you assess your own skill level? 
12. When you go out to skateboard recreationally do you tend to go alone or with a group of people?

13. Do you have any favorite hills, skate spots, or skateparks in Portland (depending on answer to previous question)?

14. Do you feel that skateboarding should be allowed in public spaces, such as urban plazas? Do you think the exclusion of skateboarding from these spaces is justified?

15. When skateboarding recreationally in public spaces do you feel accepted by other users?

\section{Now I will ask you more specific questions regarding your use of skateboarding as a form of transportation.}

17. How long have you been skateboarding before you started to use it as a form of transportation (if used recreationally first)?

18. What was it that made you decide to start using skateboarding as a form of transportation?

19. When you are skateboarding for transportation purposes do you tend to travel with friends or alone?

20. How is skateboarding transportation important to you?

b. What makes it convenient to you as an individual?

21. More generally, what do you think are the greatest benefits to skateboarding transportation?

22. In your opinion, what are the biggest barriers to skateboarding transportation?

a. Are there any disadvantages to using your skateboard as a form of transportation?

23. What sort of things impact the route that you choose when you are traveling by skateboard?

a. What sort of street level factors are desired and avoided?

24. Do you ever use other forms of transportation when you travel by skateboard (e.g. bus, train, car, etc.)?

25. What sort of trips do you usually make by skateboard (e.g. shopping, dining out, going to work)? 
trips?

a. Why do you choose skateboarding over other forms of transportation for these

27. How would you compare your speed on a skateboard to someone on a bicycle?

28. When you are riding on the street do you tend to skate on the sidewalk, in the motor vehicle lane, or in designated bike lanes?

29. On a trip you make regularly is there anything that may redirect your route (e.g. traffic lights, construction, etc.)?

30. Have you ever fallen or crashed while traveling on your skateboard?

a. What was the severity of the injury?

b. Was there another party involved in the crash?

c. Does the fear of falling stop you from using your skateboard?

31. When traveling by skateboard do you tend to use the sidewalk, bike lanes, or motor vehicle lanes? Why?

31. Does the volume of traffic impact your comfort level when riding your skateboard in the street? How so?

32. How about the speed of traffic?

33. Does the presence of bicycles impact your comfort levels when you are skating?

34. What about pedestrians, does your comfort level change when riding on a busy sidewalk compared to an emptier sidewalk?

35. Do you consider the regulations and prohibitions against skateboarding while riding? a. Have you ever run into any issues with law enforcement?

36. How do you think you, as a skateboarder, are perceived by others using the transportation system?

37. Would you say that Portland's transportation system is skateboarder friendly?

a. Is the city easy to navigate by skateboard?

b. Do you feel that your needs are considered by transportation planners?

\section{Almost done now just a few wrap-up questions.}

38. What sort of changes would you like to see happen to improve your experiences as a person who utilizes skateboarding as transportation? 
39. Is there anything the city could do to make you more likely to increase the number of trips that you make by skateboard?

40. Are there any other positive or negative experiences that you have had traveling by skateboard that you would like to share?

I greatly appreciate the time you have taken to participate in this survey. Here is a $\$ 10$ gift card to one of the local skate shops to compensate you for your time. If you have any follow up questions please feel free to contact me, here is my information. 


\section{Appendix C: Recruitment Flyer}

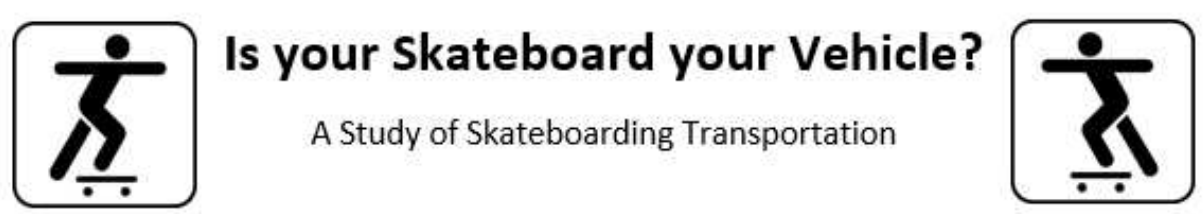

I am recruiting individuals to participate in my study on skateboarding transportation. I am interested in how skateboarders navigate throughout the city by skateboard and the key factors behind the decision to make a given trip by skateboard. The results of this study will provide a more complete understanding of how skateboarding is used as a mode of transportation and could illuminate ways in which cities within the United States could create more inclusive transportation networks. Contact Michael Harpool at mjh22@pdx.edu with any questions.

If you are interested in my research and would like to participate in an important study I would greatly appreciate your time.

Who: Participants must be at least 18 years old and have experience using their skateboard as a means to get around

What: A short survey and/or a 45 minute interview

Where: Surveys can be taken online and interviews will be conducted at Portland State University Campus (will make arrangements if this is inconvenient)

When: At your convenience before March, 2018

Why: Skateboarding is a viable source of transportation for many, but in order for cities enhance opportunities and conditions for those who choose to skateboard we must begin to understand how and why these choices are made.

Each participant that completes a survey will be entered to win a $\$ 50$ gift card to Daddies Boardshop. Interviewees will each receive a $\$ 10$ gift card to Daddies Boardshop.

\section{Survey can be found at: https://tinyurl.com/y9b39p4z}

Michael Harpool is receiving his Masters of Urban Studies at Portland State University This study has been approved by the PSU Institutional Review Board Office of Research Integrity 


\section{Appendix D: HSRRC Approval Memo}

\section{P Portland State}

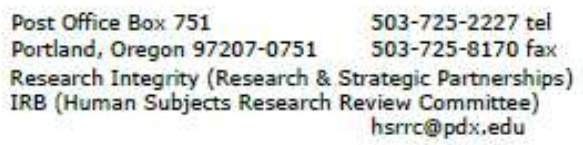

Date: October 16,2017

To: Jennifer Dill/ Michael Harpool, School of Urban Studies and Planning

From: Lindsey Wilkinson, IRB Chair

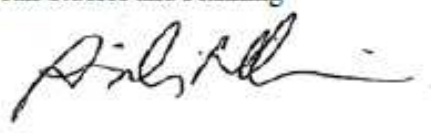

Re: $\quad$ RB approval for your protocol \# 174365, entitled: "Traveling by Skateboard: Exploring Mode and Route Choice Factors of Skateboarding."

Approval-Expiration: October 16, 2017 - October 15, 2018

Notice of IRB Review and Approval - Initial Review

Expedited Review Categories 6, 7; as per Title 45 CFR Part 46

In accordance with your request, the PSU Institutional Review Board (Human Subjects Research Review Committee) has reviewed and approved the project referenced above for compliance with PSU policies and DHHS regulations covering the protection of human subjects. The IRB is satisfied that your provisions for protecting the rights and welfare of all subjects participating in the research are adequate. Please note the following requirements:

Approval: You are approved to conduct this research study only during the period of approval cited above, and the research must be conducted according to the plans and protocol submitted (approved copy enclosed).

Consent: You must use IRB-approved consent materials with study participants.

Changes to Protocol: Any changes in the proposed study, whether to procedures, survey instruments, consent forms or cover letters, must be outlined and submitted to the IRB immediately. The proposed changes cannot be implemented before they have been reviewed and approved by the IRB.

Continuing Review: This approval will expire on 1015/2018. It is the investigator's responsibility to ensure that a Contimuing Review Report is submitted to the IRB two months before the expiration date, and that approval of the study is kept current. The Contimuing Review Report is available on the Research Integrity website.

Adverse Reactions and/or Unanticipated Problems: If any adverse reactions or unanticipated problems occur as a result of this study, you are required to notify the Research Integrity within 5 days of the event. If the issue is serious, approval may be withdrawn pending an investigation by the IRB.

Completion of Study: Please notify the IRB as soon as your research has been completed. Study records, including protocols and signed consent forms for each participant, must be kept by the investigator in a secure location for three years following completion of the study (or per any requirements specified by the project's funding agency).

If you have questions or concerns, please contact the Research Integrity office in Research \& Strategic Partnerships at hsrre a pdx.edu or (503) 725-2227. 


\section{Appendix E: Significant Differences in Perceptions}

Gender:

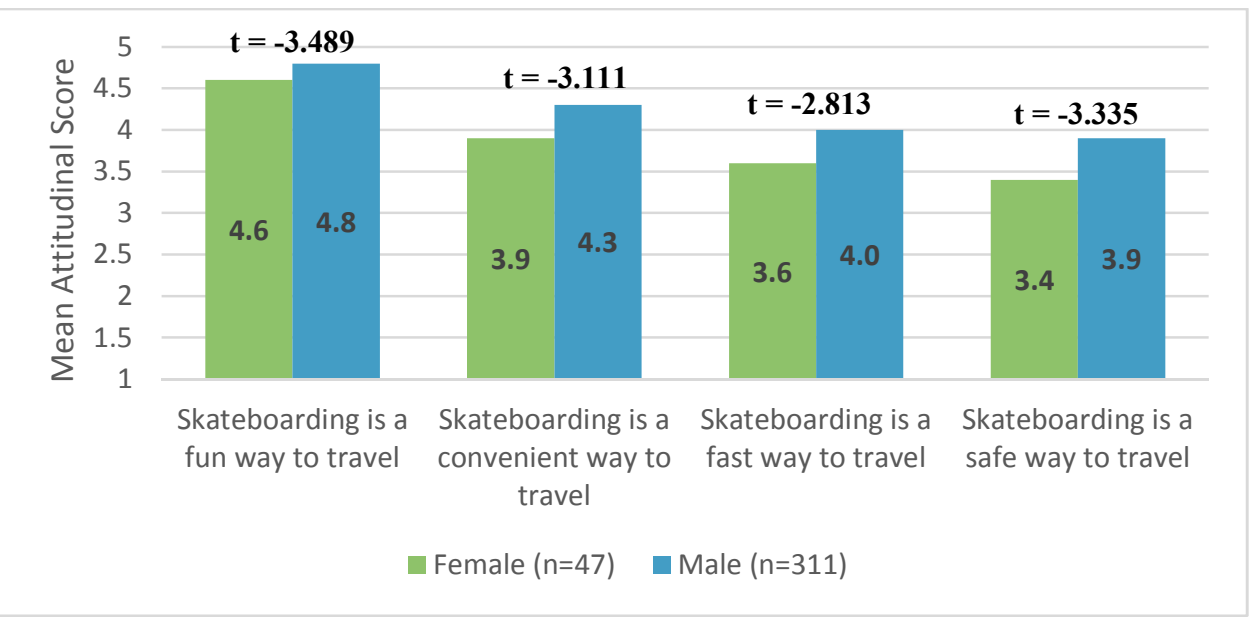

H0: Female $\overline{\mathrm{x}}=$ Male $\overline{\mathrm{x}}$; HA: Female $\overline{\mathrm{x}}<$ Male $\overline{\mathrm{x}} ; \mathrm{p}<.001$

\section{Experience:}

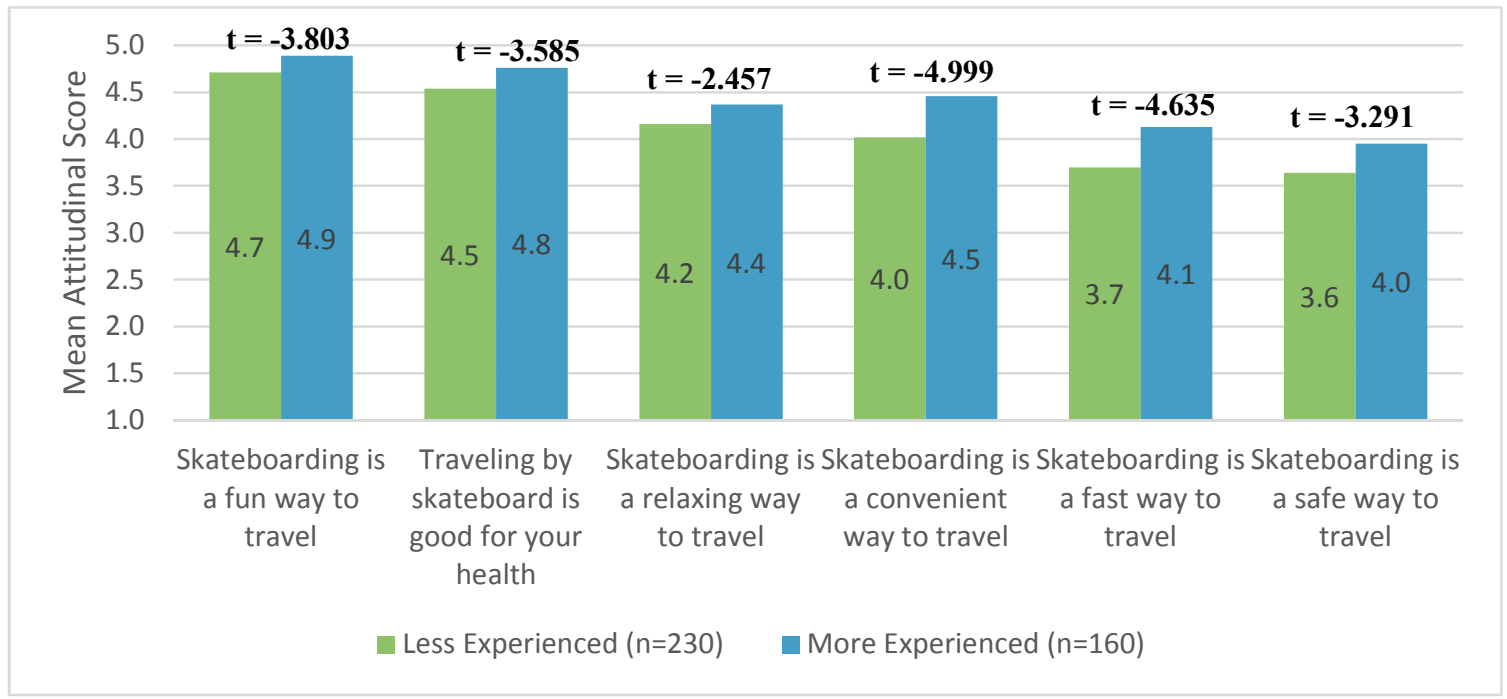

H0: Less Experienced $\overline{\mathrm{x}}=$ More Experienced $\overline{\mathrm{x}} ;$ HA: Less Experienced $\overline{\mathrm{x}}<$ More Experienced $\overline{\mathrm{x}} ; \mathrm{p}<.001$ 
Frequency of Use:

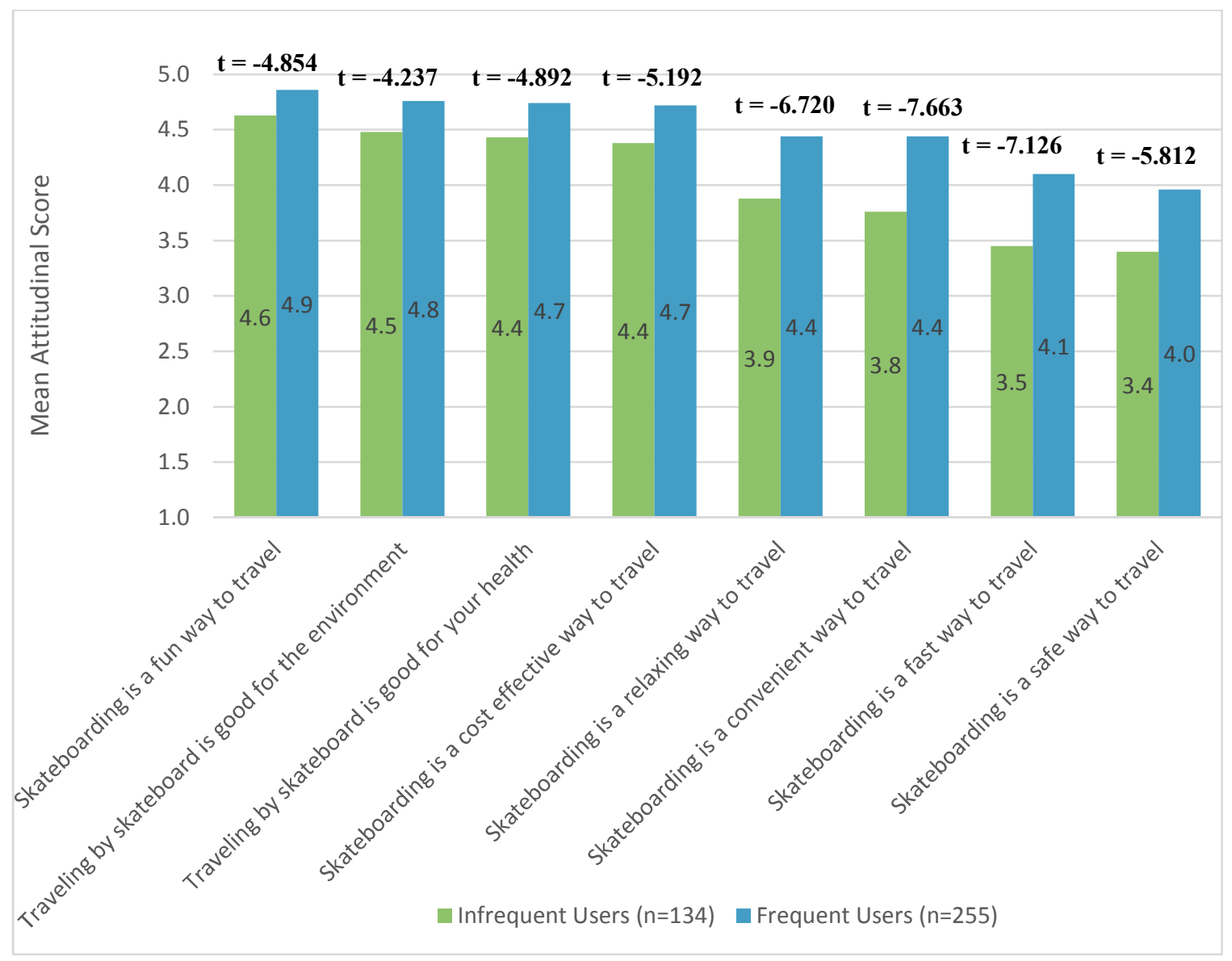

H0: Infrequent Users $\bar{x}=$ Frequent Users $\bar{x} ;$ HA: Infrequent Users $\bar{x}<$ Frequent Users $\bar{x} ; p<.001$ 


\section{Appendix F: Binary Logistic Regression}

\begin{tabular}{|c|c|c|c|c|c|c|c|}
\hline \multicolumn{8}{|c|}{ Variables in the Equation } \\
\hline & & $\mathrm{B}$ & S.E. & Wald & df & Sig. & $\operatorname{Exp}(B)$ \\
\hline \multirow[t]{4}{*}{ Step $1^{a}$} & Skill level Recode & .911 & .240 & 14.439 & 1 & .000 & 2.488 \\
\hline & Are you male or female? & 1.590 & .439 & 13.146 & 1 & .000 & 4.905 \\
\hline & $\begin{array}{l}\text { Frequent and infrequent } \\
\text { transpo skateboarders: } \\
\text { once a week or less }\end{array}$ & .746 & .256 & 8.517 & 1 & .004 & 2.108 \\
\hline & Constant & -4.004 & .623 & 41.280 & 1 & .000 & .018 \\
\hline
\end{tabular}

a. Variable(s) entered on step 1: Skill level Recode, Are you male or female?, Frequent and infrequent transpo skateboarders: once a week or less. 